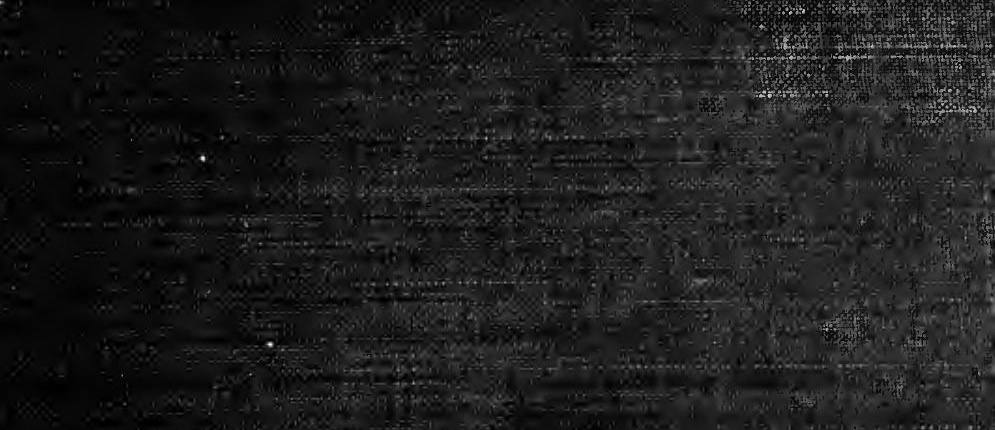

Next (1)

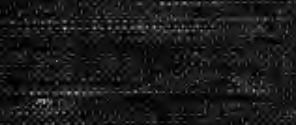

$$
\text { (10) }
$$


4 
Digitized by the Internet Archive in 2008 with funding from Microsoft Corporation 



\section{THE ISOMORPHISM AND THERMAL PROPERTIES OF THE FELDSPARS.}

PART I-THERMAL STUDY, ARTHUR L. DAY and E. T. ALLEN.

PART II-OPTICAL STUDY, - J. P. IDDINGS.

WITH AN INTRODUCTION BY

GEORGE F. BECKER.

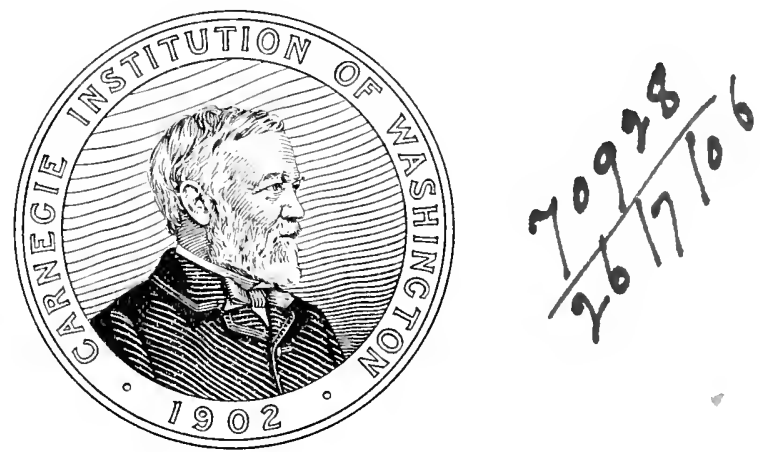

Washington, D. C. :

Purlished by the Carnegie Institution of Washington. 1905. 
CARNEGIE INSTITUTION OF WASHINGTON

Publication No. 3 I

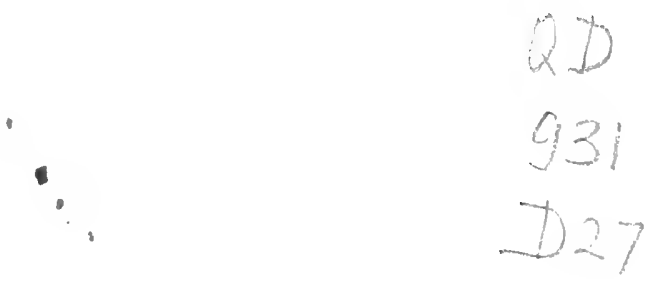

PRESS OF GIBSON BROS.

WASHINGTON, D. C. 


\title{
INTRODUCTION.
}

\author{
BY GEORGE F. BECKER.
}





\section{INTRODUCTION.}

The prime duty of a geological survey is to make a geological map of the country. Those who are unfamiliar with the duties of a geologist are apt to suppose that no great amount of knowledge is needed to produce a satisfactory map of this kind. Those who have tried it know better. The field geologist is at once confronted by the theoretical aspects of his science in such a manner that he is compelled to adopt at least tentative views. He must decide what is to be mapped, and this decision implies that he knows or assumes relations between the various members of the series with which he has to do. All geologists worthy of the name are continually and painfully aware that they deal largely in uncertainties or matters of opinion, and they can not fairly be reproached with the insufficiency of the grounds which they sometimes have to show for the views they adopt, unless they lay themselves open to the accusation of neglecting results established by theory and experiment.

Geology is not a seience, but the application of the seiences to the elueidation of the history of the earth. Its best developed and oldest branch is zoological geology or paleontology, and next in order of development, though substantially the latest in chronological order, is mineralogical geology as represented by petrography. The rapid advance in the description of rocks is die, as everyone knows, to the introduction of the microscope and of exact optical methods in the determinations of minerals. Less advance has been made in the wider subject ealled petrology or lithology, as well as in orogeny, vuleanism, and ore deposits. The resources of the terrestrial laboratory so far transcend those which can be equipped by man that vast groups of geological phenomena still await even approximate explanation.

Observations on the lithosphere alone will not suffice to elucidate these dark regions. As Messrs. Day and Allen very properly insist, "'geological field research is a study of natural end-phenomena, of completed reactions, but with a very imperfect record of the earlier intermediate steps in the earth-making processes." In fact, the unknown quantities outnumber the equations which field observation puts at our disposal. In their present state of development the sciences of physies and chemistry can aid the geologist only to a moderate extent. We do not know in most cases whether the laws of 
physics as established under ordinary conditions retain their validity at temperatures exceeding $1000^{\circ} \mathrm{C}$., while of the chemical behavior of substances at these temperatures chemists can tell us little more than that affinities are radically different from those observed at $100^{\circ}$. Similarly elasticians can discuss the small strains in a building or a bridge with some approach to completeness, but they do not even make the attempt to deal with deformations which are sensible to the eye and which are almost universal in geological exposures.

It was in recognition of the need for researches in physics which would throw light on geological problems that Dr. Carl Barus was appointed physicist on my staff in the United States Geological Survey as far back as 1880 , and that a physical laboratory was established under that Survey in 1882 . This was discontinued in 1892 , not because its importance was underestimated by the Director, but on account of a failure of appropriations. The laboratory was reestablished in 1901 because it was felt that without the aid to be derived from physical determinations the efficiency of the Survey must suffer. There was nothing novel in the appreciation thus displayed of the importance of physics to geology; indeed, several great geophysical problems have been recognized by natural philosophers for more than a century; and their difficulty, not their unimportance, has stood in the way of experimental investigation.

The field geologist meets with phenomena in all the ruggedness of their utmost complexity, and he is sometimes tempted to face and make an assault upon the situation as he finds it. A little consideration shows that in such circumstances a frontal attack must lead to disaster. The outposts must be overcome one by one. We must patiently begin with the simplest problems that can be devised and, aided by the most perfect appliances known, study them exhaustively before proceeding to more difficult and complex cases.

In a plan submitted to the Director when the new physical laboratory of the Survey was first contemplated, I laid especial stress upon the study of isomorphism and eutexia. These subjects, witl the determinations of thermal constants which they imply, have occupied the attention of the plysical laboratory during the greater part of the time since its reestablishment, and will continue to take the first place in the researches there undertaken.

It would appear that the relations between liquids must be reducible to very general groups. Liquids must either be miscible or immiscible, and miscible liquids must exhibit either isomorphic properties or cutectic ones. It is possible that magmas are in some cases 
imniscible; thus zircons separate out in the process of consolidation so early, so completely, and in such minute crystals as to suggest immiscibility. On the other hand, Alexejew reached the conclusion that in all cases where solutions do not react upon one another chemically, they become miscible above a certain temperature. Again, all researches on the genesis of minerals from fused magmas show that, as a rule, the crystals are precipitated from undercooled glasses or from miscible liquids. With some possible exceptions, therefore, which, so far as is yet known, are unimportant, the investigation of liquid magmas reduces to the study of isomorphous mixtures (in which the physical properties are continuous functions of the composition) and of eutectic ones.

A main aim of lithological studies for many years has been to classify rocks. It is difficult to overestimate the importance to the whole history of the earth of a natural and rational petrological taxonomy. The earliest classifications were largely chemical. After the introduction of the microscope they becane chiefly mineralogical, but with Lagorio's famous paper on the nature of the glass base and the processes of crystallization in eruptive magmas, 1887 , chemical considerations again become predominant. In nny opinion, classification of rocks on a basis of composition alone can never be satisfactory or final. It is possible, of course, to classify analyses; but rocks are at least for the most part very variable mixtures, without analogy to definite chemical compounds, and this method thus fails to cover the ground or to reveal the relations of parts to the whole.

On the other hand, physical chemistry seems to me to open the road to a classification which must be helpful and nay possibly be final. Among the ten or a dozen important rock-forming minerals*

* In Bulletin 228 of the United States Geological Survey Professor Clarke has given an estimate, based on nearly 700 analyses, of the approximate relative abundance of the more important minerals found in igneous rocks and aggregating 94.2 per cent. Adding the more important of the minerals which elnded separate computation in one sum, this table takes the following form, which is very suggestive with reference to important silicate solutions:

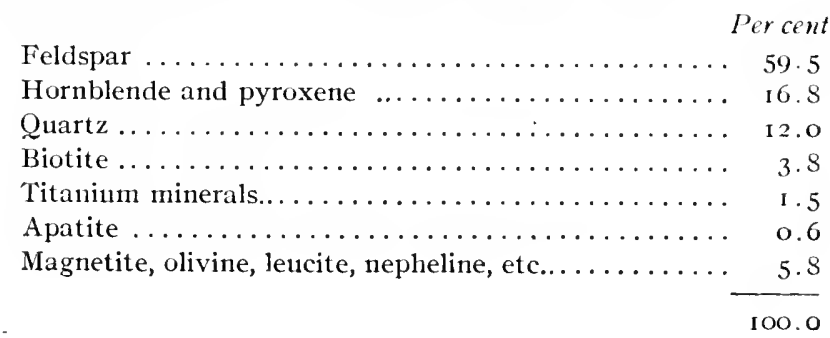


there can be only a limited number of isomorphous series and a limited number of eutectic combinations. The most important isomorphous series forms the subject of this publication. It is well known to be probable also that the amphiboles, the pyroxenes, and the micas each constitute isomorphous groups. No other isomorphous groups appear to have much lithological importance. In general, it is manifest that isomorphism is to be expected only within groups of closely allied compounds, and it is even a matter of surprise that the orthosilicate anorthite and the polysilicate albite should exhibit complete isomorphism of the simplest type, as Messrs. Day and Allen have shown that they do. It seems lardly possible, therefore, that a satisfactory classification of rocks can be based on the study of isomorphous series; indeed the mineralogical rock definitions of twenty-five years ago were little else than such a classification, which has been rejected as inadequate.

No serious attempt has yet been made to group rocks on eutectic principles, one very sufficient reason being our ignorance of eutexia in magmas. Professor Lagorio refers briefly to eutexia, but regards the important solvent in magmas as a silicate of the alkalies, the glass least subject to devitrification. ${ }^{*}$ Mr. Teall, in 1888 , discussed eutexia very lucidly and showed its importance in the physics of rocks, $\nmid$ but he did not propose employing it as a basis of classification. In I90I I briefly set forth some of the advantages of such a system.

The applicability of eutexia to rock classification depends upon the fact that it makes the systematic discussion of magmatic mixtures possible. Inasmuch as the subject-matter of lithology consists of mixtures, their classification must be carried out in terms of definite or standard mixtures, while the only mixtures possessing appropriate distinguishing properties are the eutectics. Thus in dealing with magmas or other heteromorphous miscible liquids the eutectics seem to afford not only the best but the only natural and rational standards of reference. With any eutectic as a basis, a series of magmas may be prepared, each differing from the eutectic by containing an excess of one or more constituents. Thus if $a b c$ represents an entectic of three substances, a mixture composed of $a, m b$, and $n c$ may be re-

* There is no fundamental difference between fluid solvents and solutes, and no objection to regarding the alkaline glass as the solvent if found on other grounds expedient.

† Brit. Petrography, 1888, p. 394.

$\ddagger$ Report on the geology of the Philippine Islands. Twenty-first Ann. Rep. U. S. Geol. Surv., Pt. III, 1901 , p. 519. 
garded as the eutectic plus $(m-\mathrm{I}) b$ plus $(n-\mathrm{I}) c$. In some cases at any rate the ground mass of a rock (as Mr. Teall pointed out) represents an eutectic. This is probably not true in general but, if it were, the scheme proposed would be to group together in one genus all the rocks which have the same ground mass and to regard the phenocrysts as minor or specific characteristics. The size of crystals is no index of the rapidity of their formation, and Messrs. Day and Allen have shown that anorthites of the size of very large phenocrysts may form in a few minutes, while in more viscons magmas small feldspar crystals may form with extreme slowness. Hence great care is requisite in deciding microscopically the question which crystals were the last to form.

It is worthy of note that the geological behavior of an intrusive or effusive rock is conditioned largely by the character of the entectic. So long as this remains liquid the phenocrysts are, mechanically speaking, mere flotsam and jetsam in the stream. The character of the eutectic must decide whether a lava pours down a gentle declivity as does a basalt, or piles up about the orifice like a rhyolite. Now, if it be not essential to consider such geologically important properties in the classification of rocks, it is at all events desirable to do so. Such properties must sooner or later be dealt with methodically by geologists, and a thoroughly rational classification of rocks will correlate physical and chemical properties.

These last paragraphs deal with plans rather than achievements, and have been written chiefly to emphasize the importance of the work done by Messrs. Day and Allen as one step in a broader scheme. Evidently every step of the larger plan involves accurate studies of the melting points and thermal properties of the rock-forming minerals, and first of all that most important group, the lime-soda feldspars, which make up approximately one-half of the lithosphere. In the meantime, since my proposal to use eutectics as a basis of rock classification was printed, some valuable work has been done on eutectics, chiefly by J. H. L. Vogt.*

Only the first step has been taken in this investigation - the study of the triclinic feldspars in dry fusion. It has been attended with great difficulties, many of them only touched upon in the paper which follows, but of which I have been cognizant in detail. Except for Dr. Day's resourcefulness and experimental skill, success would not have been achieved, but a road has now been broken out in this ultra-

\footnotetext{
* Die Silikatschmelzlösungen. Christiania, I903. Mr. Vogt printed a preliminary communication early in 1902 .
} 
tropical jungle which will almost certainly lead to further successful explorations.

Meantime the results reached are of great importance. The melting points of the triclinic feldspars have been determined with an accuracy never before attained in determinations at such temperatures. Any future correction of them must be of very trifling amount. These points, considered with reference to composition, and the very fine series of specific gravity determinations on chemically pure feldspars, seem to settle beyond question the isomorphism of the plagioclases. The first cogent arguments for this isomorphism were given by Sartorius von Walthershausen in 1853 , but the more thorough investigation of Tschermak in 1864 has properly connected the theory with his name. Nevertheless, some of the ablest investigators have been unconvinced that the isomorhpism was complete, and I confess to surprise that the proof is so irrefragable as Messrs. Day and Allen have made it.

The study of the feldspars and sodium tetraborate (dehydrated borax) have confirmed results of Professor I,agorio, which are thus summarized by Mr. Teall (op. cit., p. 397):

Silicate solutions differ from aqueous solutions in the realiness witl which they form amorphous glass when cooled rapidly. This appears to be connected with the fact that they may be readily overcooled, and that when in this state they are highly viscous, so that a rapid approach of the molecules is prevented. The meiting point of glass is lower than that of the same substance in a crystalliue condition. A glass, therefore, results from the solidification of an overcooled liquid.

Messrs. Day and Allen show that crystallization can be bronght about at very different degrces of overcooling or at very different temperatures, so that the solidifying temperature of crystals out of undercooled liquids is not a physical constant, while soliclification to the amorphous state almost or quite eludes determination by the means found adequate to fix the melting points of crystals.*

* The properties of amorphous substances are very perplexing. It is well known that some physicists class glasses at any temperatures as liquids, and there is no question that it is hard to draw the line betwcen them and liquids. On the other hand, Mr. Spring has recently shown that mere deformation of crystalline metals at ordinary temperatures changes their densities and electrical potentials, so that mere derangement of crystalline particles, without any absorption of energy comparable with that accompanying true fusion, suffices to impart to lead, silver, bismuth, etc., properties analogous to those of glasses. The whole subject demands fuller investigation which, to be successful, must harmonize thermal, electrical, and mechanical phenomena. 
Mr. Roozeboom's discussion of isomorphous mixtures seems admirably verified by this investigation of the feldspars. When considered in connection with the high viscosity of the materials, it also explains the fact that the curve of melting points closely follows Küster's rule. It would seem, therefore, that not only concentrated solutions but isomorphous ones form exceptions to the accepted laws of dilute aqueous solutions. Such isomorphous solutions as those of the feldspars here dealt with could in fact hardly be considered as dilute, and some of them (as for instance $A b_{1} A n_{1}$ ) must be very concentrated solutions, whichever of the components is considered as solvent.

The specific volumes of the feldspars seem to bear a relation to the composition so nearly linear that the differences may be ascribed to unavoidable errors in synthesis and analysis. It should not be furgotten, however, that the specific volumes are determined at something like $1000^{\circ}$ below the temperature of crystallization, and that, since the coefficients of contraction of $\mathrm{Ab}$ and An doubtless differ to some extent, variations in density as determined at $25^{\circ}$ might be due not to a lack of isomorphism, but to the difference in contraction of the two components.

The artifieial feldspars prepared at the cost of great labor are pure, while natural crystals are not so. Hence lithologists, in making separations by heavy solutions, should substitute the densities here found for those hitherto employed. The changes are not great, but they are sufficient in some cases to affect conclusions.

A very noteworthy result of the investigation is the apparent superheating of the albitic feldspars. It is pointed out by Messrs. Day and Allen that this may be only apparent and clue to the extreme viscosity of the melt. In fact, the separation of molecules in melting and their deorientation must be successive processes, so that in any fusion, if the operation could be instantaneously arrested, a layer of molecules would be found separated from the solid mass but not yet deoriented. Such material would differ from a liquid erystal by not being in a condition of stable equilibrium.

Prof. J. P. Iddings kindly undertook the detailed examination of the slides made from the feldspar preparations. He shows in his report that to one per cent, or less, the feldspars correspond optically to the mixtures prepared. A closer correspondence could not be hoped for in materials so viscous that diffusion afforded searcely any aid in attaining homogeneity. He has discussed many interesting features of the crystallization of the feldspars, most of them familiar 
in effusive rocks. Spherulitic structure in particular is brilliantly illustrated in the slides, and in the nature of the microlites of artificial feldspar he has found nothing to suggest essential differences between the experiments and natural processes the results of which constantly come under the observation of lithologists. Professor Iddings has also examined the refractive indices of the artificial feldspars and has found them accordant with isomorphism.

I can not conclude this review without a mention of the tireless energy and watchfulness which Messrs. Day and Allen have exercised, and of which I have been a daily witness, in a most laborious task attended by so many difficulties that it sometimes seemed almost hopeless.

The vastness of the field open to geophysical research is partially indicated in the preceding pages, and I have recently endeavored to enumerate somewliat more fully the pressing problems of geophysics.* The Government of the United States has of late years pursued the enlightened policy of niaking yearly grants for chemical and physical researches under the Geological Survey, but the appropriations are inadequate for the more difficult and costly studies in this field. This is not strange, for though geophysics has already proved technically valuable, so that mining engineers display a hearty interest in it, and althongh it will assuredly lead to the solution of certain welldefined economic problems of the first importance, its fundamental researches are somewhat remote from industry, and large public appropriations are hardly to be hoped for in the near future.

The Trustees of the Carnegie Institution of Washington, recognizing these facts, have supplemented the Congressional appropriations by grants to Dr. Day and to myself, and the work described in this paper, though begun under the Survey, was completed at the expense of the Carnegie Institution. In these circumstances the Director of the Survey consented that it should be offered to the Institution for publication with this due recognition of the coopperation of the Survey. The Institution has accepted it as its first contribution to geophysics and defrays the cost of publication. It is surely a matter of congratulation that the Government and a private institution should coöperate in the advancement of knowledge. Such an alliance brightens the prospects of Science.

\footnotetext{
* International Scientific Congress of St. I.ouis, 1904, printed in Science, October 28,1904 .
} 


\section{PART I.}

\section{The Isomorphism and Thermal Properties of the Feldspars.}

ARTHUR L. DAY AND E. T. ALLEN. 


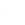




\section{THE ISOMORPHISM AND THERMAL PROPERTIES OF THE FELDSPARS.*}

The investigation here recorded is the first chapter in a rather comprehensive plan for the study of the rock-forming minerals at the higher temperatures. In its broader outlines, at least, it is by no means a new plan. Mr. Clarence King and Dr. George F. Becker were inspired by a desire to reach the mineral relations from the experimental side, which is recorded in the very earliest records of the U.S. Geological Survey, and much of the remarkable ground-breaking work of Prof. Carl Barus was undertaken in furtherance of a carefully prepared scheme of research along these lines. The matter has been advanced but little in the intervening years. The present renewal of the effort in this direction is again due to Dr. Becker and has had the benefit of his wide field experience and enthusiastic and effective coöperation throughout.

In October, 1900, one of the authors was called from the Reichsanstalt to equip a laboratory in the U. S. Geological Survey in which the exact methods and measurements of modern physics and physical chemistry should be applied to the minerals. The ultimate purpose was geological, to furnish a better basis of fact for the discussion of the larger problems of geology, but it appeared highly probable also that a quantitative study of the thermal phenomena in this class of substances would offer new relations of intrinsic interest and of considerable theoretical value. This inference has been happily substantiated quite recently through the publication by Tammann of an extended treatise on melting and crystallization, $\dagger$ in which he offers some very interesting speculations on the conditions of equilibrium for substances above and below the melting temperature under different pressures. The behavior of crystalline minerals which melt at temperatures considerably higher than he was able to command offer peculiarly advantageous opportunities for verifying the truth of his inferences and of contributing further to the knowledge of this most important change of state of matter.

* A preliminary paper containing the chief results of this investigation was read before the Geological Society of Washington, March 23, 1904, and a brief abstract published in Science (vol. xix, p. 734), May 6, igo.. A second abstract appeared in the American Journal of Science (4), 19, p. 93, 1905.

† Tammann, " Krystallisiren !nd Schmelzen.." Leipzig, Igo3. 
TEMPLRATURE: MEASUREMENTS.

It is only a short time since it becanc possible to measure even moderately high temperatures with certainty and to express them in teru1s of a well-established scale. Temperature is a peculiar function in that it is not additive. Two bodies, each at a temperature of $50^{\circ}$, can not be united to obtain a temperature of $100^{\circ}$, nor can any number of bodies at a temperature of $50^{\circ}$ or below give us information about the temperature $51^{\circ}$ or above. Furthermore, temperature is not independently measurable; we can only measure phenomena like the expansion of gases or the conductivity of platinum wire or the cnergy of thermal radiation, which we have good reason to suppose will vary with the temperature uniformly or according to a known law.

The measure of temperature now generally accepted as standard is the expansion of hydrogen gas between the melting point of ice and the normal boiling point of water, divided into roo equal increments or degrees. Temperatures above this point have been determined by continuing the expansion of hydrogen or nitrogen* in the same units, as far as it has been found possible to provide satisfactory containing vessels for the expanding gas. Such determinations are then rendered permanent and available for general use by establishing fixed points, such as the melting temperatures of easily obtainable pure metals, at convenient intervals. Beyond I I $5^{\circ}$ no trustworthy gas measurements have bcen made, and we have, therefore, no standard scale. For higher temperatures it is usual to select some convenient phenomenon which is measurable up to the temperature desired, to compare it with the gas scale as far as the latter extends, and then to continue on the assumption that the law of its apparent progression below $1150^{\circ}$ will continue to hold above that point. In this way we obtain degrees which, if not identical with the degrees of the gas scale, approximate very closely to them, and can receive a small correction if necessary, whenever the gas scale shall be extended or another scale substituted.

The application of measurable high pressures at the higher temperatures has never been successfully accomplished, and until something can be done in this direction, our knowledge of the rock-forming minerals, and in fact all the generalizations relating to equilibrium

* To $600^{\circ}$, Chappuis et Harker, 'Travaux et mémoires du bureau international des poids et mesures, 12, 1902 . To $1150^{\circ}$, Holborn and Day, Ann. der Physik, 2, 505, 1900. English translation, Am. Journ. Sci., (4), 10, p. 171, 1900. 
between the states of niatter, which have bccn established for moderate temperatures, must be regarded as more or less tentative and subject to eventual revision. We have been accustomed to assume, both in geology and in plysics, with rather more confidence than scientific experience justifies, that established relations for ordinary temperatures and pressures will hold in comparable ratio for the higher temperatures and pressures also. Experimentation under extreme conditions is slow and technically difficult, and it is, therefore, not strange that simple relations which are verifiable within easily accessible conditions should now and then be accorded the dignity of natural laws without sufficient inquiry into the more remote conditions.

\section{GENERAL PLAN.}

Our plan on entering this field was to study the thermal behavior of some of the simple rock-making minerals by a trustworthy method, then the conditions of equilibrium for simple combinations of these, and thus to reach a sound basis for the study of rock formation or differentiation from the magma. Eventually, when we are able to vary the pressure with the temperature over considerable ranges, our knowledge of the rock-forming minerals should become sufficient to enable us to classify many of the earth-making processes in their proper place with the quantitative physico-chemical reactions of the laboratory.

\section{RELATION TO GEOLOGICAL RESEARCH.}

The relation which this plan bears to general geological research may perhaps be expressed in this way. Geological field research is essentially a study of natural end-phenomena, of completed reactions, with but a very imperfect record of the earlier intermediate steps in the earth-making processes. The records of the splendid laboratory experiments in rock synthesis which have already been made are also of this character. The final product has been carefully studied, but the temperatures at which particular minerals have separated out of the artificial magma, and the conditions of equilibrium before and after such separation, have not been determined. In fact, except for a limited number of determinations of the melting points of natural minerals, no exact thermal measurements upon minerals or cooling magmas have been made, and it is in this direction that a beginning is to be attempted. The temperatures of mineral reactions under atmospheric pressures are nearly all within reach of existing laboratory apparatus and methods. 


\section{FXISTING METIIODS.}

I'urthermore, the methods which have been used hitherto in determining these mineral melting points seem to the authors to be open to serious objection, both in principle and in application. They depend, almost without exception, upon the personal judgment of the observer, and not upon the actual measurement of any physical constant. For this reason, perhaps, more than any other, the results obtained by different observers upon the same mineral from the same source do not agree within considerable limits, much larger than can be properly ascribed to impurities in the specimens. Familiar examples will best illustrate this point. Among the determinations of the mineral melting points, two have received much more general acceptance than others - those of Joly* and of Doelter. $\dagger$

The melting temperatures which they obtained for some of the typical feldspars are as follows:

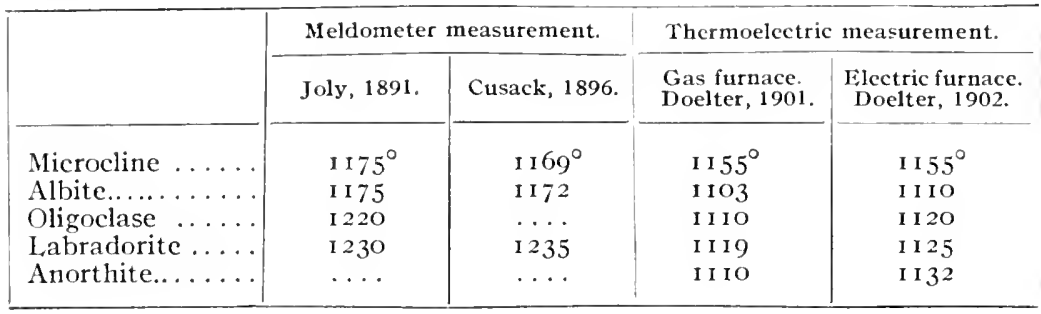

The determinations agree in recording higher melting points toward the calcic end of the series, but the differences between corresponding melting points by the two methods is greater than the observed differences between different feldspars.

Joly's method was novel. He stretched a thin strip of carefully prepared platinum foil between suitable clamps, placed a few grains of the powdered mineral upon it, and mounted a small microscope above, so as to be readily trained on any part of the strip. The foil was then heated by an electric current which could be very gradually increased, and the temperature measured from the linear expansion of the strip at the moment when the observer at the nicroscope noticed the first signs of melting. The author of this method was able to obtain concordant results with it to within about $5^{\circ} \mathrm{C}$., but

* J. Joly, Proc. Royal Irish Acad., 3, 2, p. 38, is91. R. Cusack, Proc. Royal Irish Acad., 3, 4, p. 399, I 896.

†C. Doelter, Tschermak Min. u. Petr. Mith., 20, p. 2 10, 1901 ; 21, p. $23,1902$. 
differences several times greater than $5^{\circ}$ appeared in our observations with the Joly apparatus, unless the grains were prepared with the greatest care and all the observations made by the same observer. The size and form of the grains, the care used in locating them exactly in the middle of the strip, every draught of air, but most of all the judgment of the observer as to when the substance appeared to melt, all entered into the restilt to a very considerable degree. There is also another source of error with which we afterward became familiar, which may serve to account for the very large differences between Joly's results and our own later values with some of the well-known minerals, though not with all. In certain of the minerals, after melting, the resistance to change of shape, due to viscosity, is of the same order of magnitude as that due to the rigidity of the crystal just before melting, a fact which may well have led to large errors of judgment in this method of detecting melting points.

The possibility of working very expeditiously with minute quantities of a substance led us to study this method with great care, and we were fortunate enough to possess an instrument of Professor Joly's own model, made by Yeates $\&$ Son, Dublin, but the results obtained with it, even under most favorable conditions, are more in the nature of personal estimates than of exact measurements of the change of state. Its value for qualitative study, and in eases where only a very minute quantity of a substance is available, is unquestioned.

Doelter has employed electric furnaces, modeled after that in use at the Reichsanstalt by Holborn and Day, for the determination of the melting points of the metals. He measured his temperatures with thermo-elements, and used several grams of material in his determinations, but he also judged of the approach of the melting point by the appearance of the charge and usually recorded two temperatures-the first approach of viscous melting and the point where the niaterial appeared to have gone over into a thin liquid.

\section{DE'TAILED PLAN.}

We determined from the first to get rid of this personal factor. However carefully such observations may be made, and however well supported by the reputation of a particular scientist for skilful and exact work, they can not have a permanent value. Melting points of pure minerals are not different, in principle at least, from the melting points of other chemical compounds or of metals. They occur at less accessible temperatures and involve some complicating phenomena, as we shall see presently, but the change of state of a solid crystalline 
mineral to a liquid numst of course be defined by an absorption of heat. Whether the appearance of the mineral charge in the furnace will offer a trustworthy index through which to locate this absorption may well be expected to differ with different substances. Nearly all observers have recorded the fact that many substances of this class remain very viscons after melting, and that the transition is not well marked in the appearance of the material.

We therefore planned an apparatus which should be as sensitive as possible to heat changes over a long range of temperatures, and then prepared to examine the thermal behavior of simple minerals of natural or artificial composition when gradually heated or cooled. Changes of crystalline form (Umwandlungen) or of state (melting and solidifying) must involve a more or less sharply marked absorption or release of heat, and be recorded as breaks in a smooth curve in the same way as in the determination of metal melting points or the singularities of any of the well-known chemical compounds at lower temperatures.

APPARATUS.

The apparatus used in these determinations may be assumed to be fairly well known. It is the same in all essential particulars as that used by Holborn and Day* in establishing the high-temperature scale with the gas thermometer at the Reichsanstalt. And yet it is plain that such a scale requires some care in the transplanting, particularly as the authors were without a gas thermometer and were, therefore, not in position to make direct comparisons with the gas scale.

THERMO-ELEMENTS.

The temperatures were measured with thermo-elements exclusively. We obtained from Dr. Heraeus (Hanau, Germany) a set of fout elements cut successively from the same roll of wire, which, when joined together, proved to be identically alike in their readings over the range of temperatures covered by the gas scale of the Reichsanstalt $\left(250^{\circ}\right.$ to $\mathrm{I} 5 \mathrm{O}^{\circ} \mathrm{C}$.) within the limits of observation error. Through the courtesy of Prof. Holborn these were taken to the Reichsanstalt and measured in the original melting-point furnace with the same elements in terms of which the gas-thermometer scale had been expressed, and five careful comparisons made. These were the melting points of the pure metals, cadmium (in air), zinc (in air), antimony (reducing atmosphere), silver (reducing atmosphere) and copper (in

\footnotetext{
* Ludwig Holborn and Arthur L. Day, Am. Journ Sci (4), 8, p. I65, I 899
} 
air). A fortunate circumstance made it possible to send these carefully calibrated elements to Washington by messenger, which made it certain that they suffered nothing in transit.

The elements were then further conpared in an electric furnace, which will be described below, and the melting points of the same group of metals again determined in our laboratory. The metals used, however, were from other sources than those which had served for the ealibration at the Reichsanstalt. When this test was finished, we were able to assure ourselves that, although all the constants in the measuring apparatus - thermo-elenents, resistances, standard cells, metals, etc.- - had been clianged in the transfer from the Reichsanstalt to the Geological Survey at Washington, the aggregate error nowhere exceeded $1^{\circ}$ over the entire range from $250^{\circ}$ to $1150^{\circ}$. It will be remembered that $1^{\circ}$ was about the accuracy which the standard gas thermometer showed at $1000^{\circ}$. Our thermo-electric system is, therefore, now doubly establislied-(1) by direct comparison and (2) through an independent series of metal melting points-upon the gas-thermometer scale of the Reichsanstalt within the limits of error of the latter, and can be verified at any time with the help of two of the elements which have been laid aside for this purpose, or the melting points of the metals. The scale is, therefore, permanent.

\section{TEMPERATURE SCALE.}

As the introduction of the standard high temperature scale of the Reichsanstalt into this country and its establishment by proper fixed points may be a matter of considerable interest to other investigators, some further detaiis regarding the metals clıosen for these fixed points are added here. We tried to find metals which should not only be of the purity necessary for such standards, but which should be easily obtainable in uniform quality. With four of the five metals of the Reichsanstalt series-cadmium, zinc, silver, and copper-no difficulty was experieneed, but we were not able to find satisfactory antimony in this country. This neerl not prove an obstacle, for the four points mentioned will serve most purposes without a fifth, while if the needs of an experiment are so exacting as to require an intermediate melting point, antimony can be imported from Kahlbaum, of Berlin, without great delay or excessive cost, in the same purity as that originally used at the Reichsanstalt.

The cadmium and zine in our series were taken from the regular listed ehemicals of Eimer \& Anend (zine, "C. P. in sticks;" "cadmium, metal sticks"). The silver was the well-known test silver of the 
Philadelphia Mint laboratory, while the copper was also from Eimer \& Amend ("C. P. copper (lrops, cooled in hydrogen").

Careful analyses of samples of the cadmium, zinc and copper follow:

\begin{tabular}{|c|c|c|}
\hline $\begin{array}{l}\text { Zinc. } \\
\text { (Eimer \& Amend's "C. P. } \\
\text { in sticks.") }\end{array}$ & $\begin{array}{l}\text { CADMIUM. } \\
\text { (1:imer \& Amend's in } \\
\text { sticl:s.) }\end{array}$ & $\begin{array}{l}\text { COPPER. } \\
\text { (Fimerite Amend's "C. P. } \\
\text { drops, cooled in hydrogen.") }\end{array}$ \\
\hline Percent. & Per cent. & Per cent. \\
\hline As............ None & As ........... No None & Te and Se .... None \\
\hline $\mathrm{C} r 1 . . . . . . .$. Trace & $\mathrm{Cu} \ldots \ldots \ldots \ldots$ Trace & Sb............ Trace \\
\hline $\mathrm{Pb}_{1} \ldots \ldots \ldots \ldots$ O.O412 & $1 b \ldots \ldots \ldots 0.0860$ & As............. None \\
\hline$\ldots \ldots \ldots 0.0021$ & Хп........ Trace & Bi.......... None \\
\hline Fe......... o.0053 & Fe......... 0.0025 & $\mathrm{Ag} \ldots \ldots \ldots \ldots 018$ \\
\hline Co and Ni..... None & Co and Ni...... None & $\mathrm{Pb} \ldots \ldots \ldots \ldots$ O.OOI \\
\hline S............ 0.0005 & S........ 0.0005 & $\begin{array}{l}\text { Co and Ni..... None } \\
\text { Zn ........... } \\
\text { Fe...... on }\end{array}$ \\
\hline Total impurities..0.0491 & Total inmpurities o.089o & Total impurities. 0.040 \\
\hline
\end{tabular}

* This figure is donbtless somewhat too high.

It was not deemed necessary to make an analysis of the silver. as we were assured that it contained 110 inpurity which could be quantitatively determined.

The melting temperatures of cadminm and zinc are relatively low, and those of silver and copper comparatively high on the gas scale, with a long interval between, so that it sometimes becomes very desirable to have an intermediate point. The two melting points which are most conveniently located are aluminium and antimony. Aluminium, on account of its low density, and perhaps because it has been less successfully purified than the other metals, does not give a sharp and satisfactory melting point. The melting point of Kalıbaum's antimony, of which a recently published analysis is reproduced here, serves this purpose excellently. It rarely solidifies withont considerable undercooling, but the point to which the temperature rises after crystallization begins is sensibly identical with the melting point.

Antimone (KAHLBAUM, BERLIN). $\dagger$

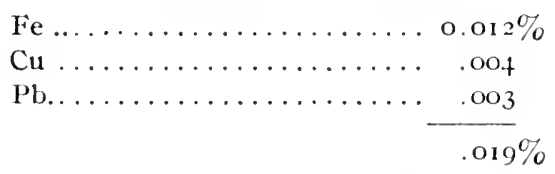

The C. P. antimony obtained from Eimer \& Amend and from Merck \& Co., in a careftll analysis, for which we are indebted to Dr.

† Fìitz Henz, Inaugural Dissertation, Zürich. Published Leipzig, igo3. 
W. F. Hillebrand of the Geological Survey, each showed about one per cent of the sulphide still present and traces of other impurities. The melting temperatures of these varied under different conditions as much as $15^{\circ}$, and were totally unsuited to this work.

Inasmuch as the melting points of these metals were determined with thermo-elements which Professor Holborn had just calibrated with the metals in use at the Reichsanstalt for this purpose, a comparison of the values obtained will show the accuracy with which one may reproduce the Reichsanstalt scale entirely from local sources:

\begin{tabular}{|c|c|c|c|c|c|}
\hline \multirow[b]{2}{*}{ Metal. } & \multicolumn{2}{|c|}{ Reichsanstalt. } & \multicolumn{2}{|c|}{ Day and Allen. } & \multirow{2}{*}{$\begin{array}{l}\text { Differ- } \\
\text { ence. }\end{array}$} \\
\hline & Source. & $\begin{array}{l}\text { Melting } \\
\text { point. }\end{array}$ & Source. & $\begin{array}{c}\text { Melting } \\
\text { point. }\end{array}$ & \\
\hline Cadmium.... & Kahlbaum. & $321.7^{\circ}$ & Eimer \& Amend & $321 \cdot 7^{\circ}$ & $0.0^{\circ}$ \\
\hline Zine. ....... & & +19.0 & Do. & +20.0 & 1.0 \\
\hline Silver ..... & $\begin{array}{l}\text { Gold u. Silber } \\
\text { Scheideanstalt. }\end{array}$ & 961.5 & Philadelplia Mint & 962.2 & 0.7 \\
\hline $\begin{array}{c}\text { Copper (in } \\
\text { air) } \ldots . . .\end{array}$ & $\begin{array}{l}\text { Haddernheim } \\
\text { Kupferwerk. }\end{array}$ & $106+.9$ & Eimer \& Amend & 1065.3 & $0 . t$ \\
\hline $\begin{array}{r}\text { Copper (re- } \\
\text { ducing at- } \\
\text { mosphere.) }\end{array}$ & Do. & $10 S_{4} \cdot 1$ & Do. & $*_{108} 3.6$ & 0.5 \\
\hline
\end{tabular}

* A single determination with one element; all others are mean values with two or more elements.

For the method of extrapolation of the scale and further information regarding the use and accuracy of thermo-elements at these temperatures, reference is made to the papers of Holborn and Day already cited.

For everyday use, four more elements were prepared and calibrated in the same way. Of these, two are of the usual form (fig. 1) and two are of a new design which has proved very effective in the determination of the melting points of non-metallic substances. It will be seen from the diagram of the insulated element that the hot junction is protected from the melting charge by a casing of platin-iridium (0.5 mm. thick) and by a protecting tube of refractory Berlin (Marquardt) porcelain ( $1.5 \mathrm{~mm}$. thick). Very early in our experiments upon the mineral silicates we became aware that the conductivity of these materials for heat would be much poorer than in similar charges of metal. Furthermore, the charge of mineral which the furnaces could carry was only one-fourth to one-third as great as the metal charges used in the calibrations, because of the great difference in specific gravity and the limited space which could be heated to a fairly uniform temperature. For these reasons the changes of state would be less sharply marked upon the heating and cooling curves than metal melting points, and it was feared that the readings of the protected 
element might prove too high or too low through inability to take on the temperature of the surrounding mass promptly. It was to discover and obviate this possible souree of error that the form of thermoelement indicated in the adjoining diagram (fig. 2) was devised. It really amounts to nothing more than the ordinary

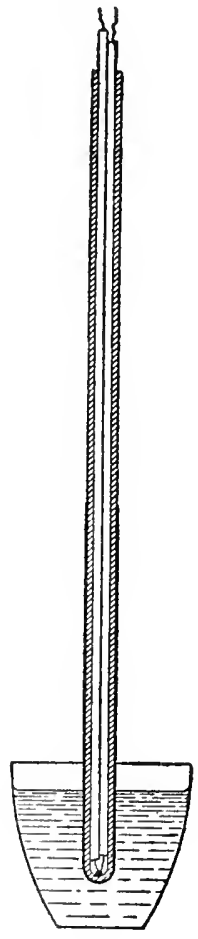

I. form of platinum-platin-rhodium element with the platinum wire insulated from the other by a very slender porcelain (Marquardt) tube and the platinrhodium wire broadened ont and wrapped around this tube like a cap over the portion which dips into the charge. The hot junction is

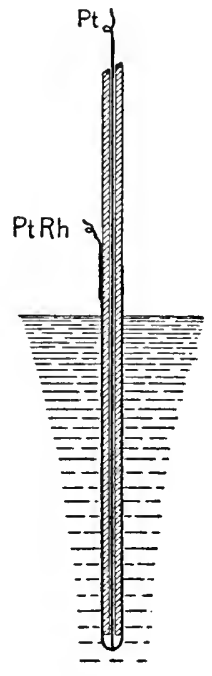

2.

FIG. 1.-Thermo-element (standard form) in position.

FIG. 2.-A new form of thermo-element. then the lower extremity of the cap where the platinum wire emerges from its insulating tube and is welded inside the plati11-rhodium cap.

' 1 his form was dictated entirely by experience to meet conditions where an exposed element might be necessary or desirable. The wires of an ordinary element, if embelded withont protection, are rather frail for the wear and tear of breaking or drilling mineral charges out of the crucibles after the measurements, and they cap not be strengthened without intro. ducing a greater error through the amount of heat conducted away from the junction than the one which it is clesired to obviate.

It has furthermore been the almost invariable experience of one of the authors* that when an element, through exposure to combustion products or otherwise, no longer gives normal readings, the seat of the trouble lies in the 5 or 6 centimeters of the platinum wire immediately adjacent to the hot junction, and not in the alloy. The pure platinum sometimes seems to absorb enough volatile or other contact products, when unprotected in a furnace at very high temperatures, to alter both its resistance and its thermo-electric potential. $\dagger$ Changes of this kind are not serions when a number of control elements are constantly available, and they

\footnotetext{
* Day. † Holburn \& Day, Am. Jonru. Sci. (4), 10, p. I 71, 1900.
} 
are usually permanently corrected by half an hour's glowing in the open air at full white heat. The glowing must be done by passing a suitable current through from end to end and not with a Bunsen burner or gas blast.

In event of a serious accident involving an exposure of the element which can not be corrected by glowing, cutting out the exposed portion of the platinum wire and reconnecting will almost always restore the normal readings.

The new form of element seeks to avoid both these difficulties; it offers the advantage of an exposed junction without exposing the platinum wire, and by making the platin-rhodium cap project but little above the surface of the melting charge it avoids excessive loss of heat by conduction away from the hot junction. In fact, in this latter particular the new form enjoys a distinct advantage over the usual form of heavily protected element. It has the disadvantage of being more frail to handle, but there is little danger of a nything more serious happening than the breaking of the porcelain tube, which is readily replaced.

These elements are calibrated in metal batlis like the others by inclosing in a porcelain protecting tube.

It need only be added that all the more important temperatures throughout this work were separately determined with three different elements. One of these was always from the Reichsanstalt set (protected) and one usually an unprotected element of the new form. No systematic differences between the readings of the two types have ever been found.

FURNACE.

The furnace, in plan, differed but little from that in use for meltingpoint determinations at the Reichsanstalt. In the working out, two important changes were introduced, in order to enable it to reach the higher temperatures of the mineral melting points. A more refractory and better insulating material (a mixture of magnesite and corundum) was substituted for fire clay in the hotter parts and the coil was wound on the inside of the oven tube instead of outside. The latter involved some little mechanical ingenuity and skill in winding, but the gain in economy and in the rapidity with which changes could be effected or constant conditions established more than repaid any additional labor in preparation.

A diagram of the furnace in section is shown in fig. 3. It could be

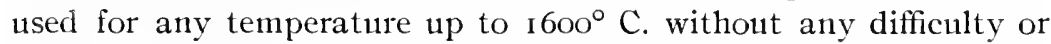
especial precautions and could be regulated to maintain a constant temperature at a particular point for long periods of time. 
The coil, which was obtained from Dr. Heraeus, was of platiniridium wire (9o parts Pt., 10 parts $\mathrm{Ir}$.), $1.5 \mathrm{~mm}$. in diameter, and

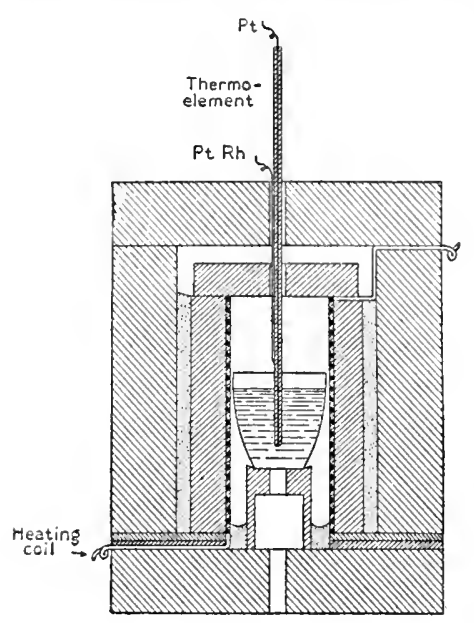

Fir. 3.- The furnace, showing thermo-element and charge. required about 3000 watts to maintain a constant temperature of $1600^{\circ} \mathrm{C}$. The furnace was carried at times on a ino-volt direct-current street main, but accurately constant temperatures could not be depended on without the storage battery.

The insulation in these furnaces was so perfect that shutting off or reversing the heating current at the highest temperatures did not produce a quiver in the galvanometer to which the thermo-element was connected, although the sensitiveness of the system was such that a leakage anounting to a single micro-volt (corresponding to less than $\left.0.1^{\circ}\right)$ at $1600^{\circ}$ would have caused a displacement of more than two millimeters on the scale.

\section{STANDARDS.}

The thermo-electrical potential was measured upon a potentiometer (Wolff, Berlin, Reichsanstalt calibration) in terms of a standard cadmium cell (saturated) prepared by ourselves. Two of these cells were used interchangeably during the earlier measurements. Toward the close of the series four fresh cells were prepared for comparison with the earlier ones and were found to agree with them within o.ooor. One of these later cells (the readings of the four were identical to the fifth significant figure) was verified by Dr. Wolft, of the Bureau of Standards, by comparison with the standard Clark cells of that institution and found to be $1.0195 \mathrm{~V}$ at $20^{\circ} \mathrm{C}$., assuming the legal value (United States) of the Clark cell, $1.434 \mathrm{~V}$, at $15^{\circ} \mathrm{C}$. Substituting the Reichsanstalt value, Clark $15=1.4328$, * our cells would give a normal potential difference of r.or 86 at $20^{\circ}$. The temperature determinations which follow are, therefore, calculated in terms of this number.

With the apparatus here described, the authors were enabled to command any furnace temperature up to $\mathrm{I} 600^{\circ}$ conveniently, to regu-

\footnotetext{
* Jaeger u. Kahle, Wied. Ann., 65, p. 926, r 898.
} 
late it quickly and with great exactness, or to hold it constant for long intervals. An oxidizing or reducing atmosphere could also be easily introduced whenever desired. It is, however, undesirable to expose either coil or thermo-element too freely to oxygen at very high temperatures on account of the considerable losses by sublimation to which the platinum metals are subject.

With the help of the standard metals mentioned, which are readily obtainable and can be used repeatedly, thermo-elements or resistance pyrometers can be calibrated in any laboratory, and used for all measurements up to the limit of the Reichsanstalt scale ( $1150^{\circ} \mathrm{C}$.) with no greater error than that inherent in the scale itself. Above this temperature up to $1600^{\circ}$ the continuation of the thermo-electrie scale probably still furnishes the most convenient and trustworthy extrapolation which has yet been perfected.

The uniformity and certainty of this extrapolation will best be illustrated by the measurements upon anorthite (the highest melting point we measured). The melting temperature of a mineral of very poor conductivity for heat and relatively low specific gravity is much more difficult to measure than that of a metal, but the agreement of the results tabulated below (see Anorthite, p. 37) is sufficiently good to demonstrate the aceuracy of the extrapolation. The thermoelectric potential, therefore, appears to deserve entire confidence for consistent extrapolation through the $450^{\circ}$ immediately above the present Reichsanstalt seale.

\section{FIRST GROUP OF MINERALS INVESTIGATED.}

The particular group of minerals chosen for the first investigation was the soda-lime feldspar series, and orthoclase. The reasons for this choice will be fairly obvious. Aside from its being altogether the most important group of rock-forming minerals, unusual interest has been attracted to it through Tschermak's theory that these feldspars bear a very simple relation to one another. that they are (orthoclase excepted, of course) in fact merely isomorphous mixtures of albite and anorthite. This hypothesis has given occasion for serious and extended study, both from the optical and thermal sides.

A complete revicw of the literature of the feldspars will not be attempted here. Although opinion is still somewhat divided,* it is probably fair to say that the optical researehes have not yet definitely established or disestablishcd the isomorphism of the albite-anorthite

\footnotetext{
* Fouqué et Iévy, Synthèse des Minéraux et des Roches, p. I 45, I882; C. Viola, Tschermak Min. \& Petr. Mittl., 20, p. 199, I901; Lane, Journ. Geol., XII, 2, p. 83,1904 ; J. H. L. Vogt, “Die Silikatschmelzlösungen,” Christiania, 1903.
} 
group. Investigation from the thermal point of view has been even less satisfactory by reason of the subjective methods employed, to which reference has already been made, though the recorded results indicate with reasonable nnanimity that the melting point of anorthite is above that of albite and that the intermediate feldspars will probably fall between the two.* Beyond this conclusion, the great body of evidence is more or less contradictory and sonuetimes controversial in character.

\section{Orthoclase (Preliminary).}

Somewhat muluckily, our measurements began with natural orthoclase (microcline) from Mitchell County, North Carolina, a quantity of which was placed at our disposal by the U. S. National Museum. The material was powdered so as to pass readily through a roo-mesh sieve, and placed in $100 \mathrm{cc}$. or $125 \mathrm{cc}$. platinum crucibles, sometimes open and sometimes covered, in charges of from 100 to 150 grams. These charges were heated slowly in the electric furnace from $600^{\circ}$ to above $1400^{\circ} \mathrm{C}$., but, although the thermal apparatus was sufficiently sensitive to detect an unsteadiness of a tenth oi a degree with certainty not the slightest trace of an absorption or release of heat was found. The charge at the beginning of the heating was a dry crystalline powder which was prodded from time to time with a stont platinum wire to ascertain its condition as the heating progressed. At about $1000^{\circ}$ traces of sintering were evident; at $1075^{\circ}$ it had formed a solid cake which resisted the wire, at $I 50^{\circ}$ this cake had softened sufficiently to yield to continued pressure, and at $\mathrm{I} 300^{\circ}$ it had become a viscous liquid which could be drawn out in glassy, almost opaque threads by the wire. Under the microscope the opacity was seen to be due to fine included bubbles, the material being entirely vitreous. The cooling was equally uninstructive; the vitreous mass solidified gradually without recrystallization or the appearance of any thermal phenomenon. Frequent repetitions with fresh charges and varied conditions added nothing to our knowledge of the melting temperature, and the matter began to look very unpromising.

We also reheated charges of the resulting glass, which was sometimes repowdered and sometimes in the cake as it had cooled. But except to observe that the glass powder began to sinter earlier $\left(800^{\circ}\right)$, no new facts appeared. $\dagger$

* J. H. L. Vogt, loc. cit., p. 154, expresses the opinion that the soda-lime feldspars fall under 'Type III of Roozeboom's types of isomorphons series with a minimum between anorthite and albite.

$\dagger$ These sintering temperatures varied within considerable linits with the fineness of the material and, therefore serve only in a very rough way to define the state of the charges. 
Then we tried by various means to recrystallize the melted orthoclase. We mixed crystalline powder with the glass, we applied successive quick shocks to the cooling liquid for several hours with an electric hammer below the crucible, we varied the rate of cooling and even tried rapid see-sawing between $800^{\circ}$ and $1300^{\circ}$. We circulated air, water vapor, and carbonic dioxide through the charge throughout the heating, and finally introduced a rapid alternating current sent directly through the substance while cooling, but no trace of crystallization resulted. An extremely viscous, inert mass always remained, which gradually hardened into a more or less opaque glass. It appeared somewhat transhucent if very high temperatures had been reached, but was never clear.

Following orthoclase, a number of specimens of natural albite were tried under similar conditions and with entirely similar results.

Later on, when more experience had been acquired, these minerals were taken up again and a satisfactory explanation for their behavior was found. But for the moment all the defining phenomena appeared to be so effectively veiled by some property, presuniably the viscosity, that we were constrained to look about for some similar compound which should give us a better insight into the behavior of mineral glasses and their thermal relations, and to lay aside the feldspars until they could be more successfully handled.

This outline of our unsuccessful experiences is given here in some detail, in order to show the actual difficulties which confront the student in working with the feldspars, in the face of which it is certainly not surprising that uncertain and contradictory conclusions have been reached.

\section{BORAX.}

The substance chosen for this preliminary work was ordinary anhydrous borax (sodium tetraborate). We chose this merely because it was a simple glass and unlikely to undergo chemical change. It is easily obtainable pure and its thermal phenomena are within easy reach. The study of borax proved to be most instructive. It gave us an effective insight into the behavior of this class of substances, and in particular served to define the phenomena of melting and solidifying in substances which undergo extreme undercooling and which recrystallize with difficulty, or not at all. The results of this study of borax were, therefore, of much interest in themselves and were given in a paper before the National Academy of Sciences at its spring meeting in Washington last year (April 2 I, 1903), but were not printed at that time. 
The borax glass mpon which our measurements were made was prepared in the usual way by heating the crystals until the water of crystallization had been driven off and the viscons mass was reasonably free from bubbles. If the borax is pure, the anhydrous product, when cooled, is a brilliant, colorless glass, isotrophic, of conchoidal fracture, and specific gravity 2.37 . The specific gravity was determined in the fraction of kerosene boiling above $185^{\circ} \mathrm{C}$. About $100 \mathrm{~g}$. of this glass were then broken up and placed in a platinum crucible in the electric furnace. The thermo-element was placed in position as indicated in fig. 3, the lieating eurrent properly regulated, and observations of the temperature made at intervals of one minute, while the glass softened and passed gradually over into a thin liquid $\left(800^{\circ}\right)$. Then the current was reduced and the cooling curve observed in the same way. These observations gave an unbroken curve, both for the heating and cooling, as in the case of all the glasses, * without a definite melting or solidifying point, although the arrangements for detecting an absorption or release of heat were very sensitive. Prodding at intervals with a platinum rod showed the change to be perfectly gradual from a clear, hard cake through all degrees of viscosity to a fairly thin liquid and back again. This observation is of considerable interest as showing that the absence of bounding phenomena between the cold glass, which fulfills the mechanical conditions for a solid very perfectly, and the liquid, is not confined to mixtures of complicated chemical composition, but is exhibited also by true chemical compounds of undoubted purity. It is, therefore, not conditioned by composition, but by the physical nature of the substance.

Having verified this behavior of anhydrous borax by several repetitions of the experiment, varions disturbing influences were applied to the slowly cooling liquid in the hope that some temperature or range of temperature would be found within which the vitreous condition would prove unstable and erystallization be precipitated. The jar produced by an electric hammer pounding upon the outside of the furnace during cooling proved to be sufficient to bring down the entire charge as a beautiful crystalline mass of radial, fibrous structure, brilliant luster, rather high refractive index, and increased volume. I iig. 4 will give a good idea of the appearance of the anhydrons crystalline borax in the crucible. Its specific gravity proved to be 2.28 as conıpared with 2.37 for the glass, a somewhat unusual relation, $\dagger$ which may, in part, account for the quasi stability of the vitreous form during cooling.

\footnotetext{
* See Tammann, loc. cit.; also Roozeboom, "Die heterogenen Gleichgewichte, etc.," Braunschweig, i9or.

+ Tammann, loc. cit., p. 47 et seq.
} 


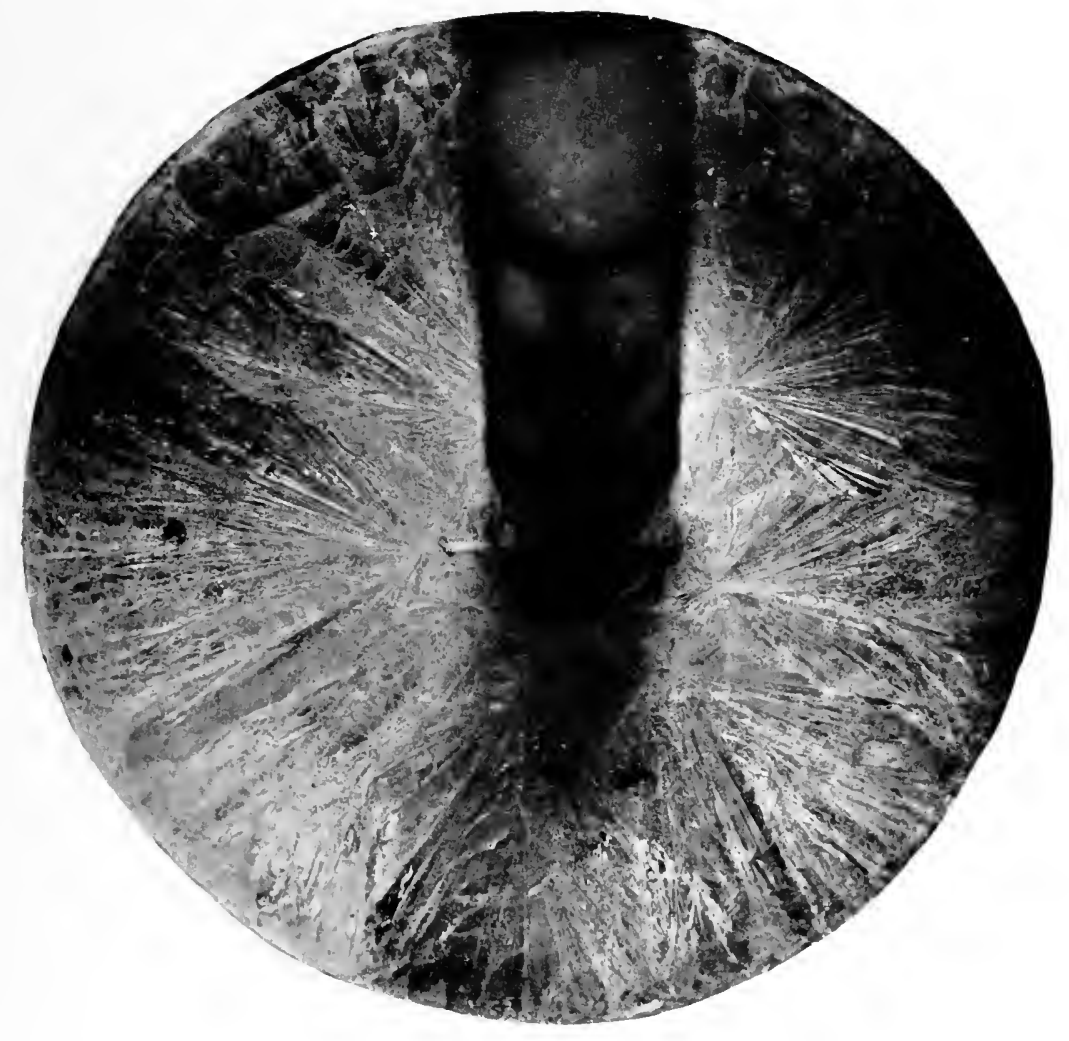

FIG. 4.

CHEMICALLY PURE BORAX ANHYDROUS', CRYSTALLIZED FROM THE GLASS. 

Observations were then undertaken upon the crystalline borax with a thermo-element as before, to determine the melting temperature and solid modifications, if such existed, but none of the latter were found. The charge melted uniformly at $742^{\circ}$ and the melting point was well defined. A curve showing the minute-to-minute observations on the crystalline borax between the temperatures $650^{\circ}$ and $775^{\circ}$ is shown in fig. $5, a$.

Having determined the melting point of crystalline anhydrous borax satisfactorily, we examined more closely into the conditions

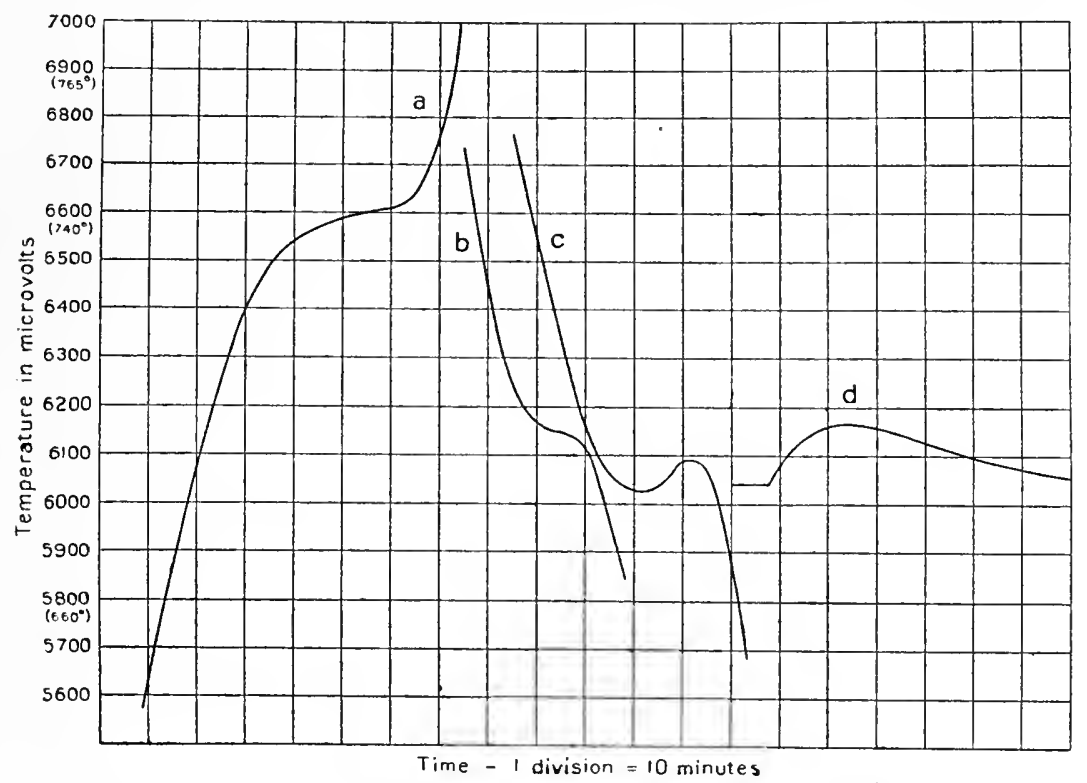

FIG. 5.- $a$, Melting-point curve; $b, c, d$, curves showing undercooling and crystallization at different temperatures.

under which it solidified. As has been said, if the melted charge was allowed to cool slowly, undisturbed, no return to the crystalline state occurred. It merely thickened gradually into a transparent glass without releasing the "latent" leat which it had taken on in melting (fig. $7, b$ ). If it was subjected to the jarring produced by the electric hammer on the furnace wall, it cooled down a few degrees below the melting point and then began to crystallize, the heat of fusion was set free, and a rise in temperature immediately appeared, represented by a lumup upon the cooling curve, as shown in the figure (fig. $5, b, c, d$ ). Up to this point the phenomenon differs but little from the usual behavior of liquids which undercool in solidifying. We next varied the experiment by first cooling quietly to about $100^{\circ}$ below the melting point 
and then introducing a few crystal fragments or starting the pound ing. Crystallization and release of the latent licat followed at once. In fact over a range of some $25^{\circ}$ immediately below the melting point it proved to be within our power to precipitate the crystallization of the undercooled n11ass entirely at will. It was even possible to cool the melted cliarge quictly down to the temperature of the room and remove it from the furnace as a clear glass, then, on a subsequent day, to reheat to some point in this sensitive zone and pound judiciously, when crystallization would at once begin, marked by the release of the latent heat of the previous fusion as before (fig. 6, $a, b$ ). The accompanying curves show the situation clearly. Curves $a a^{\prime}$ and $b b^{\prime}$, fig. 7 , were obtained from charges of crystalline and vitreous borax, respectively, of exactly equal weight, which were cooled and reheated in the same clectric furnace under like conditions. The radiation from the furnace for like temperature conditions is practically the same, so that the more rapid rate of cooling and of reheating in the crystalline charge indicates a much smaller specificlicat than for the vitreous form.

From the point of view of the usual definition of the solidifying point of a substance, a diffi-

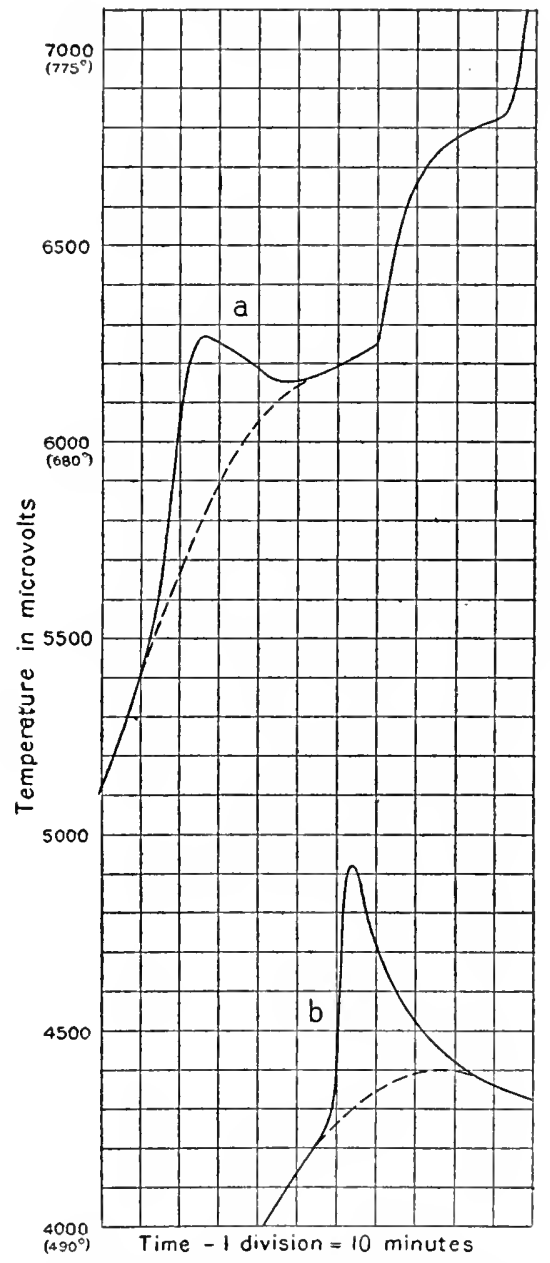

F1G. 6.-Curves showing the release of the heat of fusion at widely different temperatures. culty confronts us here: (1) We were able to vary the beginning of solidification (crystallization) at will over a range of $250^{\circ}$, and (2) the temperature to which the charge rose after the undercooled liquid had begun to crystallize did not reach the melting point, although 
once crystallization was induced only $10^{\circ}$ below it in a furnace of

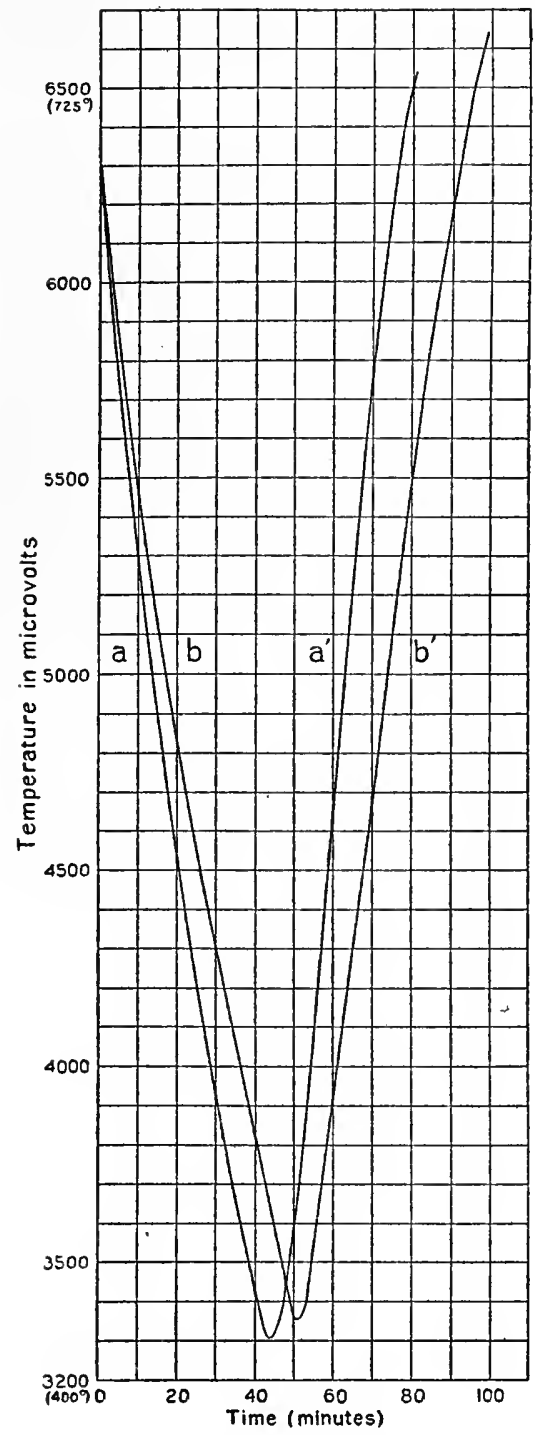

Fig. 7.-Curves showing difference in specific heat between crystalline $\left(a a^{\prime}\right)$ and vitreous $\left(b b^{\prime}\right)$ borax under like conditions of cooling and reheating. constant temperature. The rapidity with which the crystallization and the accompanying release of the latent heat go on depends in part upon the rate of cooling and the character of the disturbance which has been applied, $i$. $e$, upon accidental rather than characteristic conditions. It thus happens that the amount of the heat of fusion and its slow rate of liberation in the case of liquids which can be greatly undercooled and become very viscous may be such as to deprive it of its usual significance as defining a solidifying point. It is, of course, a consequence of the phase rule that the solidifying temperature of an undercooled liquid is established, if only equilibrium between solid and liquid (and vapor) is reaclied before complete solidification is accomplished, but equilibrium is not necessarily attained during solidification, and the devices usually employed (sowing with crystals, agitating) are often totally inadequate to effect it. The temperature to which a crystallizing liquid rises after undercooling is not necessarily constant or in any way related to the melting point and is, therefore, not, in general, entitled to be regarded as a physical constant.

We then endeavored to ascertain whether the unstable domain had a lower limit also. For this purpose we mixed a quantity of the 
crystals with the glass and powdered them together to about the fineness represented by a $150-m e s h$ sieve and heated them very slowly. In this condition the glass proved to be very unstable and erystallized readily with a rapid release of its latent heat at about $490^{\circ}$. Very slow heating (10 minutes per 1 degree) gave a temperature a few degrees lower, but such variations as could be applied within the period of a working day did not suffice, under the most favorable conditions, to change this temperature materially. The first evidence of molecular mobility in borax glass, shown in the sticking together of the finest particles (sintering), and the first traces of crystallization and release of latent heat, appeared consistently at about $490^{\circ}$ to $500^{\circ}$. Still a third phenomenon attracted our attention to this temperature. On every occasion when borax glass was heated rapidly, either powdered or in the solid block, a slight but persistent absorption of heat appeared in this same region and continued over some $20^{\circ}$, after which the original rate of heating returned. We were entirely unable to explain an absorption of heat in an amorphous substance under these conditions except by assuming an actual change of state to exist between amorphous glass and its melt, in which case the absorbed heat would reappear somewhere upon the corresponding cooling curve, which it failed to do. We then reasoned that any assumed change in the molecular structure which would account for an absorption of heat would also be likely to eause an interruption in the continuity of the curve of electrical conductivity, and the relative conductivity was determined throughout this region, but no such interruption appeared.

Finally the matter was abandoned. The evidence did not appear sufficient to establish any discontinuity in the cooling curve of the glass, so long as no crystallization took place.

When these relations had been clearly established, we turned again to the feldspars.

It beeame clear very early in the investigation that only artificially prepared and ehemically pure specimens would be adequate for our purpose. Eacl of the end members of the series, anorthite and albite, as found in nature, is always intermixed with some quantity of the other, while the intermediate nembers generally contain iron and potash, and all are liable to inclusions.

There was nothing new in this plan. Fouqué and Lévy* had demonstrated the possibility of making pure feldspars by chemical synthesis and had studied their optical properties some years ago. We undertook to prepare much larger quantities than they (2oo grams)

* Synthèse des Minéraux et des Roches. 
and to make a careful study of their heating and cooling curves under atmospheric pressure - the conditions under which anorthite and the plagioclases crystallize, the relations between the amorphous and crystalline forms, the sintering of crystalline and vitreous powders, in short, their entire thermal behavior, as we had done with the borax. At the same time it was our purpose to make careful determinations of the specific gravities of both the vitreous and the crystalline products, analyses of such portions as might be of special interest, and also to prepare microscopic sections wherever they were likely to throw light on the relations involved. The latter, after preliminary examination, were very thoroughly studied by Prof. J. P. Iddings of the University of Chicago, whose large petrographic experience with mineral crystallites makes his judgment of very exceptional value. His analyses (see Part II) of the slides form an important part of this discussion. We are also indebted to Mr. W. Lindgren of the United States Geological Survey for valuable assistance in the microscopical study of our products.

Analyses of Artificial Feldospars.

\begin{tabular}{|c|c|c|c|c|c|c|c|c|}
\hline & \multicolumn{2}{|c|}{ An. } & \multicolumn{2}{|c|}{$\mathrm{Ab}_{1} \mathrm{An}_{\mathrm{n}_{3}}$} & \multicolumn{2}{|c|}{$\mathrm{Ab}_{1} \mathrm{An}_{2}$} & \multicolumn{2}{|c|}{$\mathrm{Ab}_{2} \mathrm{An}_{1}$} \\
\hline & Found. & $\begin{array}{l}\text { Caleu- } \\
\text { lated. }\end{array}$ & Found. & $\begin{array}{l}\text { Caleu- } \\
\text { lated. }\end{array}$ & Found. & $\begin{array}{l}\text { Calcti- } \\
\text { lated. }\end{array}$ & Found & $\begin{array}{l}\text { Caleu- } \\
\text { lated. }\end{array}$ \\
\hline $\mathrm{SiO}_{2} \ldots \ldots \ldots$ & $43 \cdot 33$ & +3.28 & 47.10 & 47.18 & 5 I .06 & $5 \mathrm{I} \cdot 3 \mathrm{O}$ & 60.01 & 59.81 \\
\hline $\mathrm{Al}_{2} \mathrm{O}_{3} \ldots \ldots$ & 36.21 & 36.63 & $3+.23$ & 34.00 & $3 \mathrm{I} \cdot 5 \mathrm{O}$ & $31.2 I$ & $24 \cdot 95$ & $25 \cdot 47$ \\
\hline $\mathrm{Fe}_{2} \mathrm{O}_{3} \ldots \ldots \ldots$ & .29 & $\cdots \cdots$ & .15 & $\ldots \ldots$ & .22 & $\ldots \ldots$ & .29 & $\cdots \cdots$ \\
\hline $\mathrm{CaO} \ldots \ldots \ldots$ & 20.06 & 20.09 & 17.00 & 16.93 & 13.65 & 13.68 & 7.09 & 6.98 \\
\hline $\mathrm{Na}_{2} \mathrm{O} \ldots \ldots \ldots$ & . I I & $\ldots \ldots$ & I. 74 & I. 87 & 3.68 & 3.79 & 7.79 & $7 \cdot 73$ \\
\hline & 100.00 & & 100.22 & $\ldots \ldots$ & IOO. I I & & 100.13 & \\
\hline
\end{tabular}

The constituents used in our syntheses were precipitated calcium carbonate, anhydrous sodium carbonate, powdered quartz (selected crystals), and alumina prepared by the decomposition of ammonium alum. None of these contained more than traces of impurities, if we except the quartz, in which 0.25 per cent of residue, chiefly oxide of iron, was found after treatment with hydrofluoric and sulphuric acids. All but the calcium carbonate were carefully calcined and cooled in a desiccator before weighing. To obtain a homogeneous product, the weighed constituents were mixed as thoroughly as possible mechanically and heated in large covered platinum crucibles ( Ioo ce. capacity) in a Fletcher gas furnace.* After some hours' heating, during which the temperature usually reached $I 500^{\circ}$ or more, the product was removed from the furnace, cracked out of the crucibles, powdered,

* Buffalo Dental Company, No. 4r A. A Fletcher furnace of this type, with ordinary city gas pressure and a small blast motor, will melt all of the feldspars. 
passed through a "roo-mesh" sieve, and then melted again. This process probably gives a fairly homogeneous mixture, though a third fusion in the resistance furnace was generally made before determining the constants.

We prepared in this way albite $(A b)$, anorthite $(A n)$, and the following mixtures of the two: $A b_{1} A n_{5}, A b_{1} A n_{2}, A b_{1} A n_{1}, A b_{2} A n_{1}, A b_{3} A n_{1}$, $A b_{4} A n_{1}$. All of these were obtained in wholly or partially crystalline form, by crystallization from the melt, except albite. The syntheses were controlled by analyses of a number of the products, the results of which are shown in the table on p. 35.

\section{- Anorthite (Plate I).}

Of the whole series of feldspars, anorthite is in many respects the simplest to deal with. It is of relatively low viscosity when melted, and crystallizes easily, very rapidly, and always in large, welldeveloped crystals. A roo-gram charge crystallized completely in ten minutes. Sudden chilling gave a beautiful clear glass entirely free from bubbles, somewhat slower cooling usually resulted in a partial crystallization from few nuclei, the crystals always being large. In appearance it resembles the natural mineral in every respect. Its hardness is also equal to that of natural anorthite. Thin sections show good cleavage, and twinning according to the albite law is frequent. The extinction and other microscopic characteristics are as well marked as in natural specimens.

The heating curve of crystalline anorthite is perfectly smooth except for the single break which inarks the melting point. No trace of a second crystalline form (Umwandlung) appeared in this or any other of the feldspars within the temperature range of the observations $\left(300^{\circ}\right.$ to $\left.\mathrm{I} 600^{\circ}\right)$. Some undercooling always oceurs in solidification even if the rate of cooling is slow, but it is less, under like conditions, with anorthite than with any other member of the series. The heating curve of the glass shows a strong evolution of heat which may occur as low as $700^{\circ}$, when crystallization takes place. The melting point of crystalline anorthite was determined by three different thermo-elements upon two different mineral preparations. It will be seen from the table on p. 37 that the determinations agree remarkably well. This is of considerable significance with reference to the method of temperature measurement employed. It will be remembered that the established temperature scale ends at $150^{\circ}$ and that temperatures beyond that point are extrapolated with the help of some trustworthy phenomenon which varies with the temperature. IVe chose for this purpose the thermo-electric force developed between pure 
platinum and platinum alloyed with io per cent of rhodium. Now the constants of such thermo-elements will usually differ among themselves and require to be determined for each element by calibration with the gas thermometer or with the melting points of the metals. It therefore offers an excellent test of the value of the extrapolation if some sharp melting point can be found in the extrapolated range to serve as a point of reference. The melting point of crystalline anorthite serves this purpose exceedingly well, and separate determinations of it with three separate thermo-electric systems, gave identical valıes within the linits of error of observation. Our

ANORTHITE.

FIRST PREPARATION.

\begin{tabular}{|c|c|c|c|c|}
\hline Date. & Element. & $\begin{array}{l}\text { Electromotive } \\
\text { force in MV. }\end{array}$ & $\begin{array}{l}\text { Tempera- } \\
\text { ture. }\end{array}$ & Remarks. \\
\hline $\begin{array}{l}\text { Oct. } 7,1903 \\
\text { Do. } \\
\text { Oct. IO, } 1903 \\
\text { Do. } \\
\text { Do. } \\
\text { Do. } \\
\text { Do. }\end{array}$ & $\begin{array}{l}\text { A } \\
\text { A } \\
\text { A } \\
\text { No. } 3 \\
\text { No. } 3 \\
\text { No. } 3 \\
\text { No. } 2\end{array}$ & $\begin{array}{l}15,939 \\
15,914 \\
15,978 \\
16,074 \\
16,058 \\
16,068 \\
16,095\end{array}$ & $\begin{array}{l}1534^{\circ} \\
1532 \\
1530 \\
1533 \\
1532 \\
1532 \\
1532\end{array}$ & $\begin{array}{l}\text { Solid charge, open crucible } \\
\text { Do. } \\
\text { Covered crucible. } \\
\text { Do. } \\
\text { Do. } \\
\text { Do. } \\
\text { Do. }\end{array}$ \\
\hline \multicolumn{5}{|c|}{$\begin{array}{c}\text { Mean I } 53^{\circ} \\
\text { SECOND PREPARATION. }\end{array}$} \\
\hline $\begin{array}{l}\text { Jan. I6, 1904 } \\
\text { Do. } \\
\text { Jan. } 20, \text { I } 904 \\
\text { Do. } \\
\text { Do. } \\
\text { Mch. 31, 1904 }\end{array}$ & $\begin{array}{l}\text { A } \\
\text { A } \\
\text { No. } 3 \\
\text { No. } 2 \\
\text { No. } 2 \\
\text { No. } 3\end{array}$ & $\begin{array}{l}\text { I } 5,860 \\
\text { I } 5,86 ; \\
\text { I } 5,960 \\
\text { I } 6,102 \\
\text { I } 6,092 \\
\text { I } 5,932\end{array}$ & $\begin{array}{l}\text { I } 532^{\circ} \\
\text { I } 532 \\
1533 \\
\text { I } 532 \\
\text { I } 532 \\
\text { I } 531\end{array}$ & $\begin{array}{l}\text { Covered crucible. } \\
\text { Do. } \\
\text { Do. } \\
\text { Do. } \\
\text { Do. } \\
\text { First and second prepara- } \\
\text { tions together. }\end{array}$ \\
\hline \multicolumn{5}{|c|}{ Mean $1532^{\circ}$} \\
\hline
\end{tabular}

Melting temperature, $1532^{\circ}$.

confidence that the extrapolation for these $375^{\circ}$ is reasonably correct would, therefore, appear to be justified. Until the gas scale can be extended over this range, the melting point of pure anorthite $\left(1532^{\circ}\right)$ determined in this way will serve as a useful point in thermometry.

$$
\mathrm{AB}_{1} \mathrm{AN}_{5} \text { (Plates II, III, IV, V). }
$$

This feldspar decidedly resembles anorthite in its relatively low viscosity, the readiness with which it crystallizes, the well-marked break in the heating curve at the melting point, and in its tendency to form comparatively large crystals. In general, we may say that all these characteristics are somewhat less marked than in anorthite. Our determinations of the melting temperature follow. 
$A B_{1} A N_{5}$.

FIRST PREPARATION.

\begin{tabular}{|c|c|c|c|c|}
\hline Date. & Iilement. & $\begin{array}{l}\text { Iilectromotive } \\
\text { force in } \mathrm{MV} \text {. }\end{array}$ & $\begin{array}{l}\text { Tempera- } \\
\text { ture. }\end{array}$ & Remarks. \\
\hline $\begin{array}{ll}\text { Dec. } 9, & 1903 \\
\text { Dec. II, } & 1903 \\
\text { Do. } & \\
\text { Dec. I2, } & 1903 \\
\text { Do. } & \\
\text { Do. } & \\
\text { Do. } & \end{array}$ & $\begin{array}{c}\text { A } \\
\text { A } \\
\text { No. } 3 \\
\text { No. } 3 \\
\text { No. } 3 \\
\text { No. } 3 \\
\text { A }\end{array}$ & $\begin{array}{l}15,501 \\
15,363 \\
15,507 \\
15,599 \\
15,594 \\
15,604 \\
15,518\end{array}$ & $\begin{array}{l}1504^{\circ} \\
1+93 \\
1498 \\
1505 \\
1505 \\
1506 \\
1505\end{array}$ & $\begin{array}{l}\text { Slow heating. } \\
\text { Rapid heating. } \\
\text { Do. } \\
\text { Do. } \\
\text { Do. } \\
\text { Slow heating. } \\
\text { Do. }\end{array}$ \\
\hline \multicolumn{5}{|c|}{ SI:COND PREPARATION. } \\
\hline $\begin{array}{l}\text { Apr. } 9,1904 \\
\text { Do. }\end{array}$ & $\begin{array}{l}\text { No. } 3 \\
\text { No. } 2\end{array}$ & $\begin{array}{l}15,520 \\
15,637\end{array}$ & $\begin{array}{l}1+99^{\circ} \\
1497\end{array}$ & $\begin{array}{c}\text { Slow heating. } \\
\text { Do. }\end{array}$ \\
\hline
\end{tabular}

Melting temperature, $1500^{\circ}$.

In one instance, while cooling the molten mass at a rapid rate, we

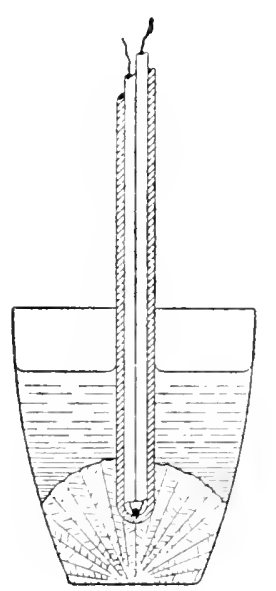

Fig. 8. obtained a result which has a most important bearing on the relation of the feldspars to one another, which will be referred to again in the concluding discussion of the experimental data. When the charge had cooled, it was found to consist of a compact mass of rather large crystals, radial in structure, at the botton of the crucible (fig. 8 ), and a beautifinl, transparent glass above. It was easy to separate the crystalline portion from the glass and to analyze the two separately. The conposition of the two portions is practically identical, save for a slightly higher percentage of -iron in the crystals. (A small quantity of iron was contained in the quar:z used in preparing the feldspars.) In larmony with this latter circumstance the color of the crystals was a decided amethyst brown, while the glass was but slightly tinted. The analyses follow:

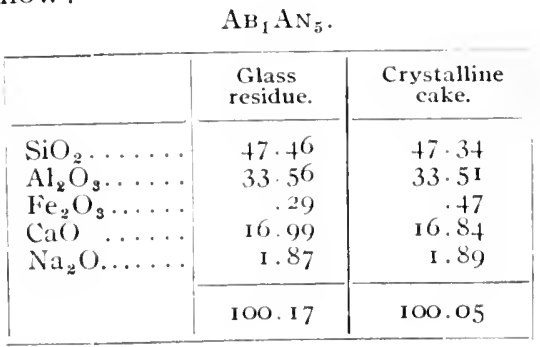


It is at once clear from these determinations that the solid phase has the same composition as the liquid phase, so far as it is within the power of chemical analysis to establish it.

$$
A_{1} A_{1} \text { (Plates VI, VII, VIII, IX, X, XI). }
$$

In this feldspar we observe the same characteristics as in the two preceding, but they are still less sharply marked. The viscosity is greater, both solidification and melting take place more slowly, and the undercooling is so persistent that the furnace must be cooled slowly or the charge will come out wholly or partly vitreous.

$$
\mathrm{AB}_{1} \mathrm{AN}_{3} \text {. }
$$

\begin{tabular}{|c|c|c|c|c|}
\hline Date. & Element. & $\begin{array}{l}\text { Electromotive } \\
\text { force in MV. }\end{array}$ & $\begin{array}{l}\text { Tempera- } \\
\text { ture. }\end{array}$ & Remarks. \\
\hline $\begin{array}{l}\text { Oct. } 16,1903 \\
\text { Do. } \\
\text { Oct. } 21,1903 \\
\text { Do. } \\
\text { Oct. } 22,1903 \\
\text { Do. } \\
\text { Dec. } 15,1903 \\
\text { Do. } \\
\text { Dec. } 16,1903 \\
\text { Do. } \\
\text { Do. } \\
\text { Do. }\end{array}$ & $\begin{array}{l}\text { A } \\
\text { No. } 3 \\
\text { No. } 3 \\
\text { No. } 3 \\
\text { No. } 3 \\
\text { No. } 3 \\
\text { No. } 3 \\
\text { No. } 3 \\
\text { No. } 3 \\
\text { No. } 3 \\
\text { No. } 3 \\
\text { A }\end{array}$ & $\begin{array}{l}14,895 \\
15,1+2 \\
15,101 \\
15,220 \\
15,204 \\
15,160 \\
15,116\end{array}$ & $\begin{array}{l}1+59^{\circ} \\
1+60 \\
1+57 \\
1+66 \\
1+65 \\
1+62 \\
1+67 \\
1+66 \\
1+67 \\
1+62 \\
1+62 \\
1+67\end{array}$ & $\begin{array}{l}\text { Rapid heating. } \\
\text { Slow heating. } \\
\text { Rapid heating. } \\
\text { Extremely slow heating. } \\
\text { Rapid heating. } \\
\text { Powdered charge, open } \\
\quad \text { crucible. } \\
\text { Powdered charge, slower. } \\
\text { Solid cake, covered. } \\
\text { Very fast. } \\
\text { Same, slower. }\end{array}$ \\
\hline \multicolumn{5}{|c|}{$\begin{array}{c}\text { Mean } 1463^{\circ} \\
\text { SECOND PREPARATION. }\end{array}$} \\
\hline $\begin{array}{l}\text { Feb. 19, 1904 } \\
\text { Feb. 20, } 1904 \\
\text { Feb. 25, } 1904\end{array}$ & $\begin{array}{c}\text { A } \\
\text { No. } 3 \\
\text { No. } 2\end{array}$ & $\begin{array}{l}14,945 \\
15,096 \\
15,239\end{array}$ & $\begin{array}{l}1+60^{\circ} \\
1+66 \\
1+67\end{array}$ & $\begin{array}{l}\text { Covered, slow. } \\
\text { Covered, faster. } \\
\text { Fast. }\end{array}$ \\
\hline \multicolumn{5}{|c|}{ Mean $1 t^{6} t^{\circ}$} \\
\hline
\end{tabular}

FIRST PREPARATION.

Melting temperature, $1463^{\mathrm{c}}$.

Here again we made an attempt to discover a possible difference in composition in the first portions to crystallize out of the melt, this time by optical means. We first cooled the charge so rapidly that only a relatively small portion crystallized out in fine, reddish-brown spherulites at the surface and near the wall of the crucible. Without disturbing these, the crucible was then replaced in the furnace and slowly reheated (about five hours) until the remaining vitreous material had also become completely crystallized. Upon removing from the furnace, the charge presented a singular appearance. The reddish-brown stars remained undisturbed, while the later crystals were perfectly white. But though so different in appearance, the micro- 
scopic examination of slides cut from the different portions showed the two to be optically identical.

We have here another instance of the tendency of the iron to concentrate in the crystals which first form, a tendency which was often noticed throughont our work.* It also appeared to matter little whether the first crystals formed at the surface or at the bottom of the charge. This phenomenon may have significance in ore deposition, but we have not thus far been able to give it adequate attention.

$$
\mathrm{AB}_{1} \mathrm{AN}_{1} \text { (Plates XII, XIII). }
$$

With this member of the feldspar group a difficulty in effecting crystallization in the molten mass becomes noticeable. Undercooling will continue until the vitreous melt becomes rigid, unless the cooling is slow or some special effort in the way of mechanical disturbance or the introduction of nuclei is applied. Furthermore, when once precipitated, crystal formation goes on slowly, even when the charge is finely powdered, and the crystals are always small. Of the feldspars at least it is possible to say that the size of individual crystals varied chiefly with the viscosity; the thinner, calcic feldspars always gave large individuals, while $A b_{1} A n_{1}, A b_{2} A n_{1}, A b_{3} A n_{1}$ and $A b_{4} A n_{1}$ crystallized in closely interwoven, increasingly smaller fibers, which gave much difficulty in microscopic study. In comparison with this apparent effect of the viscosity, the rate of cooling was altogether insignificant in determining the size of individual crystals.

Several days were required to complete the crystallization of Ioo grams of $A b_{1} A n_{1}$ under the most favorable conditions which we were able to bring to bear upon it. The melting temperature of the crystalline feldspar was still fairly well marked, however, and crystallization began in the powdered vitreous material as low as $700^{\circ}$.

The melting point of this feldspar is:

\begin{tabular}{|c|c|c|c|c|}
\hline \multicolumn{5}{|c|}{$\mathrm{AB}_{1} A \mathrm{~N}_{1}$. } \\
\hline Date. & Element. & $\begin{array}{l}\text { Electromotive } \\
\text { force in } \mathrm{MV} \text {. }\end{array}$ & $\begin{array}{l}\text { Tempera- } \\
\text { ture. }\end{array}$ & Remarks. \\
\hline Fieb. 9,1904 & A & 14,402 & $1+16^{\circ}$ & $\begin{array}{l}\text { Covered cliarge, heating } \\
\text { rapid. }\end{array}$ \\
\hline Do. & A & $1+, 400$ & $1+16$ & \\
\hline Feb. 10, 1904 & No. 3 & $1+, 529$ & $1+21$ & Very rapid. \\
\hline Feb. 12,1904 & No. 2 & 14,572 & $1+15$ & \\
\hline Fels. 27,1904 & No. 2 & 14,709 & $1+26$ & Very small cliarge. \\
\hline \multicolumn{5}{|c|}{ Mean $1+19^{\circ}$} \\
\hline
\end{tabular}

Melting temperature, $1419^{\circ}$

* See also J. P Iddings, Bull. Phil. Soc. IVash., Vol. XI, p. 97, 1888-1891 


$$
\mathrm{AB}_{2} \mathrm{AN}_{1} \text {. }
$$

To effect the complete crystallization of this substance, it is best to reduce it to a fine powder and heat very slowly, holding the temperature for many days at $100^{\circ}$ to $200^{\circ}$ below the melting point. IWhen thoroughly crystallized, it has a melting temperature which is determinable with reasonable certainty, but neither this nor any of its thermal phenomena approach the more calcic feldspars in sharpness. For this reason a considerably greater variation will be noticed in the melting points tabulated below:

$$
\mathrm{AB}_{2} \mathrm{AN}_{1} \text {. }
$$

\begin{tabular}{|c|c|c|c|c|}
\hline Date. & Element. & $\begin{array}{l}\text { Electromotive } \\
\text { force in MV. }\end{array}$ & $\begin{array}{l}\text { Tempera- } \\
\text { ature. }\end{array}$ & Remarks. \\
\hline $\begin{array}{l}\text { Dec. 10, } 1903 \\
\text { Dec. 15, } 1903 \\
\text { Dec. 16, } 1903 \\
\text { Do. } \\
\text { Jan. 18, } 1904 \\
\text { Feb. } 29,1904 \\
\text { Do. }\end{array}$ & $\begin{array}{l}\text { A } \\
\text { A } \\
\text { A } \\
\text { A } \\
\text { No. } 3 \\
\text { No. } 3 \\
\text { No. } 3\end{array}$ & $\begin{array}{l}13,726 \\
13,887 \\
13,969 \\
13,728 \\
13,967 \\
13,812 \\
13,854\end{array}$ & $\begin{array}{l}1362^{\circ} \\
1374 \\
1381 \\
1362 \\
1376 \\
1363 \\
1366\end{array}$ & $\begin{array}{l}\text { Very rapid heating. } \\
\text { Poor. } \\
\text { Covered. } \\
\text { Do. } \\
\text { Do. }\end{array}$ \\
\hline \multicolumn{5}{|c|}{ Mean $1369^{\circ}$} \\
\hline Feb. 5, 1904 & No. 2 & 13,990 & $1369^{\circ}$ & Covered. \\
\hline \multicolumn{5}{|c|}{ THIRD PREPARATION. } \\
\hline $\begin{array}{l}\text { Mch. 25, 1904 } \\
\text { Mch. 29, I } 904 \\
\text { Apr. 5, I } 904\end{array}$ & $\begin{array}{l}\text { No. } 3 \\
\text { No. } 2 \\
\text { No. } 3\end{array}$ & $\begin{array}{l}13,752 \\
13,995 \\
\text { 1 } 3,756\end{array}$ & $\begin{array}{l}135^{\circ} \\
1370 \\
135^{\circ}\end{array}$ & \\
\hline & & & $1362^{\circ}$ & \\
\hline
\end{tabular}

FIRST PREPARATION.

Melting temperature, $1367^{\circ}$.

From here on to the albite end of the series, viscosity becomes very troublesome in restraining crystallization. The breaks which mark the melting temperature on the heating curve of $\mathrm{Ab}_{3} \mathrm{An}_{1}$ are so slight as to make the determination difficult and somewhat uncertain. It is not that temperature measurement is less accurate here than elsewhere, for these temperatures are more accessible than the melting point of anorthite to which reference has been made in this connection. These ultra-viscous materials do not melt at a constant temperature but over a considerable range of temperature, as we shall undertake to show in some detail, with illustrations from photographs, in the discussion of albite. A glance at a series of curves (fig. 9) plotted from our observations upon metallic silver and the feldspars An, $A b_{1} A n_{5}, A b_{1} A n_{2}$ and $A b_{1} A n_{1}$, in such a way as to bring their melting points together, will show clearly the nature of this difficulty. The melting point of the metal is sharp, but with anorthite a change in the 
character of the phenomenon is noticeable. Its poor conductivity for heat and its viscosity, which, though small compared with the other feldspars, are very great compared with silver, have rounded off the corners until a really constant temperature for a period of a minute or more during the melting is nowhere to be found. The nearest ap-

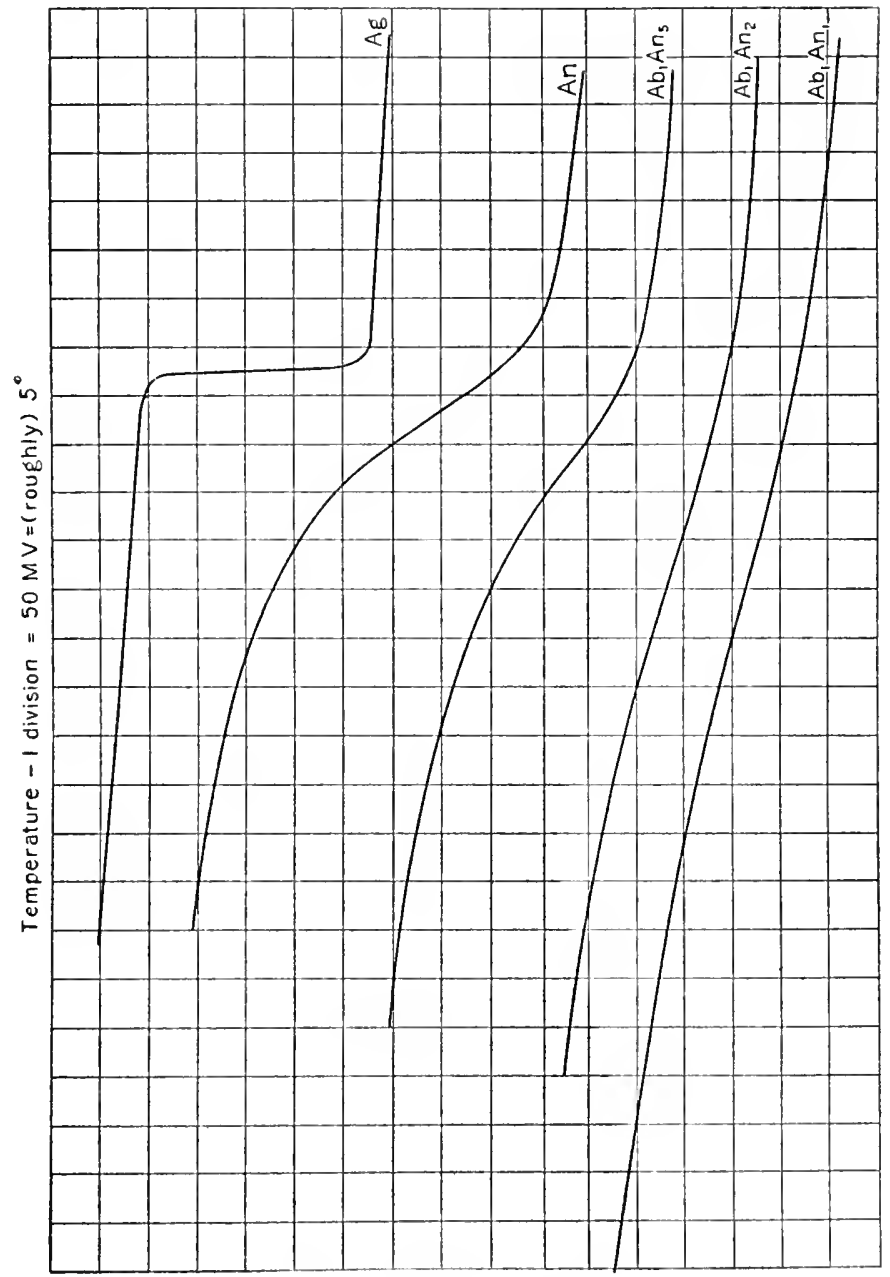

Time -1 division $=5$ minutes

FIG. 9.-Melting point curves of various feldspars compared with silver.

proach to a melting point is where the rise in temperature is slowest, and this will occur when the portion nearest to the thermo-element (see fig. 3) melts.

A series of melting-point curves containing a typical one for each of the observed feldspars is reproduced on page 43 exactly as observed: 
Trme Curves.

(In microvolts as observed).

\begin{tabular}{|c|c|c|c|c|c|c|c|c|c|c|c|}
\hline \multicolumn{2}{|c|}{ An. } & \multicolumn{2}{|c|}{$\mathrm{Ab}_{1} \mathrm{An}_{5}$} & \multicolumn{2}{|c|}{$\mathrm{Ab}_{1} \mathrm{An}_{2}$} & \multicolumn{2}{|c|}{$\mathrm{Ab}_{1} \mathrm{An}_{1}$} & \multicolumn{2}{|c|}{$\mathrm{Ab}_{2} \mathbf{A} \mathbf{n}_{1}$} & \multicolumn{2}{|c|}{$\mathrm{Ab}_{3} \mathrm{An}_{1}$} \\
\hline$M V$. & $\Delta V$. & $M V$. & $\Delta V$. & $M V$ & $د V$ & $M V$ & $د V$. & $M V$ & $\Delta V$. & $M V$ & $\Delta V$. \\
\hline I 5050 & I 56 & 13530 & 300 & I 1700 & 510 & I 3400 & 39 & 12480 & & I 2754 & \\
\hline I 5206 & 135 & I 3830 & 300 & 12210 & $4+5$ & I $34^{89}$ & 84 & 12533 & 53 & I 2793 & $\begin{array}{l}39 \\
41\end{array}$ \\
\hline I 534 I & 100 & I + I 30 & $2+0$ & $\begin{array}{l}12655 \\
12060\end{array}$ & 305 & 13573 & $\begin{array}{l}74 \\
74\end{array}$ & 12590 & $\begin{array}{l}51 \\
58\end{array}$ & 12834 & $\begin{array}{l}4 t \\
43\end{array}$ \\
\hline I $5+4$ I & 85 & 14370 & 190 & 12960 & 276 & I 3647 & $\begin{array}{l}68 \\
68\end{array}$ & 12648 & 53 & I 2877 & 39 \\
\hline I 5526 & 68 & $1+560$ & 153 & 13236 & 205 & 13715 & 63 & 12701 & $\begin{array}{l}53 \\
51\end{array}$ & 12916 & $\begin{array}{l}39 \\
38\end{array}$ \\
\hline I $559+$ & 56 & $1+713$ & 125 & $134+1$ & 154 & 13778 & $5^{8}$ & 12752 & 45 & I 2954 & 35 \\
\hline $1565^{\circ}$ & +7 & 14838 & 104 & $\begin{array}{l}13595 \\
13722\end{array}$ & 127 & 13836 & 55 & 12797 & & 12989 & 33 \\
\hline I 5697 & $4 \mathrm{I}$ & $1+9+2$ & 86 & 13722 & I IO & I 389 I & $\begin{array}{l}5 \mathrm{I} \\
5 \mathrm{I}\end{array}$ & I 2840 & $\begin{array}{l}43 \\
+1\end{array}$ & I 3022 & $\begin{array}{l}53 \\
31\end{array}$ \\
\hline 15738 & 35 & I 5028 & 73 & I 3832 & 100 & I 3942 & $\begin{array}{l}31 \\
49\end{array}$ & I 2581 & 36 & I 3053 & 29 \\
\hline 15773 & 29 & $\begin{array}{l}15101 \\
5161\end{array}$ & 63 & $\begin{array}{l}13932 \\
14022\end{array}$ & 90 & I 3991 & +7 & 12917 & 35 & I 3082 & 27 \\
\hline I $5 \mathrm{SO} 2$ & 27 & $\begin{array}{l}15164 \\
5218\end{array}$ & 54 & $\begin{array}{l}14022 \\
4007\end{array}$ & 85 & I + 038 & +1 & 12952 & 35 & 13109 & 25 \\
\hline 15829 & 24 & $\begin{array}{l}\text { I } 5218 \\
5\end{array}$ & 46 & $\begin{array}{l}1+107 \\
1+186\end{array}$ & 79 & $\begin{array}{l}14083 \\
14125\end{array}$ & 4 & I 2987 & 33 & I 31.34 & 26 \\
\hline I 5853 & 22 & $1526 t$ & 39 & $1+256$ & 70 & $\begin{array}{l}1+125 \\
1+166\end{array}$ & +1 & I 3020 & 33 & I 3160 & $2+$ \\
\hline 15875 & I 6 & I 5303 & 36 & $1+323$ & 67 & $\begin{array}{l}14100 \\
14206\end{array}$ & to & $\begin{array}{l}13053 \\
13088\end{array}$ & 35 & 13184 & 23 \\
\hline $\begin{array}{l}\text { I } 589 \text { I } \\
\text { I } 50066\end{array}$ & I 5 & $\begin{array}{l}\text { I } 5339 \\
\text { I } 537 \text { I }\end{array}$ & 32 & $\begin{array}{l}1+3=3 \\
1+393\end{array}$ & $7^{\circ}$ & $\begin{array}{l}1+2-00 \\
1+2+5\end{array}$ & 39 & $\begin{array}{l}13088 \\
13121\end{array}$ & 33 & $\begin{array}{l}13207 \\
13220\end{array}$ & 22 \\
\hline I 5906 & I4 & $\begin{array}{l}\mathbf{I} 537 \mathbf{1} \\
\mathbf{1} 5398\end{array}$ & 27 & $1+456$ & 63 & $\begin{array}{l}+2+3 \\
1+28+\end{array}$ & 39 & $\begin{array}{l}13 \\
1\end{array}$ & 33 & 13229 & $2 \mathrm{I}$ \\
\hline I 5920 & 13 & $\begin{array}{l}15398 \\
\text { I } 5+23\end{array}$ & 25 & $1+5 \mathrm{I}+$ & $5^{8}$ & I +323 & 39 & $\begin{array}{l}13154 \\
13584\end{array}$ & 30 & $\begin{array}{l}13250 \\
132-0\end{array}$ & 20 \\
\hline 15933 & 12 & $\begin{array}{l}\text { I } 5+2.3 \\
\text { I } 5+47\end{array}$ & 24 & $\mathrm{I}+57 \mathrm{I}$ & 57 & $\begin{array}{l}1+363 \\
\end{array}$ & to & $\begin{array}{l}13215 \\
13215\end{array}$ & $3 I$ & $\begin{array}{r}13270 \\
13289\end{array}$ & I 8 \\
\hline $159+5$ & I I & $\begin{array}{l}\text { I } 5+47 \\
\text { I } 5+68\end{array}$ & $2 \mathrm{I}$ & $1+620$ & 49 & $\begin{array}{l}7503 \\
1+402\end{array}$ & 39 & I 3248 & 33 & 13285 & 18 \\
\hline I 5956 & 9 & $\begin{array}{l}15+68 \\
15+88\end{array}$ & 20 & $1+670$ & $5^{\circ}$ & $1+4+4$ & $t^{2}$ & $\begin{array}{l}13240 \\
13283\end{array}$ & 35 & 13306 & I 5 \\
\hline I 5965 & 9 & $\begin{array}{l}15488 \\
15504\end{array}$ & I 6 & $\begin{array}{l}1+2 \mathrm{I} \\
1+1\end{array}$ & +4 & $1+488$ & +4 & $\begin{array}{r}3208 \\
13318\end{array}$ & 35 & 13321 & 16 \\
\hline I $597+$ & 9 & $555^{\circ} 4$ & 17 & $1+750$ & 45 & $1+538$ & 50 & 13355 & 37 & 13337 & 17 \\
\hline I 5983 & 9 & I $552 \mathrm{I}$ & 16 & $\begin{array}{l}1.39 \\
41707\end{array}$ & $3^{8}$ & $\begin{array}{l}1+300 \\
1605\end{array}$ & 67 & $\begin{array}{l}13355 \\
1258\end{array}$ & 33 & I $335+$ & 19 \\
\hline I 5992 & 6 & I 5537 & I 5 & I 4797 & +2 & $1+4005$ & $7 \mathrm{I}$ & 13388 & 33 & I3373 & 20 \\
\hline I 5998 & 6 & I $555^{2}$ & I 5 & I 4839 & 38 & $1+070$ & & $\mathrm{I} 3+2 \mathrm{I}$ & 30 & 13.393 & 22 \\
\hline 16004 & 8 & $\begin{array}{l}15567 \\
\end{array}$ & It & 14877 & 35 & & & I $345 \mathrm{I}$ & 32 & I $3+$ I 5 & 24 \\
\hline 16012 & 8 & I 55 I & I 3 & $1+912$ & 35 & & & $13+83$ & 33 & I $3+39$ & 27 \\
\hline 16020 & 8 & I 5594 & If & 14947 & 35 & & & 13516 & 31 & $13+66$ & 27 \\
\hline 16028 & 5 & I 5608 & I 4 & $\begin{array}{l}14982 \\
15013\end{array}$ & $3^{I}$ & & & $135+7$ & 29 & I 3493 & 27 \\
\hline 16033 & 7 & I 5622 & 15 & 15013 & 33 & & & I 3576 & 26 & 13520 & 28 \\
\hline 16040 & 8 & I 5637 & 17 & I $50+6$ & 36 & & & I 3602 & 25 & $1354^{\circ}$ & 28 \\
\hline $160+8$ & 8 & I 5654 & I 8 & 15082 & $3^{6}$ & & & I 3627 & $2 \mathrm{I}$ & 13570 & \\
\hline 16056 & 8 & I 5672 & 23 & 15 IIS & $t^{2}$ & & & $136+8$ & IS & & \\
\hline I 6064 & 7 & I 5695 & 38 & $\begin{array}{l}15160 \\
15211\end{array}$ & $5 \mathrm{I}$ & & & $\begin{array}{r}13664 \\
367\end{array}$ & I I & & \\
\hline I 607 I & 7 & $\begin{array}{l}\text { I } 5733 \\
5706\end{array}$ & 63 & $\begin{array}{l}1521 \mathrm{I} \\
15306\end{array}$ & 95 & & & $\begin{array}{l}13075 \\
\text { I } 3606\end{array}$ & $2 I$ & & \\
\hline $\begin{array}{l}16078 \\
16087\end{array}$ & 9 & I $579^{\circ}$ & & $\begin{array}{l}15300 \\
15+19\end{array}$ & I I 3 & & & $\begin{array}{l}13096 \\
13724\end{array}$ & 28 & & \\
\hline $\begin{array}{l}16087 \\
16099\end{array}$ & 12 & & & & & & & I $375^{8}$ & 34 & & \\
\hline $\begin{array}{l}16110 \\
161\end{array}$ & 11 & & & & & & & I 3794 & 30 & & \\
\hline 16122 & 12 & & & & & & & I 3833 & $\begin{array}{l}39 \\
40\end{array}$ & & \\
\hline 16134 & I 5 & & & & & & & 13573 & +1 & & \\
\hline $161+9$ & 14 & & & & & & & I 3914 & to & & \\
\hline I 6 I 63 & 18 & & & & & & & $\begin{array}{l}13954 \\
13908\end{array}$ & 44 & & \\
\hline I 6 I I I $^{-}$ & I6 & & & & & & & $\begin{array}{l}3990 \\
14050\end{array}$ & 52 & & \\
\hline $\begin{array}{l}16197 \\
16213\end{array}$ & 16 & & & & & & & & & & \\
\hline $1623^{2}$ & I9 & & & & & & & & & & \\
\hline
\end{tabular}

The numbers represent the electromotive force of the thermoelements at intervals of one minute, together with a column of differences at the right of each record. The E. M. F. will be seen to approach a minimum as melting progresses and to increase again when it is complete. This minimum rise in the temperature, of course, indicates the maximum absorption of heat. For purposes of rough orientation to MV may be considered equivalent to one degree. 
There is no circulation in these viseous melts and nothing to assist in distributing the heat uniformly. The melting point is, therefore, not marked by a constant temperature but by the point of greatest inclination of the tangent to the eurve, with a linit of error which inereases with increasing viseosity. With $\mathrm{Ab}_{3} \mathrm{An}_{1}$ it was barely discernible, and with $A b_{4} A n_{1}$ all trace of the heat of fusion was lost.* Slow heating or rapid heating merely aets to change the general inclination of the curve but not to enphasize the absorption of lieat.

By way of eonveying a concrete impression it may be added that $\mathrm{Ab}_{3} \mathrm{An}_{1}$ just above its melting temperature resists the introduetion of a stout platinum wire ( $1.5 \mathrm{~mm}$. diameter) unless the cold wire is thrust in very quiekly and vigorously. If the wire is first allowed to beeome lot in the furnace, it will give way itself instead. No aceeleration of the melting process tending to sharpen the break in the curve appears to be possible without the introduction of new substances or new conditions (water vapor under pressure for example) which would take the experiment outside the definition of a "dry melt." We have undertaken some preliminary experiments in these directions, but they belong to another phase of the subject.

A number of efforts were made to locate the melting temperature of $\mathrm{Ab}_{3} \mathrm{An}_{1}$, which are given in the list below. Although two days were required to erystallize each eharge of the material sufficiently for a determination, the recorded numbers possess but little significance, as will be clear from the foregoing.

\begin{tabular}{|c|c|c|c|}
\hline Date. & lilement. & $\begin{array}{c}\text { Electromotive } \\
\text { force in MV. }\end{array}$ & $\begin{array}{l}\text { Tempera- } \\
\text { ture. }\end{array}$ \\
\hline $\begin{array}{l}\text { Nov. 23, } 1903 \\
\text { Nov. 25, } 1903 \\
\text { Nov. 25, } 1903 \\
\text { Dec. 26, } 1903 \\
\text { Jall. 14, } 1904\end{array}$ & $\begin{array}{c}A \\
A \\
A \\
A \\
N O 3\end{array}$ & $\begin{array}{l}\ldots \ldots \\
13,+15 \\
13,698 \\
13,319 \\
13,893\end{array}$ & $\begin{array}{l}1325^{\circ} \\
1336 \\
1359 \\
1325 \\
1370\end{array}$ \\
\hline \multicolumn{4}{|c|}{ Mean $1344^{\circ}$} \\
\hline $\begin{array}{l}\text { Mch. I I, } 1904 \\
\text { Mch. I t, } 1904\end{array}$ & $\begin{array}{c}\text { A } \\
\text { No. } 3\end{array}$ & $\begin{array}{l}13,218 \\
13,469\end{array}$ & $\begin{array}{l}1320^{\circ} \\
1335\end{array}$ \\
\hline & & & $1329^{\circ}$ \\
\hline
\end{tabular}

Approximate melting temperature, $1340^{\circ}$.

* Only a small portion of the charge cot1ld be crystallized. The relatively small heat of fusion of the crystallized portion was, therefore, siperposed upon the larger specific heat of the glass. This, together with the effect of the viscosity, destroyed all record of the melting. 


\section{$\mathrm{AB}_{4} \mathrm{AN}_{1}$. (PLATE XVII).}

With $A b_{4} A n_{1}$ a third proof of the identity of composition of the first crystals to separate and the vitreous residue was obtained. The optical identification of this feldspar is absolute. If we could obtain crystals at all in a melt of this chemical composition, therefore, it would offer a crucial test of the relation of the solid and liquid phases in a part of the curve where no melting point or specific gravity determination upon crystals was possible. After some days of nearly continuous heating at a temperature somewhat below its assumed melting point, a number of crystals of $\mathrm{Ab}_{4} \mathrm{An}_{1}$ were obtained and identified.

ALBITE.

From the experiments upon natural albite and orthoclase, which have been described, and after observing the effect of the increasing viscosity as we approached the albite end of the artificial plagioclase series, we had no expectation of finding a melting point for either in the ordinary sense. Nor did we in fact succeed in locating a point of any real significance in this connection. The various trials which were made were simply calculated to throw all the liglit possible upon the character of the change from (crystalline) solid to liquid in such extremely viscous substances. The return change or recrystallization of such substances from the melt (solidifying point) witlout the introduction of modifying conditions has never been accomplished. The time required to do it is certainly very great, probably much greater than the demonstration is worth at the present stage of experimentation in this field.

Crystalline albite has been produced under exceptional conditions several times - by Hautefeuille,* by heating a very alkaline aluminosilicate with sodium tungstate for 3 o days at $900^{\circ}$ to $1000^{\circ}$; by Friedel and Sarasint, using an atmosphere of water-vapor under very high pressure and a moderately high temperature (an aqueo-igneous fusion); by J. Lenarčičł, at ordinary pressure and high temperature by crystallization out of a mixture of melted albite and magnetite (1 part magnetite, 2 parts albite by weight), and by others. It may be noted in passing that, entirely apart from the solution relations, the lastmentioned process reduces the viscosity to an entirely different order of magnitude from that of pure albite; magnetite melts to form a thin liquid almost of the consistency of water and even in $1: 10$ solution with albite forms a fairly mobile liquid. We endeavored to repeat

\footnotetext{
* Hautefeuille, Annales de 1'École Normale Supéricure, 2d ser., 9, p. 363, 1880.

$\dagger$ Friedel \& Sarasin, Bull. Min., p. I 58, 1879; p. 71, I 881 .

$\ddagger$ J. Lenarčic, Centralblatt f. Min., 23, p. 705, 1903 .
} 
portions of the work of Hautefenille and Lenarcic, but were obliged to post pone a systematic inquiry into the conditions of crystallization, which involved the addition of other components or extraordinary pressures, until our plant could be somewhat extended.

Hautefeuille describes his successful preparation as a "solution" of the alkaline alumino-silicate in sodiun tungstate, out of which the albite slowly crystallizes after long heating, but he remarks that the crystallization does not take place if the mixture is heated sufficiently to melt the components of the charge into a homogeneous glass. In that case he obtained only a vitreous white enamel. His case does not appear, therefore, to be one of simple solution, ont of which the same solid phase always reappears upon reproducing given conditions of temperature and concentration. On the contrary, as Hantefenille describes the experiment, the components of the albite remain as independent solid phases, which are then assembled in some manner through the intermediary action of the melted tungstate.

Notwithstanding the fact that our interest was confined for the moment to the mere production of a small quantity of chemically pure crystalline albite, we ventured to proceed along the lines of Hautefeuille's unsuccessful trial. We first prepared a chemically pure albite glass, $i . e$., we melted the components into a homogeneous mass before adding tungstate. This glass was then finely powdered, thoroughly mixed with an excess of powdered sodium tungstate, and maintained contintously for 8 days at $\mathrm{I} 100^{\circ}$. Upon removing from the furnace at the close of the heating, both albite and tungstate were found to have been completely melted and to have separated in to two distinct layers according to their specific gravities, the albite glass being above, and showing no trace of crystallization. A second charge was then prepared with equal parts of tungstate and albite, powclered and mechanically mixed as before, and maintained at a temperature of $900^{\circ}$ for $\mathrm{I} 7$ days. This time we were successful. After the sodium tungstate had been dissolved away with water, the albite appeared as a powder of about the fineness to which it had originally been pulverized, except that the fragments were now crystalline and apparently homogeneous albite. In thin section, under the microscope, to our considerable surprise, it appeared that the original glass fragments were unchanged in form. The bounding surfaces were all conchoidal fractures, as they came from the hammer, and evidently had not been in solution with the tungstate at all. Its optical properties showed it to be undotibted albite and the specific gravity was 2.620 .

The preparation of albite which we had synthesized by heating with an equal weight of sodium tungstate was first purified by thor- 
ough washing with warm water, but this was not sufficient to remove all the tungstate. A determination of tungstic acid showed 0.62 per cent still present, which is equivalent to 0.78 per cent of sodium tungstate. After removing the water by heating carefully to a dull redness, the product was submitted to a microscopic examination, which showed it to be entirely crystalline and apparently homogeneous. Determinations of the specific gravity gave 2.620 (see table, p. $5^{\delta}$ ). If this is corrected for 0.78 per cent of sodium tungstate of specific gravity 4.2 , we obtain 2.607 .

A portion of the preparation was then purified further by fusing for a few minutes with acid sodium sulphate (Hautefenille) at as low a temperature as practicable, after which the excess of sulphate was extracted with water and the product dried (the temperature was raised to a dull red heat to remove all water) and analyzed.

\begin{tabular}{|c|c|c|}
\hline & Found. & Calculated \\
\hline $\mathrm{SiO}_{2} \ldots \ldots \ldots$ & $68.7 t$ & 68.68 \\
\hline $\mathrm{Al}_{2} \mathrm{O}_{3}$ and $\mathrm{Fe}_{2} \mathrm{O}_{3}$ & $19.5^{6}$ & $19 \cdot 49$ \\
\hline $\mathrm{Na}_{2} \mathrm{O} \ldots \ldots \ldots \ldots$ & I 1.73 & 11.83 \\
\hline $\mathrm{SO}_{3}^{\sim} \ldots \ldots \ldots \ldots \ldots$ & .02 & $\ldots \ldots$ \\
\hline \multirow[t]{2}{*}{$\mathrm{WO}_{3} \ldots \ldots \ldots \ldots \ldots$} & .16 & $\ldots \ldots$ \\
\hline & 100.21 & \\
\hline
\end{tabular}

The specific gravity of it was 2.604 , which may be corrected as before for the remaining trace of tungstic acid assumed to be in the form of the sodium salt. The value then falls to $2.60 \mathrm{I}$.

A second portion of the same albite was purified by another process. Instead of fusing with acid sodium sulphate, the powdered sample was first digested for a short time with dilute hydrochloric acid $(1: 1)$, which set free tungstic acid. The excess of hydrochloric acid was removed with water, the tungstic acid with ammonia, and finally the excess of reagent and the ammonium tungstate by further washing with water. When dried at a low red heat, the preparation had the following composition:

\begin{tabular}{|c|c|c|}
\hline & Found. & Calculated. \\
\hline \multirow{6}{*}{$\begin{array}{l}\mathrm{SiO}_{2} \ldots \ldots \ldots \\
\mathrm{Al}_{2} \mathrm{O}_{3} \ldots \ldots \ldots \\
\mathrm{Fe}_{2} \mathrm{O}_{3} \ldots \ldots \ldots \\
\mathrm{Na}_{2} \mathrm{O} \ldots \ldots \ldots \\
\mathrm{WO}_{3} \ldots \ldots \ldots \ldots \\
\mathrm{H}_{2} \mathrm{O} \ldots \ldots \ldots\end{array}$} & $68.9 \mathrm{I}$ & 68.68 \\
\hline & $18.95 ! 19.13$ & 19.49 \\
\hline & IS II 59 & I I .83 \\
\hline & .22 & $\ldots \ldots$ \\
\hline & . I 3 & $\ldots$ \\
\hline & 99.98 & $\ldots \ldots$ \\
\hline
\end{tabular}


The specific gravity determination gave 2.615 , which, when corrected for the small quantity of sodium tungstate becomes 2.612 . If, as is possible after the above treatment, the tungstic acid is present as the anhydride, sp. gr. 7.1, the correction would lower the value to 2.605 , in excellent agreement with the other determinations.

The products of both methods of purification were carefully scrutinized by the microscope, but no conclusion conld be reached as to which was the purer. Neither the sodium sulphate fusion, nor the digestion with acid and ammonia appeared to have changed the particles in the slightest degree. Diligent search was made for opaque or amorphous matter on the surface of the grains, or any other indication of decomposition, but none was found. While the chemical analysis indicates a rather higher purity for the first product, purified by fusion, the differences are nearly within the limits of error and, therefore, hardly conclusive. Both powders were ground finer than usual for the specific gravity determinations to avoid errors introduced by a spongy structure.

Reverting now to Hautefeuille's directions, it is clear that glass of albite composition crystallizes homogeneously under substantially the conditions which he obtained, as well or better than the mechanically mixed component parts; but the part played by the tungstate requires some further experimental study before a conclusion can be reached.

Except for the specific gravity, the experiments upon crystalline albite and orthoclase which follow were made upon natural specimens from well-known localities (a fragment of the Mitchell County albite is shown in plate XVIII), for which we are indebted to Dr. G. P. Merrill of the United States National Museum and Dr. Joseph Hyde Pratt, State Mineralogist of North Carolina. The specimens were selected with great care, but like all natural specimens, they contained other feldspars and inclusions. The analyses follow:

\begin{tabular}{|c|c|c|c|c|c|c|}
\hline & \multicolumn{2}{|c|}{$\begin{array}{c}\text { Albite, Amelia Co.,Va. } \\
\text { Nat. Mins. }\end{array}$} & \multicolumn{2}{|c|}{ Albite, $\underset{\text { (Pratt). }}{\text { Mitchell Co., N.C. }}$} & \multicolumn{2}{|c|}{$\begin{array}{l}\text { Orthoclasc, Mitchell Co.. } \\
\text { N. C., Nat. Mus. }\end{array}$} \\
\hline & Found. & $\begin{array}{l}\text { Calculatcd to } \\
\text { anhydrous } \\
\text { composition. }\end{array}$ & Found. & $\begin{array}{c}\text { Calculated to } \\
\text { anhydrous } \\
\text { composition. }\end{array}$ & lound. & $\begin{array}{l}\text { Calculated to } \\
\text { anhydrous } \\
\text { composition. }\end{array}$ \\
\hline $\mathrm{SiO}_{2}$ & 68.22 & $68.7 \mathrm{I}$ & 66.03 & 66.42 & 65.49 & 65.8 .3 \\
\hline $\mathrm{Al}_{2} \mathrm{O}_{3}$ & 19.06 & 19.20 & 20.91 & 21.03 & 17.98 & 18.07 \\
\hline $\mathrm{He}_{2} \mathrm{O}_{3}$. & .15 & .15 & .18 & .18 & .36 & .36 \\
\hline $\mathrm{CaO} \ldots$ & .40 & .40 & 2.00 & 2.00 & .42 & .42 \\
\hline $\mathrm{Na}_{2} \mathrm{O}$ & I I . 47 & I I. 53 & 9.97 & 10.03 & 2.29 & 2.30 \\
\hline $\mathrm{K}_{2} \mathrm{O}$. & .20 & .20 & .70 & .70 & 12.95 & 13.02 \\
\hline \multirow[t]{2}{*}{$\mathrm{H}_{2} \mathrm{O}$} & .69 & $\cdots \cdots$ & .59 & $\cdots \cdots$ & $.5 \mathrm{I}$ & $\cdots \cdots$ \\
\hline & 100.19 & & I OO. 38 & & 100.00 & \\
\hline
\end{tabular}


It will be remembered that in the preliminary experiments (p. 28 et seq.) the heating curve of these natural feldspars did not show an absorption of heat which we were able to detect; our first step was, therefore, to find ont what manner of process it was by which a charge of crystalline albite or orthoclase became amorphons without leaving a thermal record behind.

We prepared a charge of albite glass from a previous melt powdered to "100-mesh." In this glass powder a sinall crystal fragment (perhaps $2 \times 5 \times$ ro $\mathrm{mm}$.) from the same original specimen and, therefore, of the same chemical composition, was embedded beside the thermo-

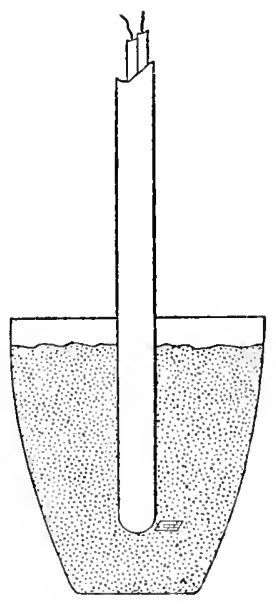

IO.

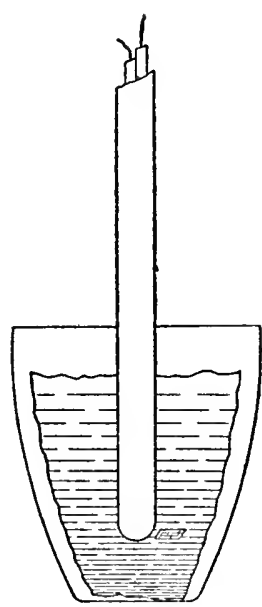

I I.

FIG. IO.-Albite crystal embedded in charge of powdered albite glass.

Fig. I I.-Same after heating.

element as indicated in fig. Io. This charge was heated slowly to exactly $1200^{\circ}$, slowly cooled again, and several thin sections prepared from the crystal fragment and its immediate neighborhood. What the microscope showed can best be seen from the accompanying illustrations (Plate XX) - groups of erystal fragments of microscopic size, preserving their original orientation (extinetion) perfectly, but with narrow lanes of glass where cleavage and other cracks had been, forming a perfect network without a trace of disarrangement. Considerable melting had taken place but no flow. Neither had the charge as a whole made any novenent to take the form of the containing vessel after sintering together (fig. I I). 
Surmising that we had accidentally hit upon the approximate melting temperature, a fresh cliarge of like material was prepared and the sane experiment carefully repeated, except that the temperature was carried up to $1206^{\circ}$ and maintained there for 30 minutes. Instead of showing the melting to be complete, the slides (Plate XXI) looked precisely like the first, save that the lanes of glass were somewhat wider and the crystal fragments relatively smaller than before. Further trials under precisely the same conditions, with the temperature increased to $1225^{\circ}$ (Plate XXII) and $1250^{\circ}$ (Plate XXIII), respectively, for like periods of time, showed only more advanced stages in the same process. In the latter case the remaining crystal fragments were relatively very small compared with the separating lanes of glass, but the orientation of the tiny particles still remained perfectly undisturbed.

The evidence contained in this series of slides shows plainly that we lave here an unfamiliar condition-a case of a crystalline compound persisting for a long time above its melting temperature for a given pressure. Albite or orthoclase glass sinters tightly at $800^{\circ}$. At the temperature where melting began, therefore (below $1200^{\circ}$ ), the charge consisted of crystal fragments of microscopic size embedded in a large vitreous mass of the same composition and known temperature. These fragments melted so slowly over the $50^{\circ}$ included between the first slide and the last, with the rate of heating slow ( $1^{\circ}$ in 2 minutes) and the upper temperature continued for 30 minutes, as to leave considerable portions unmelted at the close. Furthermore, the extreme viscosity, of which further evidence will be given directly, and the absence of any disturbance in the orientation of the particles indicating flow, assured us that the lanes of glass represented actual melting and not an inflow of glass from without. Finally, the perfectly homogeneous character of the glass and the unchanged appearance of the crystals as heating progressed gave no hint of any chemical decomposition.

In the hope of obtaining a point of value for comparison with the melting points of the other feldspars, some time and patience were expended in trying to locate the lowest temperature at which certain evidence of melting appeared. We did not extend any single trial beyond a single day, so that our results can not pretend to establish the lowest point at which albite melts. Such an effort with a natural specimen known to contain impurities would yield nothing of value. Mitchell County albite showed signs of melting after four hours at $1100^{\circ}$. Under a high power the erystal edges appeared weathered or toothed-strongly resembling the incipient melting of the ice on a frosted window pane. These extremely fine teeth could be followed 
through the slide on exposed edges. At $1125^{\circ}($ Plate XIX $\times 600)$ a four hours' heating gave unmistakable glass in tiny pockets and lanes.

The above experiments with the Cloudland albite were completed before we obtained the Anelia County material, but the latter proved to be so much nearer to the type of pure soda feldspar that nearly all the experiments were repeated with it, except that the crystal blocks were embedded in powdered crystals. We did not develop any new fact, however; the effects noted above reappeared in the same order, except perhaps that melting went on a little faster in the Amelia County specimen. As much melting was found after one-half hour at $1200^{\circ}$ with the Amelia County sample as the Cloudland (Mitchell County) albite showed in the same time at $1225^{\circ}$, which is readily enough explained by the relatively large quantity of lime (anorthite) in the latter.

Since both time and temperature enter into the delimitation of the metastable region, further trials at temperatures above $1250^{\circ}$ did not seem likely to add anything to the knowledge already obtained. And if the heating were very rapid, the temperature differences within the charge would be considerable. A few isolated crystalline fragments were found in a microcline nelt which had been heated as high as $1400^{\circ}$ for another purpose. Another which had reached nearly I $500^{\circ}$ showed no microcline, but one or two minute quartz inclusions still remained undissolved.

We made a rough attempt to get a more tangible idea of the viscosity of these feldspars at their melting temperature in the following way: A long, slender sliver (perhaps $30 \times 2 \times 1$ mm.) of albite and one of microcline were chipped from larger portions, spanned across small empty platinum crucibles, and placed side by side in the furnace. These exposed crystals were heated to $1225^{\circ}$ for three hours. When removed they were completely amorphous (melted), but retained their position with hardly a trace of sagging.

After this a number of similar slivers were prepared, mounted in the same way, and heated to temperatures of from $1200^{\circ}$ to $1300^{\circ}$ for a few moments. At their highest tempcrature a platinum rod was i11serted through a hole in the top of the furnace and allowed to rest as a load upon the middle of the crystal bridges. Under this load the partially melted slivers gradually gave way and were taken from the furnace in the various forms shown in the illustrations. Slides cut from these showed no squeezing out of the melted portion between the crystal fragments on the side toward the center of curvature, or open cracks on the outer side (Plates XXIV, XXV, and XXVI). It will be noticed that the melting began on the convex surface, where the 
strain was greatest. On the other hand, a variable extinction angle in an umbroken erystal fragment frequently gave unmistakable evidence of the bending of the crystal as well as the vitreous portion. From these qualitative experiments it seens possible to assert with conficlence that the order of magnitude of the viscosity of the molten portion (glass) is the same as that of the rigidity of the crystals at these temperatures. Plate XXIV shows a piece of Mitchell County albite heated to $1200^{\circ}$ under load. The sagging is indicated by the curved cleavage cracks. A sliver of microcline, similarly treated, is reproduced in Plate $\mathrm{XXV}$. The displacement is shown by the curvature of the crystal edges and the cleavage cracks; the black portions are glass. It is interesting to observe that while the crystal has melted completely across, there has been no displacement of the cleavage plane (indicated by a dotted line).

Plate $X V$ is from a charge of composition $A b_{3} A n_{1}$ which had been heated to $1375^{\circ}$ and completely melted. It was then allowed to cool slowly in the furnace. On the following day it was reheated to about $1250^{\circ}$ for most of the day. The slicle was made from this mass. The dark portions of the slicle are glass in which the crystals were induced by the subsequent reheating. At first sight it would seem that crystallization onglit to be complete after the mass had been allowed to cool in the furnace and had been reheated for six hours at a temperature within 125 degrees of its melting point, but the slide plainly shows that equilibrium is reached very slowly in melts of this extreme viscosity, even after nuclei have formed.

The preceding experiments gave a clear idea of the phenomena attending the melting of albite and orthoclase, and convinced us that the absorption of heat accompanying fusion, which we had searched for in vain upon the heating curves in the earlier experiments, had eluded us merely because it was extended over so long a stretel of the curve as not to be noticeable. Some very exact measurements of the temperature change from minute to minute were therefore made in the hope that a more intelligent search might be more successful. Separate cliarges of glass and of crystals of the same composition and of equal weight were prepared and stecessively heated in the same furnace with the same current. The specific heat is, of course, not identical in the two cases, but the curves were comparable in form. Above $1100^{\circ}$ we felt sure that one of the curves must contain an absorption of heat which wonld be absent from the other. Such a pair of curves (I), taken from the microcline measurements, is reprocluced in the arljoining fignre (fig. 12), and appears to show such an absorption clearly, extending from $1135^{\circ}$ to $1275^{\circ}$. The dotted line 


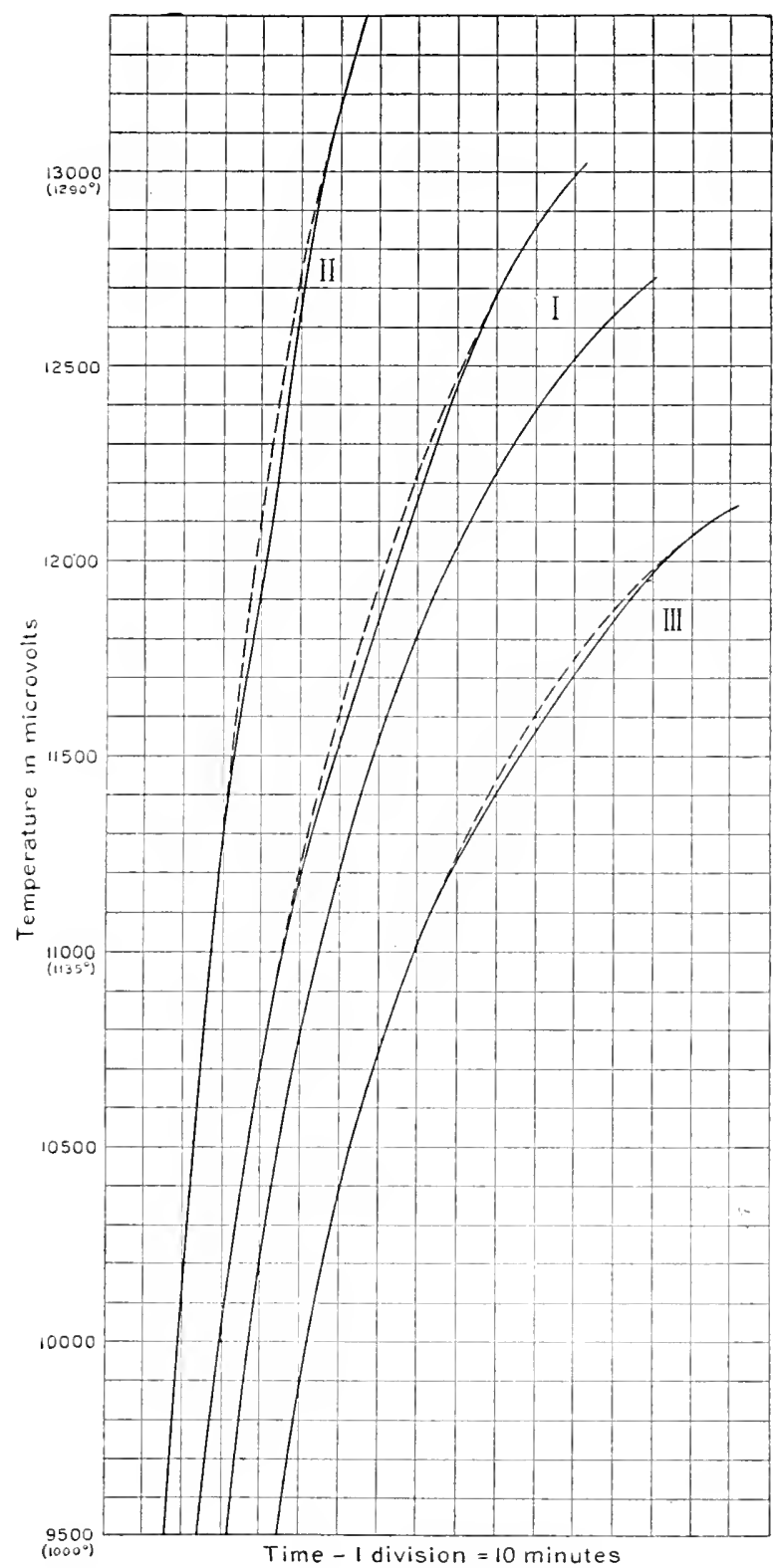

FIG. 12.-Curves showing the absorption of heat in melting orthoclase. shows the course of the curve without the absorption, as inferred from the glass curve. The same figure contains two other curves (II, III), similarly obtained, which were made tpon fresh charges of the same 
material but with different rates of heating. It will be noticed that the absorption begins to be noticeable at a slightly lower temperature if the heating is slower.

This peculiar behavior slown by componnds which melt to form hyperviscons liquids seems not to have been observed before and to contain features of more than ordinary interest. Here are evidently crystalline substances which not only can exist for considerable periods of time at temperatures far above their melting temperatures, but which melt with extreme slowness in the lower portion of this range of instability. It wonld certainly be 110 exaggeration to say that the albite with which we worked would require some weeks to reach the amorphous state if maintained at a constant temperature of $1125^{\circ}$.

An interesting question arises here as to the state of the crystalline material at temperatures above its melting point. It is easily conceivable that the erystals are merely superheated without loss of any of their properties as solids, and that they thus present an analogy to superheated liquids. In the transformation (Umwandlung) of a solid crystalline substance in to another crystal form such superheating has long been known. The change is dependent upon temperature and pressure like ordinary fusion, but it is possible to pass the transformation temperature in either direction. This must be clue to the nunfavorable opportunity for molecular motion which solids afford, and the latter should differ in no essential particular from ultraviscosity.

On the other hand, it does not seem a violation of any known principle to conceive cases of unstable equilibrium in which the molecules of a liquid are oriented as in a crystal. Maxwell's demons might arrange them much like a school of fish, and there is no apparent reason why the fluidity should be destroyed thereby. Were such an arrangement one of mininum potential, the mass would be a liquid crystal. In the supposed case such a substance would possess a melting point dependent upon the temperature and pressure above which Maxwell's definition* of a true solicl-that its viscosity be infinite-would no longer obtain, although deorientation might not become apparent, in the face of extreme viscosity, for a considerable time afterward. Such a melting point would be determinable only with the greatest dificulty, for all the functions - mechanical, thermal, or electrical-which usually become sudclenly discontinuous at the melting point would be equally powerless to define a change of state in the face of such extreme molecular inertia.

* Maxwell's Scientific Papers, vol. 2, P. 620 
In substances like these, which we found to be still viscous at the temperature of the electric arc, the sharpness of a minimum due to heat absorption, for example, is not dependent ipon the magnitude of that absorption entirely, but also upon the rapidity witl which the change which involves it proceeds. In albite and orthoclase the velocity of this change is very small.

\section{SPECIFIC GRAVITY.}

The study of the specific gravities yiclded one interesting result which was not anticipated. The artificial feldspars, being ehemically pure and homogeneous, gave a perfectly definite specific gravity which could be determined with great accuracy if the specimen was completely crystallized. If vitreous inclusions were still present, the results were of course variable and were all too low. It was anticipated that the specific gravity of pure glasses, even when transparent and free from bubbles, as they were in the nnore calcic nembers of the series, might yield values varying more or less with the rate of cooling, or after annealing, but this did not prove to be the case. Our results did not vary more than two units in the third decinal place in the same preparation, even with the more calcic feldspars, wlich required to be very rapidly chilled in order to cool the melt without crystallization.

The determination of specific gravities is a trite subject, but we have found the common methods liable to such grave errors that we venture to give some useful details. The error due to the evaporation of water about the stopper of the picnometer is very much less with finely ground stoppers than with coarse grinding, and if the stopper is slightly vaselined just before the final weighing the error from this cause will hardly affect the third deeimal place with $25 \mathrm{cc}$. picnometers. The simplest form of flask with a small capillary opening in the stopper is, in our judgment, far superior to one carrying a thermometer. The temperature should be made sure by the use of the thermostat.

For removing the air from a powdered charge, we used the device of G. E. Moore,* slightly modified, as indicated in the accompanying sketch (fig. 13). The bulb $A$ contains boiled water. When the apparatus is exhausted, the water is allowed to flow back into the picnometer containing the charge, then by tapping and warming with water at $40^{\circ}$ to $50^{\circ}$ to produce boiling within, the air is effectively removed. The material projected from the flask, if the boiling is violent, is then washed back from the tube $B$ with boiled water, and any small particles

* G. E. Moore, Journ. prakt. Chem., 2, 319, i 870. 
remaining are washed into a tared dish and finally weighed. It is very important that not the smallest grain of material shonld get into the gronnd joint between the neek and the stopper of the pienometer. To obviate this, wipe ont the neck with filter paper before stoppering and burn the paper in the tared disl. If the powder is very fine, it is advisable toallow the filled pienometer to stand for some lours in the thermostat in order that suspended material may settle. With a $25 \mathrm{ce}$. picnometer and 5 to ro grams of material, this method usually yields concordant results to the third decinal place, and the error from all causes should never be greater than 2 units $( \pm \mathrm{r})$ in the third place.

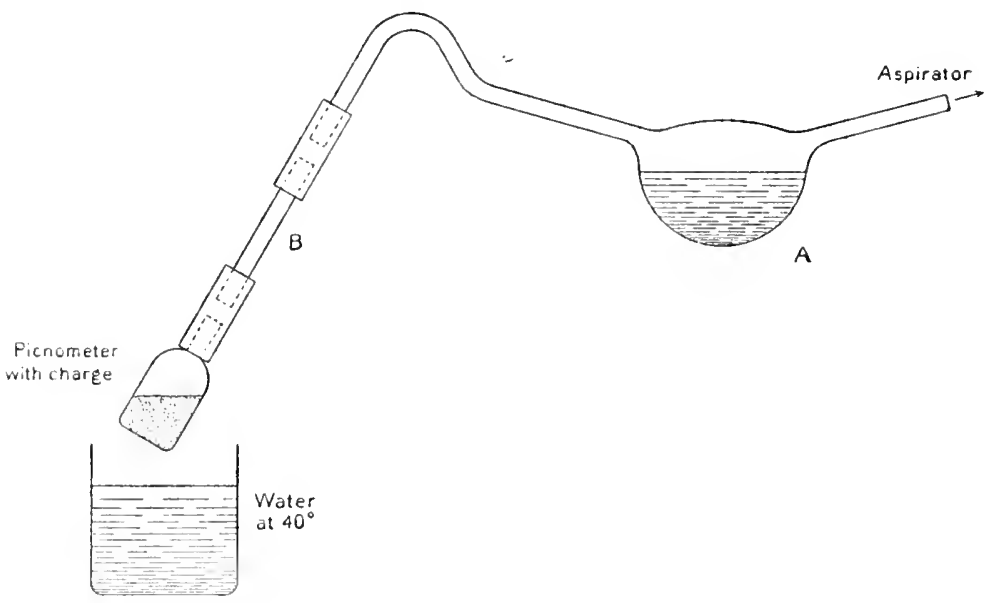

FIG. 13.-Apparatus for specific gravity determination.

A determination of this accuracy is of course subject to a correction for buoyancy, and all the numbers which follow have been thus corrected.

There is another error to which accurate specific gravity determinations upon powdered minerals will be subject unless suitable precaution is taken. The exposure to the air during the period of grinding the samples gives opportunity for the condensation of sufficient at mospheric moisture upon the grains to affect the weight in air. The amount varies measurably with the size of the grains, as will be seen from the accompanying data, and probably with the degree of saturation of the atmosphere and the time of exposure. 
Determination of Moisture in I Gram of PoWdered Mineral, UPON EXPOSURE TO THE AIR.

\begin{tabular}{|c|c|c|}
\hline Mineral. & Fineness (mesh). & Moisture. \\
\hline 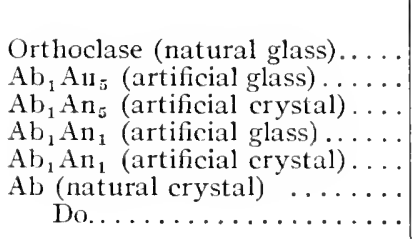 & $\begin{array}{r}<150 \\
\text { Selected, coarse } \\
<100>120 \\
<100>120 \\
<100>120 \\
\text { Coarse } \\
<150\end{array}$ & $\begin{array}{r}\text { Gram. } \\
0.0061 \\
.0000 \\
.0010 \\
.0007 \\
.0010 \\
.0006 \\
.0069\end{array}$ \\
\hline $\begin{array}{c}\text { Orthoclase (natural crystal)... } \\
\text { Do. } \quad \text { (same sample)..... } \\
\text { Do. } \quad \text { (same sample)..... }\end{array}$ & $\begin{aligned}< & \mathbf{1} 20 \\
& \geqslant 150 \\
& \geqslant 150 \\
\text { Still finer. } & \end{aligned}$ & $\begin{array}{l}.001 \mathrm{I} \\
.0031 \\
.0059\end{array}$ \\
\hline $\begin{array}{l}\text { Ortluoclase (artificial glass) .... } \\
\text { Do. (portion of same.). }\end{array}$ & $\begin{aligned} \text { Everything } & \leqslant 100 \\
& >150\end{aligned}$ & $\begin{array}{l}.0065 \\
.0022\end{array}$ \\
\hline
\end{tabular}

In the last two groups, note that the moisture in graded portions of the same sample varies with the fineness.

We also verified the conclusion of Bunsen* that this adsorbed moisture is not removed at temperatures only slightly above $100^{\circ}$, but requires $600^{\circ}$ to $800^{\circ}$ - equivalent to a low red heat. Several samples for which the moisture had been determined were laid away in corked test-tubes for a number of weeks, after which redetermination gave exactly the former value.

It is worth noting in this connection that these measured quantities of adsorbed water are of the same order of magnitude as those usually obtained for the water content in feldspar analyses, $\uparrow$ where again, of course, the finer the sample is ground for the analysis the greater the possible error from this cause. It may be that a part and occasionally all of the moisture usually found in these analyses is adsorbed and the significance of its presence there mistaken.

The number of feldspars of which specific-gravity determinations could be made was limited only by the possibility of obtaining complete crystallization within a reasonable time. Thus $\mathrm{Ab}_{2} \mathrm{An}_{1}$ was reheated many times before a constant value was reached. $\mathrm{Ab}_{3} \mathrm{An}_{1}$ required $I_{7}$ days and $A b_{4} A n_{1}$ was not completely crystallized in any of our attempts. Crystalline albite was produced under other conditions.

* Wied. Ann., 24, p. 327, I 885.

† Dana, System of Mineralogy, 6th ed., pp. 3i 4 et seq. 
The specific gravities of the glasses and of so many of the erystalline mixtures as we could obtain are tabulated below:

Specific Gravities of Artificial Cristaline Feldspars.

[Determinations in duplicate are braced together.]

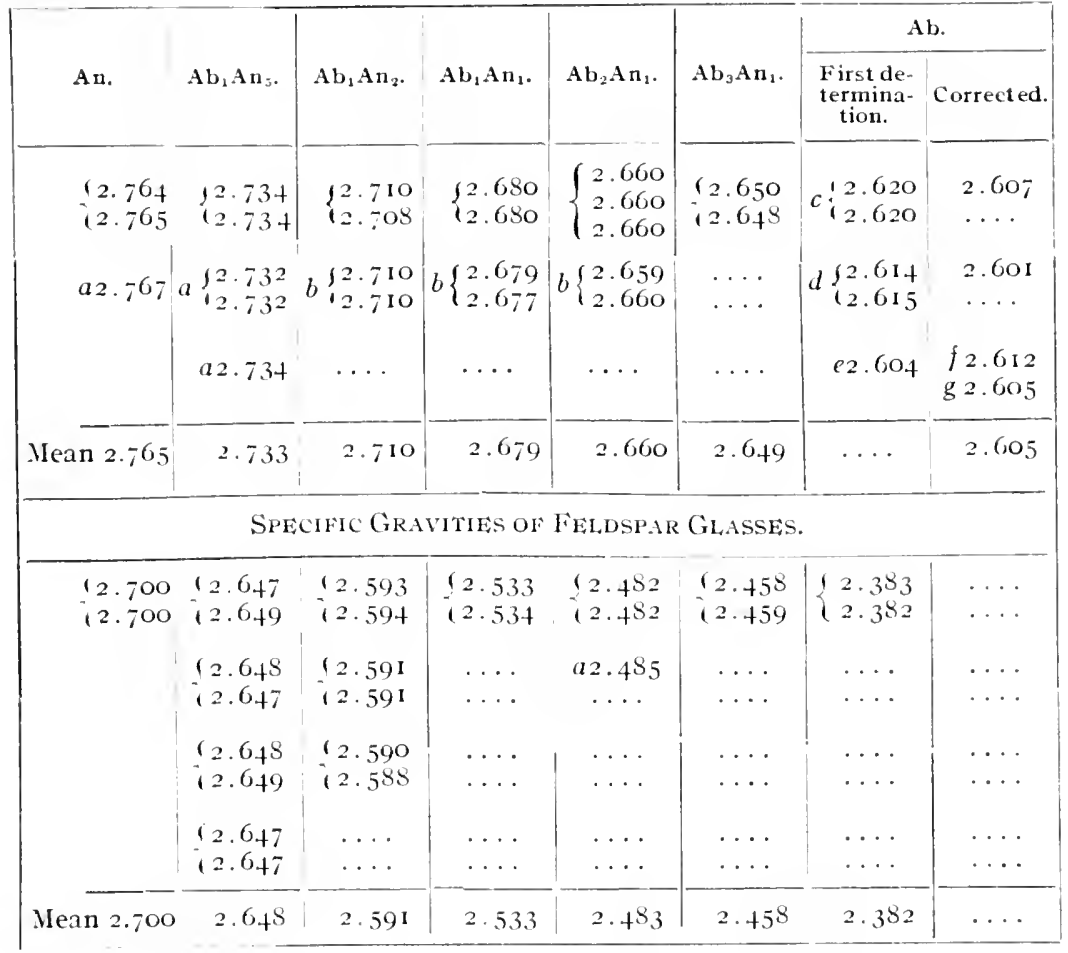

a Another preparation.

$b$ Same material reheated for several days at temperatures about $150^{\circ}$ below the melting point.

c Contained about 0.8 per cent of sodium tungstate.

$d$ Purified by warming witl dilute hydrochloric acid, then with water, and afterwards with ammonia.

$\varepsilon$ Purified by fusion witl acid sodium sulphate.

$f$ Assuming the residual tumgsten to be present as $\mathrm{Na}_{2}$ WO,

a Assuming the residual tungsten to be present as $\mathrm{WO}_{3}$.

\section{SINTERING.}

Incidental to this work upon the relation between the feldspars, we made a great many observations upon the sintering of powdered minerals, both crystalline and vitreous, of natural and artificial composition. While the results have not enabled us to offer positive conclusions of importance, they are worth a note in passing. Powdered glasses sinter slowly or rapidly several hundred degrees below the melting temperature of crystals of the same composition. When the vis- 
cosity is relatively small (anorthite) crystallization begins at a low temperature and proceeds very rapidly, the sintering probably being due to the interweaving of the crystal fibers during their formation. In viscous glasses (albite) sintering also begins at very low temperatures - the finer the powder and the slower the heating, the earlier the first traces appear. Long-continued heating, even at comparatively low temperatures, yields a perfectly continuous cake (except for the inchuded bubbles) the surface area of which constantly tends toward a minimum. There is no doubt that the sintering of powdered glasses is due to flow in the undercooled liquid and is a phenomenon in viscosity and surface tension. All the feldspar glasses sintered readily between $700^{\circ}$ and $900^{\circ}$, depending on the fineness of the powder and the time.

Powdered crystalline feldspars do not sinter readily below their melting temperature. Indeed, we were at first inclined to the view that when only pure, dry, stable crystals are present they do not sinter at all, however finely they may be powdered. We observed the plenomenon in natural albite at $1000^{\circ}$, but the crystals were not wholly free from inclusions which may have caused chemical reactions resulting in cementation. Crystalline fluorite also sinters $300^{\circ}$ below its melting temperature, but here we were able to establish a decomposition; acid fumes were evolved during the experiment, and the sintered product contained i per cent of free lime. Our final experiments with long-continued heating for specific-gravity determinations, however, showed that the purest feldspars which we could prepare, even after they had reacled their maximun density, still sinter very slowly. Thus $A b_{1} A n_{5}$ powder, which was shown by a determination of its specific gravity to be holocrystalline, formed a compact chalky mass in four hours at a temperature about $150^{\circ}$ below its melting point; in three days the cake was as hard as porcelain. Other feldspars showed the same behavior. It is hardly possible that inhomogeneities sufficient to produce diffusion between portions of different concentration could have existed in these charges. There is considerable indication that some of the crystalline nuclei grow at the expense of others-perhaps through exceedingly slow sublimation-which may account for it.

We made repeated attempts to locate some fixed sintering point which should be characteristic of a particular material by means of continuous measurements of the electrical conductivity, but they all indicated that no such point exists. The conductivity of a dry powder increases enormously after sintering begins and would, therefore, seem to offer a most sensitive test, but the phenomenon is altogether gradual, even with a crystalline feldspar containing only a small percentage of glass. We purpose to extend these observatione to other substances. 


\section{CONCLUSIONS.}

It now remains for us to gather the results together and to draw such conclusions as they appear to justify.

(I) If the melting points are $110 \mathrm{w}$ plotted in a system of which they form the ordinates, while the percentage compositions of the different feldspars form the abscissas (fig. It), we discover, within the limits of accuracy of possible measurement at these temperatures, a nearly. linear relation; the melting point varies very closely with the conposition. We have no maximum, no minimum, no branching of the curve, but from each fusion there separates a solid phase of the same

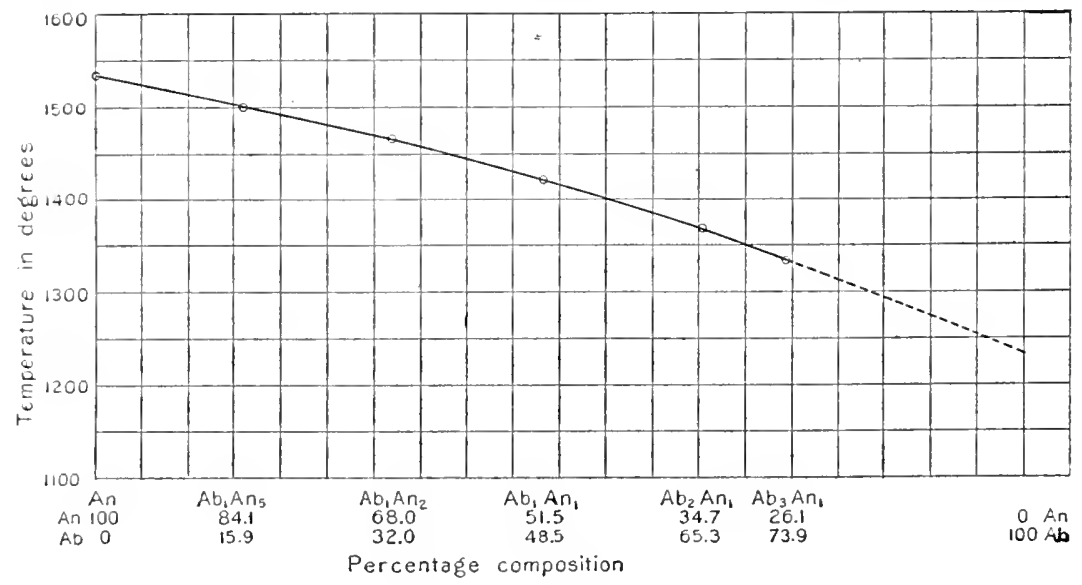

FIG. 14.-Curve of melting temperatures of the soda-lime feldspars.

composition as the vitreous matrix. In $\mathrm{Ab}_{1} \mathrm{An}_{5}$ it will be remembered that this was proved by the separation and analysis of the two phases; in $A b_{1} A n_{2}$ partial crystallization was accomplished in the first cooling and the remainder in a subsequent relieating and cooling, the two groups of crystals proving optically identical; a small quantity of $\mathrm{Ab}_{4} \mathrm{Au}_{1}$, which admits of absolute identification optically, was crystallized out of a melt of that composition and readily recognized. Horeover, evidence to show that the same phase always separated was likewise presented.

Stated in this way, the relation appears to be a simple additive one in which liquid and solid phases of like composition are stable in all proportions of the components and behave like a series of separate feldspars. But as soon as we consider it with reference to the laws of solution and the phase rule, it can not be explained in this sinple way. 
First of all, the phase rule tells us at once that we can liave no true compound liere between the components albite and anorthite, for such a compound would mean one more component and an additional pliase in every solution before equilibrium could be established. Moreover, if the mixture had been entectic in character, the component (albite or anorthite) which happened to be in excess would have crystallized out in each case, causing a continual change in the composition of the remaining glass until the eutectic proportion was reached and the resulting charge would have contained only crystals of one (or, in case of hysteresis, both) of the components and the eutectic. Our curve is continuous and the resulting charges homogencous for all proportions of the components. Lane's suggestion* that the triclinic feldspars form a entectic series in which the eutectic proportion is at or near $\mathrm{Ab}_{2} \mathrm{An}_{3}$ is, therefore, not borne out by our experiments.

Laying aside the eutectic nixture, and passing over to solutions of components which are miscible in many or all proportions, we find a small number of examples, chicfly organic compounds, which have been studied as types by Roozeboom, Kiister, Bodländer, Garelli, Bruni, Van Eyk, and others, among which our series appears to fall.

\section{APPLICATION OF THE LAWS OF SOLUTIONS.}

From the physico-chemical standpoint, the case we now have in hand closely resembles Küster's problem of $189 \mathrm{r} . \dagger$ His measurements were made upon mixtures of organic componnds of low melting point, while ours reached a maximum temperature of $1532^{\circ}$, but we have, between albite and anorthite, an exactly similar series of solid solutions the melting points $\ddagger$ of which change in nearly linear relation to the percentage of the two compounds which enter into their composition.

This simple linear relation was called by Küster perfect isomorphism, and he formulated the "Rule" which has since borne his name, that the solidifying point of an isomorphous mixture lies on a straight line joining the melting points of the components and can be calculated from the percentage composition of the mixture. If this line proved to be slightly concave or convex, as it did in most cases, imperfect isomorphism was assigned as the canse. To this rule an

\footnotetext{
* Lane, Journal of Geology, xu, 2, p. 83, 1904.

$\dagger$ F. W. Küster, Zeitschr. für Phys. Chem., 8, p. 577 , I 89 I.

$\$$ Küster measured solidifying points, but we have pointed ont above that such measurements lead to no positive result in liquids of such viscosity as the feldspars, in which equilibrium is not established during solidification. Undercooling rarely appeared at all in Küster's cases.
} 
objection was raised by Garelli* and elaborated by Bodlandert-if the solid solution behaves like other solutions, a small quantity of component $B$ added to component $A$ can only lower the solidifying point of $A$ when the solicl phase is richer in $A$ than the licpuid phase. The reasoning is this (Bodländer): Let $x_{1}$ (fig. ${ }_{15}$ ) be the vapor-tension curve of component $A$ in the liquid state, $y_{1}$ the soliclifying point $\left(t_{1}\right)$ of $A$, and $z_{1}$ the vapor-tension curve of solid $A$. Now, if a small quantity of $B$ is added and the solid phase which crystallizes out contains the same proportions of $A$ and $B$ as the liquid mixture in which it formed, the vapor tensions of the liquid and solid phases must have been lowered equally and the solidifying point will fall at $y_{2}$ with the same temperature as the pure solvent. (Equality of vapor tension

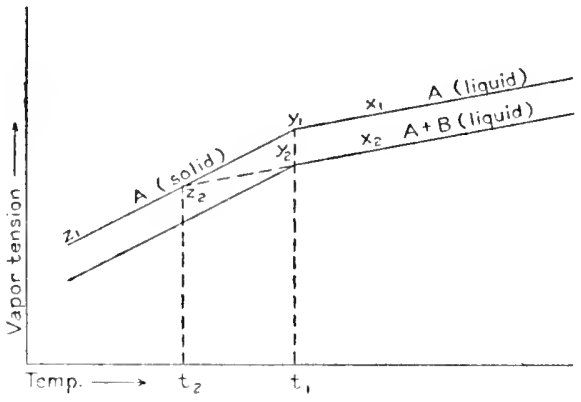

IIIG. 15 .

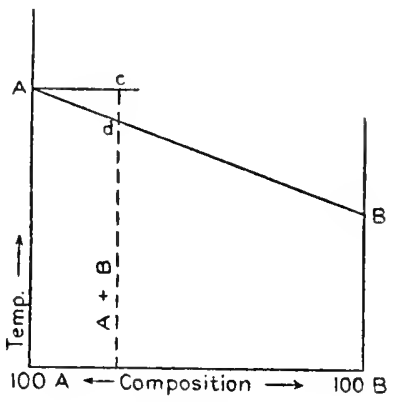

liti. 16.

in the solid and liquid phases determines the temperature of change of state.) If $A$ crystallizes alone from $A+B$, the vapor-tension curve will continue on to $z_{2}$ and the temperature of solidification fall to $t_{2}$; while if the solid plase contains both componcuts but is richer in $A$ than the liquid phase, solidification will occur at an intermediate point.

Fig. 16 will serve to show the crucial character of the issue raised. The ordinates represent temperatures and the abseissas percentages of $A$ and $B$. Küster finds his solid and liquid phases identical in composition within the limits of experimental error and the solidifying temperature on the line $A B$ at a point which can be determined from the proportions of the components-at $d$ for example. But the laws of dilute solutions tell us that if the pliases are identical in composition the soliclifying point of $A+B$ must fall at $c, i$. c., must remain the same as for pure $A$.

The temperatures at which Küster's observations were made and their painstaking character leave no doubt as to the validity of the

* F. Garelli, I. Gazzet ta Chimica Italiana, xxvı, p. 263, 1894.

$\dagger$ Bodlander, Neues Jahrb. f. Min., Beilage, Bd. xil, p. 52, 1899. 
experimental fact. Neither can it be objected that Küster's solutions were not sufficiently dilute to reveal the true relation, for the observations upon naphthaline and $\beta$-naphthol have been repeated by Bruni* with very dilute solutions of one of the components in the other, and completely verified.

Now, the laws of solutions hold for solid solutions even for moderately high concentrations (Bodländer) when the components are not isomorphous, and on the other hand, even liquid crystals, when isomorphous, follow Küster's rule more nearly than the law of solutions.

An extended discussion of existing data from this standpoint would involve us in unnecessary detail; but there can be no question that Küster's rule represents the data which have been gathered upon isomorphous mixtures - at least approximately - while the laws of dilute solutions appear to fail of application there. On the other side, the rule admits of no independent theoretical derivation. Van't Hoff $\dagger$ suggests that judgment be suspended pending the accumulation of further data and intimates that the close similarity of chemical composition and molecular structure in compounds which form isomorphous mixtures gives them an unusually close intcr-relation, and their influence one upon the other may render a simple theoretical treatment very difficult.

Our case is especially interesting when considered from this standpoint, but it distinctly emphasizes the difficulty rather than helps toward its solution: (1) Although the chemical reactions of albite and anorthite are not of such a character as to prove or disprove a close analogy between them, a comparison of their formulæ ccrtainly does not suggest an isomorphous relation. If their formula weights represent true molecules, they possess the same number of atoms to the molecule ( $\mathrm{NaAl} \mathrm{Si}_{3} \mathrm{O}_{8}, \mathrm{CaAl}_{2} \mathrm{Si}_{2} \mathrm{O}_{8}$ ) and the group $\mathrm{Si}_{2} \mathrm{O}_{8}$ in common, but the remaining atoms taken separately are not mutually replaceable. (2) The melting points of the components in the feldspar series are very far apart-more than $300^{\circ}$ - while Küster's organic mixtures were all included within a narrow temperature interval $\left(2^{\circ}\right.$ to $\left.56^{\circ}\right)$. For reasons which will appear presently, both Garellit. and Roozeboom have pointed out that the farther apart the melting points of the components the less probable is the linear relation. (3) The homogeneity of the solid phase is established within I per cent by the optical examination of the slides. Moreover, separate chemical analyses of the solid and liquid phases of the mixture $\mathrm{Ab}_{1} \mathrm{An}_{5}$

* G. Bruni, Atti della reale Accademia dei Lincei, 5, vir, p. 138,1898 .

† Van't Hoff, Vorlesungen üb. Theoret. u. Phys. Chem. (Braunschweig, 1901). Part II, p. 64.

¥F. Garelli, loc. cit. 
in an exceptionally favorable case showed still closer identity of conposition.

It appears altogether improbable that the laws of solutions can apply in the face of so extreme a controverting case.

If it has proved difficult to bring the isomorphous mixture within the general laws of solutions, a most satisfactory theoretical derivation of the conditions of equilibrium in such mixtures has been developed by Roozeboom. No other principle is required than the second law of thermodynamics as applied to solutions by Gibbs: A system of substances will be in equilibrium for a particular pressure when the thermodynamic potential (\%-function) of the system is a minimum. The scheme of representation is the graphical one proposed by Van Ryn Van Alkemade,* and is itself a powerful instrument of analysis in this field.

* Zeitschr. f. Phys. Chem., i 1, p. 2S9, is93.

Except for the suggestions of Vogt to which reference has been made, this method seems not to have been utilized for the study of mineral solutions before. A brief outline of it will, therefore, be given here.

In a system of rectilinear coördinates (fig. 17) the ordinates may represent the potential of a particular system-(Gibbs' - function, not directly measurable) and

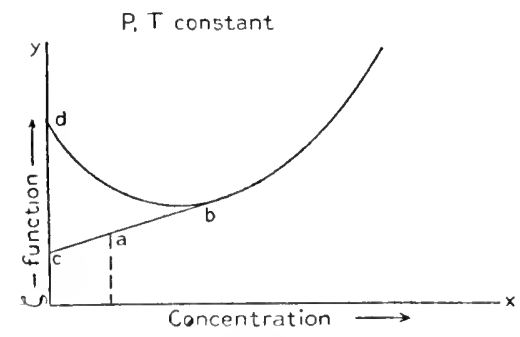

Fig. IT. the abscissas the number of gram-molecules of solvent (water for example) supposed to contain I gr. mol. of solute. In other words, every point of the curve represents a solution of which the $x$ coördinate is concentration and the $y$ coördinate the potential. The conditions of pressure and temperature are assumed constant for a particular diagram.

Every such curve for substances soluble in all proportions will be convex downward, otherwise there would be some particular point on the curve which wotsld not represent a minimum potential for a particular composition and the solution would tend to separate into two, the mean potential of which would be lower.

The condition for equilibrium between such a solution and its solir phase (pure salt) may now be readily found. Lay off on the "-axis a distance equal to the potential of the solid salt and from the point so obtained draw a tangent to the curve. This tangent is the locus of minimum potential (stable systems) for any composition. At the point $a$, for example, we have a saturated solution containing the number of gr. mol. of solvent indicated by the corresponding abscissa and the proportion $\frac{a c}{c b}$ of salt, the balance of the salt remaining in solid phase. At $b$ we have the saturated solution with all the salt included; to the left of $b$ upon the curve, supersaturated solution; and to the right unsaturated solution. With increase of temperature the form of the curve clanges and $c$ approaches $d$, the melting point of the salt. 
Roozeboom distinguishes three general classes of isomorphous mixtures:

(I) The components are miscible in all proportions from o to Ioo per cent in both solid and liquid phases.

(2) Miscibility is limited to certain concentrations.

(3) More than one type of crystal occurs.

In the feldspars we are concerned with the first class only, but here also Roozeboom distinguishes three possible types:

Type I.-Melting (or solidifying) points of the mixtures lie on a continuous curve joining the melting points of the components and containing neither maximum nor minimum.

Type II.--The curve contains a maximum.

Type III.-The curve contains a minimum.

These types are for the moment purely hypothetical and are a product of the method of analysis, though they are being rapidly identified for various isomorphous pairs by pupils of Roozeboom and by others.

The method of reasoning which yields these three possible types will be briefly described with the help of the Van Alkemade graphical analysis:

If we indicate the potential $(\xi)$ of a particular mixture by the length of the ordinate (fig. I 8 ), and the number of molecules of $A$ and $B$ by subdividing the horizontal axis $(A+B=100)$ in the proper proportion, assuming atmospheric pressure and constant temperature for each diagram, then every point within the coördinates represents a particular phase of known composition and potential. Suppose, now (Roozeboom), a temperature is assumed above the melting point of the higher-melting component; clearly, whatever the composition, only the liquid phase can have a stable existence. If potential difference represents the measure of the tendency to change and the tendency of all change is toward the mininum potential, for this temperature all change will be toward the liquid; and the potential of a solid, if one existed there, would be greater than that of the liquid for all compositions-hence the curve $S$ (solid) above the curve $L$ (liquid) throughout.

Suppose the potential to be lowered to a point where crystallization can begin. The tendency to melt no longer obtains for all compositions; the two curves will be displaced relatively and, being of different form, will intersect. Draw a common tangent to the curves and apply Van Alkemade's reasoning above noted. The trend of the potential of both phases between the points of tangency, $i$. $e$, of all mixtures between these limits of composition, is toward the minimum repre- 
sented by this tangent. Crystallization will then begin at a (fig. I 8 , II), with the mixture richest in the higher melting component, crystals of composition $a$ will be in equilibrium with the liquid phase $b$ in all proportions, ancl solidification (or melting) will not take place at a single temperature, but through a range of temperature. If we now
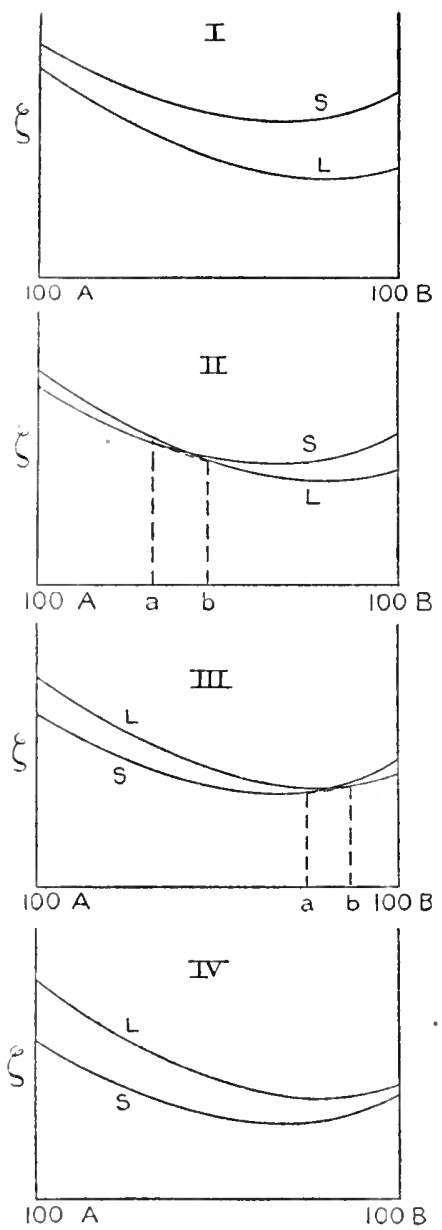

FIG. 18.

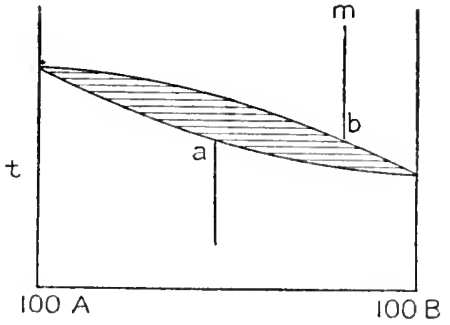

Fig. Ii).

plot the lengtlo of the abscissa corresponding to $a b$ in a separate diagram with the observed temperature range of solidifieation, adding all the other possible cases which will arise fron the continued displacement of the "-eurves, we arrive at the accompanying diagram (fig. 19) of Roozeboom's Type I. Types II and III appear in the same way when the form of the -curves clanges as indicated in figs. 20 and $2 \mathrm{I}$.

The pliysical side of the system of reasoning is readily inferred from the figures. If we start with a mixture of the composition indicated by $m$ (fig. 22) and temperature above the nielting point, crystallization will begin at $a$, the separating erystals will have the composition $b$, while that of the remaining melt approaches $d$. Upon cooling to $e$, solidification ends with crystals of this composition. Melting is exactly the reverse operation. Whether these first crystals of composition $b$ remain stable as such or undergo solid transformation or wholly or partly redissolve appears to remain nndetermined in any general way by Roozeboom's theory, and may be radically influenced by 

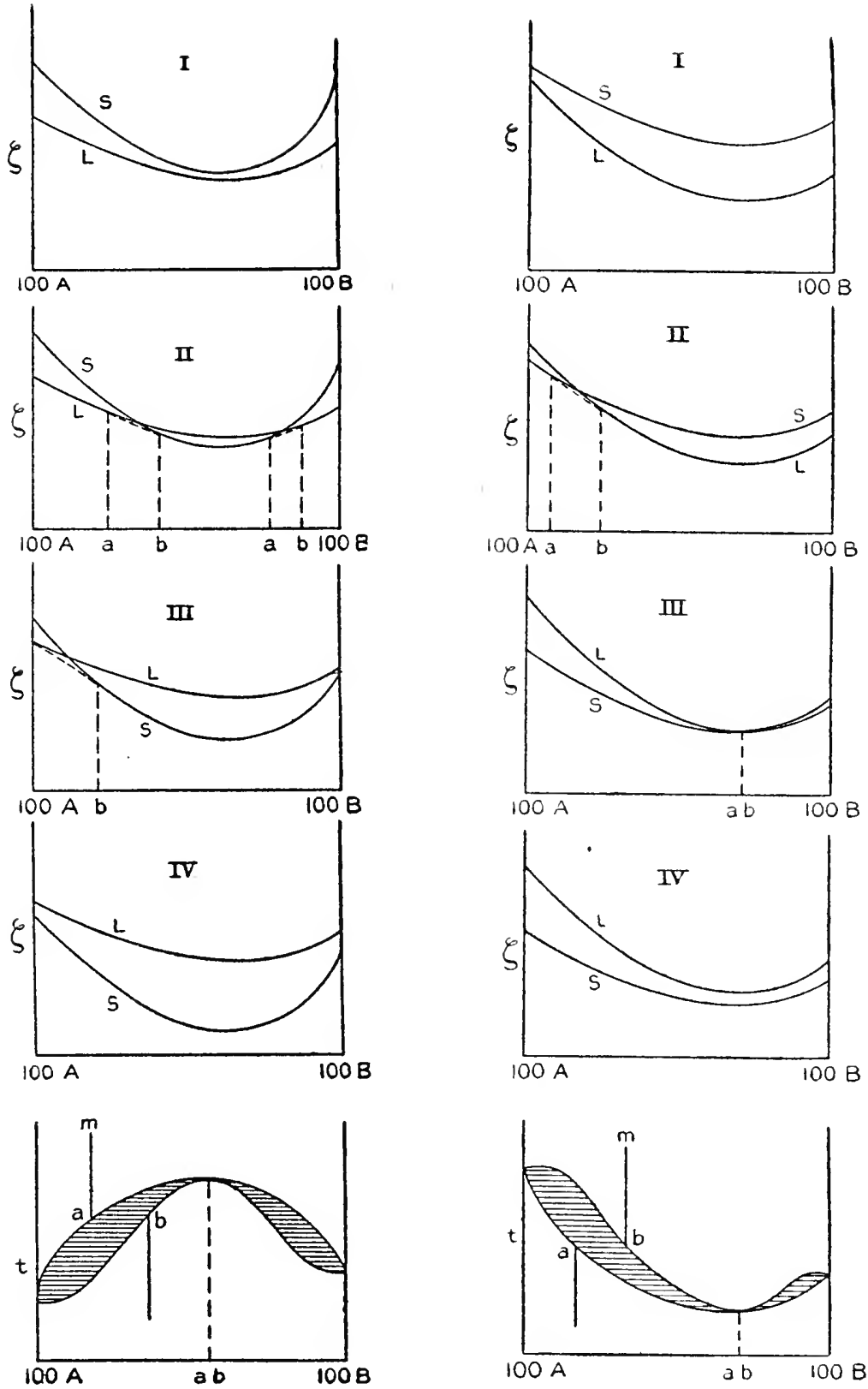

FIG. 20 .

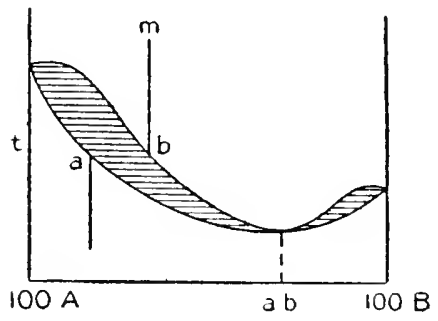

Frg. 21 .

accompanying phenomena like viscosity and undercooling. If a liquid mixture of composition $a$ undercools to $e$ before crystallization begins, crystals of composition $e$ will appear and no others (provided the re- 
lease of latent heat does not raise the temperature above $e$ again). Such a situation is certainly una voidable in viscous mixtures like the feldspars and accounts very well for the homogeneous solidification observed by us. This would classify the feldspars with Type I of Rooze-

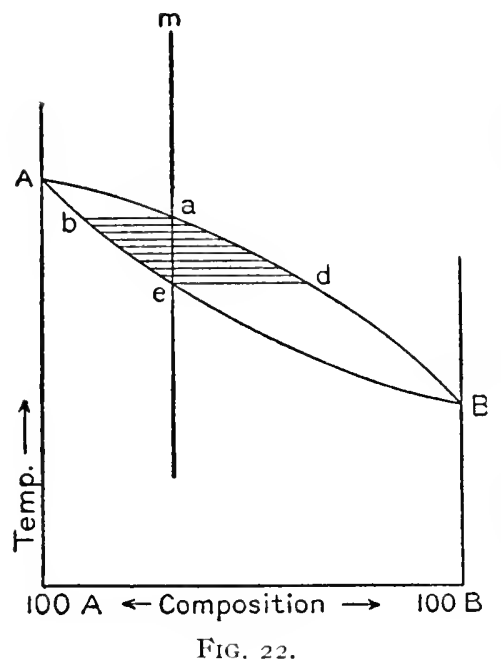
boom's series. A comparison of our melting-point curve with figs. 19, 20 , and 2 I shows this to be the only type under which it could possibly fall. There is no trace of a maximum or minimum in the feldspar curve. Vogt's expectation that they would fall under Type III, therefore, fails of fulfilment from our experiments.

That our curve so closely resembles one branch of Roozeboom's typical curve is remarkable. The difficulties of observation in those portions of the curve where the viscosity becomes so disturbing are too great to enable stress to be laid upon the form which our curve happens to take there, but near the anorthite end of the series its slight convexity is unquestionably real.

It should be added that Professor Iddings has found slight traces of inhomogeneity (less than I per cent) in the slicles of several of our intermediate feldspars. Crystals have been found which were evidently of the earliest formation, and with one exception were more calcic than the body of the charge, as Roozeboom's theory would lead us to expect. The exception was an occurrence of tiny plates of $A b_{4} A n_{1}$ discovered in a charge of $A b_{1} A n_{5}$. The extremely small quantity of the optically different feldspar, the fact that it could not be found in all the slides of this composition, and that in one case a less calcic feldspar appeared, suggest that the inhomogeneity may have been of other origin - perhaps ninerely a consequence of the tremendous difficulty in mixing a homogeneous charge where ultraviscosity precludes stirring, for example. The chemical analysis of the solid and liquid phases, it will be remembered, showed identical composition within the limits of experimental error.

It is clear that if Roozeboom's theory is valid, the line of the metting points can not become perfectly straiglit nuless the \%-curves for the solid and the liquid phases can be superposed point for point throughout, i. e., are ickentical. This wonld nean that the energy 
content per gr. 110l. of solid and liquid phase was the same for all compositions, $i . c$., that all mixtures and the components separately should have the same melting point - a case which is known (Roozeboon, $d$-and $l$-camphor oxime), but is certainly confined to optical antipodes.

Another reason for supposing the case to be much less simple than a mere linear relation with equilibrium between solid and liquid phases of identical composition appears at once from a direct application of the phase rule. A necessary condition for equilibrinum in any mixture is that the number of phases exceed the number of components by two. If the solid and liquid phases are homogeneous, the number of phases (counting vapor) is only three, and equilibrium can not obtain there.

\section{LITHOLOGICAL, APPLICATIONS.}

Supposing the case for the feldspars to be establislied, by this line of reasoning, as falling under 'Type I of Roozeboom's classification, important light is thrown on the significance of zonal structure in feldspars and also on the meaning of its absence. A very considerable proportion of the feldspars found in thin sections of rocks show zonal structure, though it is more frequent in eff 1 sive lavas than in the granular massive roeks.

Furthermore, with rare exceptions, the outer zones are more sodic than those which they inclose. The width and definition of the zones vary greatly; they are sometimes sharply separated; not infrequently they show transitions at the edges of the zones, and occasionally the gradation is a continuous one, so that the extinction during a rotation of the slide resembles a shadow moving at a uniform rate. This last case is immediately explicable by Roozeboom's theory. If a feldspar magma of any particular composition were to solidify without undcrcooling, the composition would change continuously during solidification in a perfectly definite manner, within limited ranges of temperature and composition, as has been indicated in the disenssion of the theory above, the center being always more calcic than the periphery.

Homogeneous crystals are also readily explained. If undercooling occurs the magma does not begin to erystallize until it has passed below the range of temperature at which the change in concentration can take place.

Sharply emphasized zones, or zones showing transitions only at their edges, point to changes in physical conditions during crystallization. Now abrupt changes of pressure are not likely to be frequent excepting during the act of intrusion or extrusion, but in complex 
magmas there inevitably must be local variations in temperature in consequence of the liberation of energy during the crystallization of the feldspars and of the accompanying mineral constituents, especially the ferromagnesian silicates. When the crystallization goes on slowly and smoothly, the magma may be expected to cool gradually over the range between the two curves (fig. 22), and a uniform zonal structure result, the extreme viscosity of the liquid operating to prevent any considerable diffusion, resorption, or other modifying phenomena. Any sudden or irregular release of heat which tends to prevent uniform cooling, if it occurs within the range of possible zonal formation, may be expected to result in some variation in the bands; constant temperature for a considerable interval will tend to produce broad bands of uniform composition through the resorption of more calcic crystals already formed, and sharp demarkaations. In fact, any considerable disturbance, either mechanical or thermal, would probably result in sharp demarkations between bands. Again, if the temperature change should carry the crystals below this critical region, only homogeneous crystals would form unless a near-by release of heat could raise it again. It is easily conceivable that this latter case might produce a partial reversal of the order of the bands.

In a word, if feldspar crystals begin to form within the range where a change in concentration can occur, zonal structure will probably result, and every change in the temperature will have its effect upon the arrangement of the zones. Long-continued freedom from thermal disturbance will produce broad zones, and rapid variation, either continuous or irregular, will produce narrow or sharply bounded ones.

Inversely, it would appear that whenever a set of thin sections shows traces of zonal structure, and there are few hand specimens in which this structure can not be detected, solidification of the feldspars has taken place within well-defined limits of temperature. When, as in the granites, water vapor or its components have entered into the composition of the magma, it is probable that this range of temperature is a different one, a point to be determined by further researches, but it is evidently practicable to determine for granites as well as for the nearly anhydrous lavas at what temperature the feldspars have solidified, wherever zonal structure can be found. 


\section{SUMMARY OF CONCLUSIONS.}

Reviewing this discussion briefly: (I) The triclinic feldspars are solid solutions and form together an isomorphous series. It is a sufficient condition for the latter that the curve of melting points is continuous (Bruni, loc. cit.). Like Küster's curves for organic compounds, the curve of melting points does not follow Van't Hoff's law of dilute solid solutions and does approximate closely to a straight line joining the melting points of the components. The case appears to fall under Type I of Roozeboom's theoretical classification of isomorphous mix-

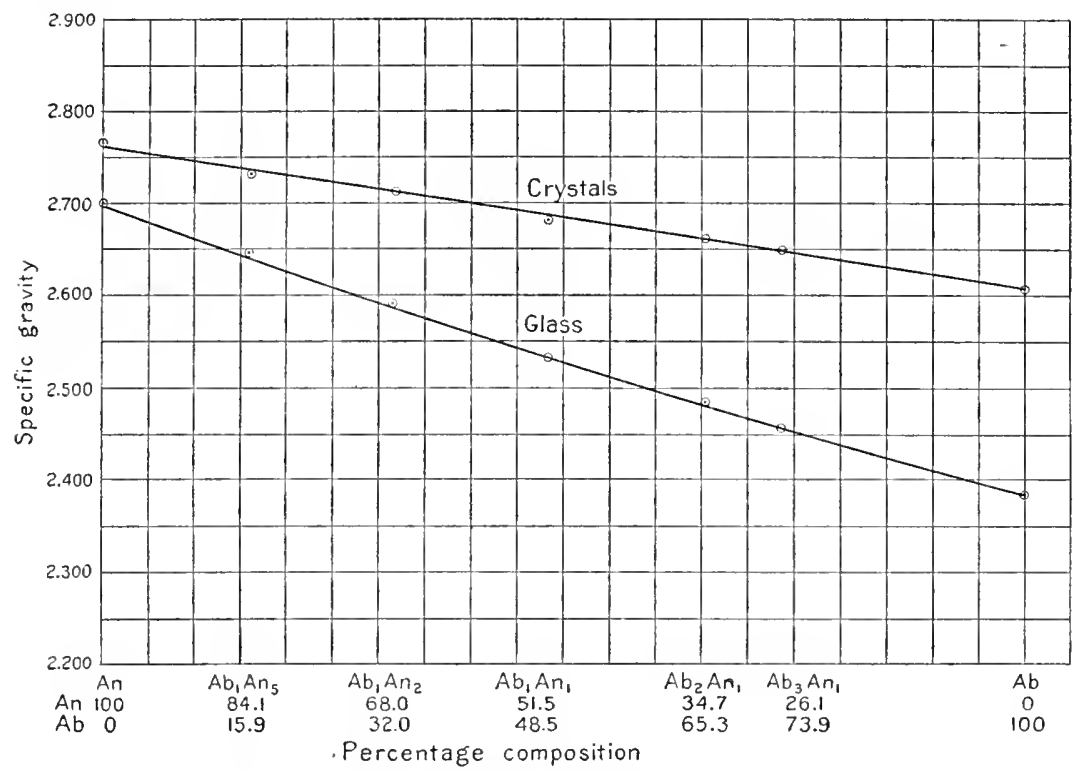

FIG. 23.-Curves of specific gravity of the feldspars and feldspar glasses.

tures, in which case the line can not become exactly straight unless the melting points of the conponents are ncarly or quite identical, nor the solidification absolutely homogeneous without reducing the number of phases to three and destroying the equilibrium. The theory also accounts for an absence of sharpness in the intermediate melting points of the feldspars, but the fact that this lack of sharpness culminated in albite instead of terminating there shows that the riscosity was the chief factor in our difficulties from this cause. Albite was clearly show1 to melt through a variable range of $5_{5}^{\circ}$ or more, while the intermediate feldspar bytownite $\left(A b_{1} A_{1} n_{5}\right)$ melted almost as

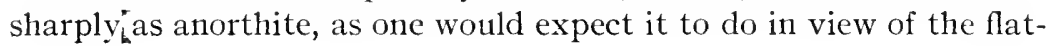


ness of the melting-point curve (p. 60). The fact that practically no differences of composition could be detected in our melts we attribute to the effect of viscosity and consequent 1ndercooling, which resulted in crystallization invariably resulting at much too low a temperature for equilibrinm to become established between the solid and liquid phases at any stage of the crystallization process

(2) When the speeific gravities are plotted, like the melting points, as a function of the composition (fig. 23), the isomorphism of the feldspars is strongly confirmed.

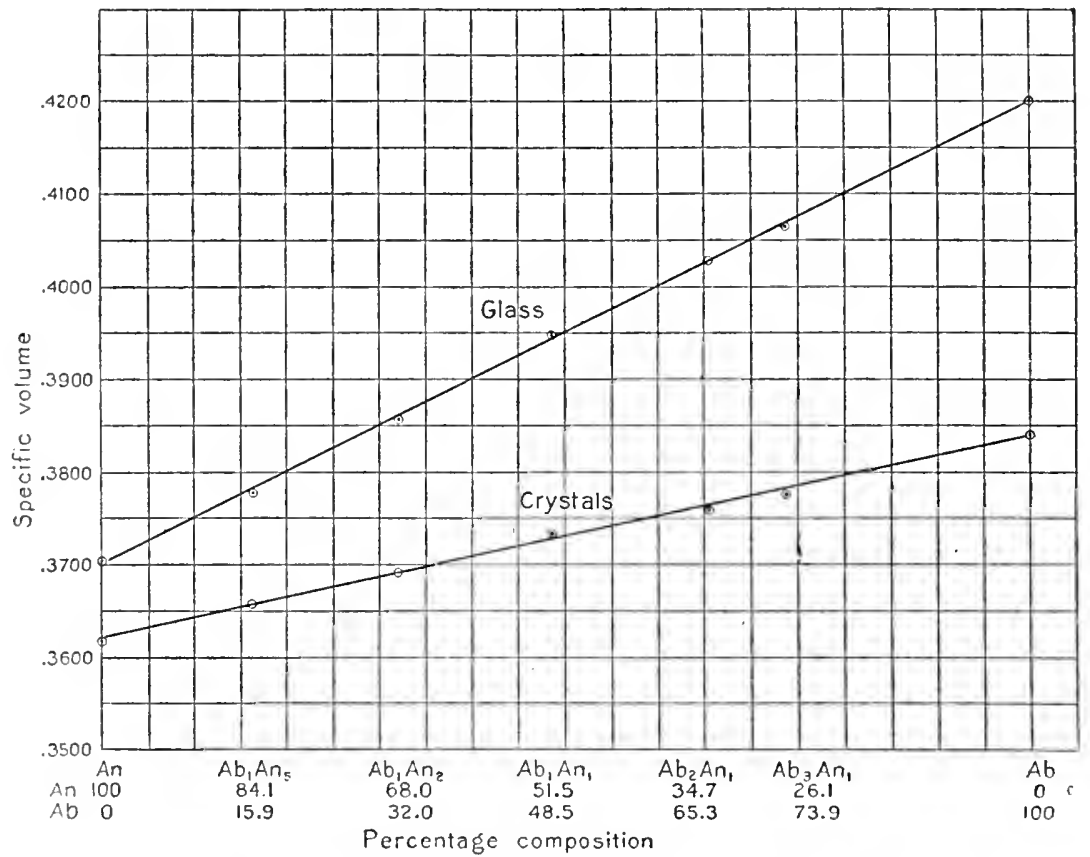

FIG. 24.-Curves of specific volume of the feldspars and feldspar glasses.

The curve indicates a perfectly continuous relation which the suecessful preparation of chemically pure albite enabled us to follow through to the end. The order of accuracy is also extraordinarily high throughout by reason of the chemical purity of all the preparations and the consistent effort made to obtain complete crystallization, even with the more viscons feldspars. Several of the charges were heated for two weeks or more consecutively, then removed for a determination, then replaced in the furnace for another week in order that we might assure ourselves, from the consistent reappearance of the same value, that a maximum, and, therefore, holocrystallization, had been reached. It is of some practical importance to note in pass- 
ing that preparations which appeared completely crystalline in the slides frequently proved not to have reached their maximum specific gravity. It is very difficult to detect the last traces of glass with the microscope.

If our confidence in these determinations is justified, the form of the specific-gravity curve is very significant. It was pointed out by Retgers* that if the isomorphous mixture is merely a "mechanical aggregate" the volume of which remains exactly equal to the sum of the volumes of the components, then the specific-volume curve of the mixtures for percentages by weight of the two components must be a straight line. He also offers a number of isomorphous pairs for which he finds the specific-volume curves to be straight lines, in support of his hypothesis that this relation is general. Our values when plotted in this way (fig. 24) also give a straight line with maximum variations amounting to 0.005 , which is probably not greater than the aggregate error in the syntheses and in the determinations of the specific gravity.

In spite of this apparent corroboration, it does not seem to us that Retgers was quite justified in assuming that this relation is entirely without limitation. The temperature at which the specific gravity is determined is so far below the temperature of solidification (in our case more than $r 000^{\circ}$ ) that the density at $25^{\circ}$ will depend, to a considerable degree, upon the coefficient of expansion of the material as well as upon composition and molecular structure. The coefficient of expansion will, in general, differ for different compositions, and is not, in general, a linear function of the temperature. Considering Retgers's generalization in the light of these facts, the relation of the specific gravities at $25^{\circ}$ would be necessarily continuous, but not necessarily linear.

The specific gravities of the glasses are also plotted (fig. 23) to slow the divergence from the line of the erystals toward the albite end of the series, $i$. e., as the percentage of albite increases the density of the glass is diminished more than that of the crystals.

There is nothing new in the conception of isomorphisin in the feldspars, but the positive character of our experimental results makes them of more than ordinary interest by reason of the fact that so good authority on the subject as Fouqué and Lévy has passed upon it adversely on the basis of optical evidence derived from artificial preparations. More recently Violat has declared that the optical evidence is insufficient to prove isomorphism in the natural feldspars

* J. W. Retgers, Zeitschr. für. Phys. Chem., 3, p. 507, r889.

$\dagger$ Loc. cit. 
The melting points and specific gravities plotted above are brought together in a convenient table liere.

\begin{tabular}{|c|c|c|c|}
\hline \multirow{2}{*}{ Feldspar. } & \multirow{2}{*}{$\begin{array}{c}\text { Melting } \\
\text { temperature } \\
\text { (degrees). }\end{array}$} & \multicolumn{2}{|c|}{ Specifie gravity. } \\
\hline & & Crystals. & Glass. \\
\hline$A n \ldots \ldots \ldots$ & $1532^{\circ}$ & 2.765 & 2.700 \\
\hline$A b_{1} A n_{5}, \ldots \ldots \ldots$ & 1500 & 2.733 & 2.648 \\
\hline$A b_{1} A_{n} \ldots \ldots$ & 1.463 & 2.710 & $2.59 \mathrm{I}$ \\
\hline $\mathrm{Ab}_{1} \mathrm{An}_{1} \ldots \ldots$ & $1+19$ & 2.679 & $2.5,33$ \\
\hline $\mathrm{Ab}_{2} \mathrm{An}_{1} \ldots \ldots \ldots$ & 1367 & 2.660 & $2 .+83$ \\
\hline $\mathrm{Ab}_{3} \mathrm{An}_{1} \ldots \ldots$ & 1340 & 2.649 & $2 .+58$ \\
\hline $\mathrm{Ab} \ldots \ldots \ldots \ldots$ & $\ldots$ & 2.605 & 2.382 \\
\hline
\end{tabular}

(3) In the melting of albite and microcline weappear to have substantial evidence of a phenomenon which is unfaniliar both to physics and to mineralogy. Microscopic crystals of a homogeneous compound, when slowly heated, were shown to persist for $150^{\circ}$ or more above where melting began, the amorphous melt renaining of the same order of viscosity as the rigidity of the crystals. By careful observation, curves were also obtained showing that the absorbed heat of fusion was distributed over this interval.

From the experimental standpoint a substance of this kind can hardly be said to have a melting point, but passes gradually from crystalline to amorphous at temperatures which can be considerably varied by merely changing the rate of heating. In moderate charges of albite or orthoclase at atmospheric pressure this melting began so slowly that it was not possible to locate even approximately a lowest temperature for the beginning of the change of state. As a matter of definition, this nininum temperature above which melting will continue (for a given pressure) more or less rapidly, according to the conditions, is the "melting point," whether it can be located or not, so far as the equilibrium of the system is concerned; and crystals which continue to exist unmelted at higher temperatures appear to form a metastable plase, perhaps comparable to that of a crystalline solid when leated above the "Umwandhurgstemperatur" without inmediate change of crystal form. It is also possible that the mass is fluid when heated above the melting point, but that deorientation of the molecules is delayed by viscosity. This metastable stage can casily extend over $150^{\circ}$ in albite and orthoclase and would persist for days in the lower portion of this range.

(4) We also found that viscous and poorly-conducting melts which solidify only after considerable undercooling do not give constant solidifying points. The solidifying point nunst not be used, therefore, without great caution as a physical constant; it bears no relation 
whatever to the melting point unless equilibrium is reestablished before solidification is complete- a condition which rarely obtains and of ten can not be produced in viscous mineral melts. Especial attention is directed to this because of the importance of the lowering of the solidifying point in the study of solutions, and the possibility of its application to mineral solutions recently suggested by Vogt.*

(5) Incidental to the experimental work upon the feldspars we were able to establish the fact that there are no differences of density in the feldspar glasses due to the rate of cooling which are greate $r$ than our errors of observation ( $\pm 0.00 \mathrm{I})$. Alsc that powdered crystalline feldspars which are free from inclusions and from glass, even when very fine, do not sinter until melting begins; powdered glasses of like composition sinter readily at relatively low temperatures $\left(700^{\circ}\right.$ to $\left.900^{\circ}\right)$, depending primarily upon the degree of pulverization. Again, that powdered feldspars when exposed to the atmosphere adsorb moisture in quantities of an order of magnitude equal to those usually quoted in analyses. (Dana's System of Mineralogy, l. c.). It is, therefore, altogether possible that the significance of this moisture has sometimes been mistaken.

* J. H. L. Vogt, loc. cit. 



\section{PART II.}

\section{The Isomorphism and Thermal Properties of the Feldspars.}

\section{OPTICAL STUDY.}

BI

J. P. IDDINGS. 
. 


\section{LIME-SODA FELDSPARS CRYSTALLIZED IN OPEN CRUCIBLES FROM FUSED CONSTITUENTS.}

\section{INTRODUCTION.}

The results of these synthetical experiments agree closely in some respects while differing in others. They agree in general in the habit and arrangement of the erystals of the different feldspars produced, while difiering in the size of the crystals of the various feldspars according to their composition. These results have an important bearing on the problem of texture and granularity in igneous rocks.

First, as to the habit of the feldspar erystals produced from solution of the feldspar constituents withont admixture of other material. So far as can be determined by microscopical study of the sections, the erystals are in most eases blade-like in form; that is, they are elongated plates. They vary, however, from one extreme to another, being in some cases equidimensional plates of extrene thinness, in other eases prisms, elongated in one direction with the other two dinensions equal. The development of these forms takes place in feldspars of various connpositions, and appears to be chiefly a function of the rate of crystallization and not of the cliemical composition of the feldspar, except as this modifies the viscosity of the solution. It is not possible to recognize any fixed relation between the habit of the crystals and the composition of the feldspar. This is, of course, in accord with the well-known isomorplism of the feldspar group.

The conmon mode of erystallization in these preparations is that of spherulitic aggregations, more or less completely developed in spherical forms.

The elements of the spherulites are bundle- or sheaf-like aggregations of long, thin blades, which blades lie nearly parallel to one another in the middle or narrower part of the bundle, and diverge at the ends into fan-like or plumose forms. Several of these bundles or blades cross one another at the middle, and when there are a sufficient number of bundles, or when they diverge sufficiently, a completely spherulitic aggregation results.

In some cases a spherulite consists of bundles or prisms that extend uninterruptedly from the center to the outer margin, the rays of the spherulite being nearly straight. In other cases the spherulite is a com- 
posite of divergent bundles shorter than the radius, which have been added to one another as though new plumes had started from the ends of earlier ones.

In most cases the middle portion of the feldspar bundles consists of stouter crystals than the outer parts. It also appears that the middle portion is more prismatic, in eertain cases somewhat euboidal, the outer parts becoming delicately tabular. This, with the divergence in position, explains the spread of the outer part of the sphere. There is a great increase in the number of individual crystals in the onter portion of the spherulite, and in some cases the crystals also increase in size in the outer part.

The shapes of the crystais are due to the flattening of the crystal parallel to the second pinacoid (oro), and its elongation parallel to the crystal axis $a$. The outlines of the plates appear to conform to traces of several pinacoids in the zone of the $b$ axis, (OOI), (20I), (101), (201), ( 304$),(\overline{2} 03)$, not all of these occurring together. It is quite probable that pinacoids in the zone of the $c$ axis also may be developed, but they were not recognized.

Bladed forms in some cases prove to be aggregates of thin plates not strictly parallel to one another in the plane of flattening, so that the blade is curved and not straight in the direction of its longest axis.

In some spherulites the component crystals are prisms throngliont, with no tabular flattening. The number of crystal prisms increases from the center of the splierulite outward by the development of new prisms at slightly divergent angles, in arborescent arrangement.

The most complex arrangements are produced by twinning and divergence combined, resulting in feather-like aggregates. I,ong, narrow, tapering blades in albite $t$ wins form a shaft, elongated parallel to the erystal axis $a$, on two sides of which diverge at a slight angle a double set of thin blades, like barbs. These consist of branched smaller blades or prisms, like barbules, the branch prisms having approximately the direction of the erystal axis $c$. The two sets in each "barb" are apparently related to one another as the halves of a manebach twin. The small prisms are composed of nuny subparallel plates flattened in the plane of the second pinacoid (oro). These correspond to barbicels in a feather.

With respect to the size of the crystals it is extremely significant that pure anorthite (An) develops in comparatively large plates, $5 \mathrm{~mm}$. thick and 20 to $30 \mathrm{~mm}$. long, in a few hours, whereas the more sodic the feldspar the smaller the individual crystals formed under almost the same conditions of cooling. Thins with oligoclase $\left(\mathrm{Ab}_{4} A n_{1}\right)$ the individual crystals composing a bundle of blades are considerably 
less than o.or mm. thick, probably about o.oor 1mm., a difference in thickness when compared with anorthite of about 5,000 to I. This as shown elsewhere is due to the greater viscosity of the liquid feldspars near their solidifying point as they approach the albite end of the series.

Any comparison of the grain of rocks, that is, the size of the constituent crystals, with a view to determining the physical conditions attending the solidification of the magma, must be based in the first instance on a knowledge of the behavior of the various rock-making minerals under similar physical conditions, both separately and in combination, that is, in solution with one another. The granularity of rocks is clearly a function of the chemical composition.

With respect to the homogeneity of the crystals separating from the liquid, it is observed that the great part of each crystal aggregation appears to be of one composition, but that in some cases a small proportion, probably less than i per cent, is different from the bulk of the feldspar, both in composition and habit. In one instance this small variant differed in composition but not in habit from the main mass of crystals.

In the first case it appears that crystallization began with feldspar richer in the anorthite molecule than the solution and developed cuboidal forms. These were prolonged into prismatic bundles, the prisms having the composition of the main mass of crystals.

In the second case the small variant crystallized toward the end of the crystallization and contained more albite molecules than the main mass of feldspar crystals. It had the same habit as the other more calcic portion, and appears to have crystallized at the same time with it, the crystals with different optical properties being by the side of one another and not in zonal relation. Neither of the feldspars represents the end mentber of the series, An or Ab.

The detailed description of the thin sections of these laboratory preparations of lime-soda feldspars follows:

\section{ANORTHite (AN).}

(19). This aggregation consists of tabular crystals 3 to $5 \mathrm{~mm}$. thick in somewhat radial arrangement, and between these are smaller tabular crystals in similar radial clusters. The clusters are twinned according to the albite law in lamellæ, o.1 $5 \mathrm{~mm}$. thick and less. The thinnest lamellæ are not always continuous throughout the length of a crystal.

The optical orientation is uniform throughout the length of each 
lamellar section without evidence of zonal structure, proving that the crystals are chemically homogeneous.

Fracture lines cross the crystal irregularly and follow possible cleavage planes to only a linited extent. In some cases lamellæ have broken apart along the composition plane, which is also the second cleavage plane (010).

In several places the albite twins have been cut at right angles to the twinning plane and also at right angles to one of the optic axes of the crystal. In one lanella it is almost exactly normal to the plane of section, in the other very slightly inclined. The plane of the optic axes in one lamella stands at $63^{\circ}$ to the trace of the twinning plane (oro); in the other lamella it is $62^{\circ} 30^{\prime}$ approximately. One of the optic axes of the crystal lies almost parallel to the pinacoid (o10). This is the position given it in Michel-Lévy's diagram* for anorthite (An).

The crystals contain numerous inclusions of colorless, apparently amorphous substance, with a refraction higher than anorthite. It appears to be isotropic. The outline is very irregular and rounded. The shapes are curved and elongated. They contain gas bubbles. These inclusions are distributed in planes, lines, and swarms, having various directions with respect to the feldspar crystals. The arrangement in some cases suggests skeleton forms. In some places the inclusions are mostly gas. But the suggested feather structure bears no fixed relation to the crystal orientation or the lamellar structure of the anorthite. It appears like the structure of something obliterated by the crystallization of the anorthite, or in some cases as though the skeleton form were completely filled up by anorthite in perfect orientation. The distribution of the inclusions in some instances is such as to suggest changes in the rate of crystallization of different parts of the crystal. In some places the crowding of minute inclusions suggests very rapid crystallization. It appears as faint cross-banding in the crystal shown in Plate I, from another preparation of anorthite (An).

The glass is probably composed of material in excess of the proportions necessary for the anorthite $\left(\mathrm{CaAl}_{2} \mathrm{Si}_{2} \mathrm{O}_{8}=\mathrm{An}\right)$. It is not $\mathrm{SiO}_{2}$ alone, for this would have an index of refraction lower than anorthite. It may be a silicate of $\mathrm{Al}$ or Ca.

$\left(5 \mathrm{O}^{\mathrm{a}-\mathrm{b}}\right)$. This preparation is similar to (19). The crystals are tabular parallel to the second pinacoid (010). The larger plates are $\mathbf{I} .5 \mathrm{~mm}$. thick. There is multiple twinning according to the albite

* Etude sur la Détermination des Feldspaths, ete. Paris, r89. Platevir. 
law, and no evidence of variation in optical orientation or zonal structure in any one crystal. The crystals are homogeneous. In sections cut at right angles to an optic axis the plane of the optic axes makes an angle of $65^{\circ}$ with the trace of the second pinacoid (o10). In some sections there is a remarkable appearance of the twinned lamellæ. They appear to be faulted in bands across the tabular crystal, as shown in Plate I. But there is no evidence of dislocation in the outline of the crystal plate; in fact, there may be continuous lamellæ on both sides of the apparently faulted belt. Close inspection of twinned lamellæ shows that the several series of discordant belts do not correspond in number or in width of the lamellæ composing them, so that they are not displaced, faulted sections of a large multiple twin of feldspar, but independent crystallizations in parallel position.

The illustration shows a cross-section of tabular feldspar cut at right angles to one optic axis and nearly at right angles to the crystallographic axis $c$. The crystal is tabular parallel to the pinacoid (oro); the belts of multiple twins, which have the appearance of being faulted, extend at right angles to (oro). Their growth appears to have progressed from one side of the tabular crystal to the other, for they are blended with a continuous lamella on one side and exhibit a broken limiting line on the other side, against another continuous lamella. They may represent a coördinated set of prismatic feldspar crystals, elongated parallel to the crystallographic axis $c$, twinning independently of one another, while thickening in the direction of the $b$ axis.

\section{Bytownite $\left(\mathrm{AB}_{1} \mathrm{AN}_{5}\right)$.}

$\left(58^{a-b}\right)$. These sections are from spherulitic aggregations of twinned crystals. The spherulite consists of radiating groups of highly twinned bladed crystals of feldspar, which are nearly parallel to one another within one group. But the different groups stand at various angles to one another. This is shown in cross-section $\left(58^{\mathrm{b}}\right)$, Plate II. The blades are not plane-faced or parallel-faced. They curve somewhat and wedge out abruptly. They vary in thickness from $0.18 \mathrm{~mm}$. to about $0.07 \mathrm{~mm}$. and less. The breadth of the blades varies considerably, averaging about $1 \mathrm{~mm}$ The groups of subparallel blades are from 2 to $5 \mathrm{~mm}$. in diameter. In length, as shown in section $\left(5^{8^{a}}\right)$, Plate III, the blades are about $10 \mathrm{~mm}$. long.

Upon magnifying these blades they are seen to be highly complex, and their outline quite irregular. Cross-sections exhibit multiple twinning according to the albite law, the lamellæ being sharply defined in some places and indistinct in others. In thin section there are 
opaque lines between blades. These are very irregular and appear to be impurities introdnced into spaces between the surfaces of blades during the grinding of the section. The surfaces of blades are composed of crystal faces at various angles which are the terminations of component lamellæ. A blade so delimited in cross-section is traversed in places by distinct, straight lamellæ, which extend without interruption from one side of the blade to the other, as shown in Plate II, On both sides of such a twinned belt the blade is composed of shorter lanellæ which appear to originate near the middle of the blade and run ontward, their cross-section being like a curved wedge whose apex is at the middle of the blade. In other places there are paralleledged lamella in two bands standing at a slight angle to each other. These lamella appear to blend or to be interwoven in the middle of the blade. They are not twinned in some cases, but are twinned in others. Each of these lamellæ terminates at the surface of the blade as an independent crystal, so that the surface consists of the angular terminations of these crystals. In some places they terminate in a common plane. As they do not always exhibit uniform optical behavior, they appear to overlie one another in thin section as inclined plates or prisns.

In longitudinal section ( $5 \mathrm{~S}^{\mathrm{a}}$ ) parallel to the rays of the spherulite the long shafts of feldspar exhibit very delicate feather-like structure. This is very intricate and is often blended to such an extent that its precise character is obscure. It appears differently according to the position in wlich the groups of bladed crystals or aggregations have been cut by the section. In some positions of the section the shaft of a "feather" consists of long, narrow, very sharply defined stripes of albite twins (Plate III), which are clearly longitudinal sections of the well-defined bands of albite twins observed in cross-sections of the blades. This shaft tapers gradually toward the apex. On both sides of this shaft are long, straight-edged lamellæ, which make an angle of $4^{\circ}$ or $5^{\circ}$ with the twimned sliaft, and farther out toward the apex an angle of $7^{\circ}$. They appear like barbs in a feather. In some places, noticeably toward the apex of the feather, the barb-like parts are crossed by delicate parallel lines, like barbules.

The position of the twinned lamellæ parallel to (oro) and the development of the pinacoidal cleavages parallel to (OIO) and (OO1) which appear in cross-sections $\left(58^{\text {b }}\right)$ show that the feather-like blade is elongated in the direetion of the crystal axis $a$, and is broadened parallel to the basal pinacoid (Oo I). Some longitudinal sections parallel to the second pinacoid (oro) slow a feather-like arrangement of somewhat curved branches or barbs, each composed of extremely thin 
plates in parallel orientation. The plates are tabular in the pinacoid (OIO) and are bounded by the planes (OOI), (IOO), (201), and (IOI). The angle at which these barbs approach the central part of the feather, though somewhat variable, is approximately $65^{\circ}$ in some sections. This suggests the manebach twinning in the portions of the aggregated blades from which such longitudinal sections are cut.

Referring to the illustrations already mentioned, it will appear that the aggregated blades, which in subparallel bundles form the rays of the spherulite, consist in certain parts of long, flat, twinned lamellæ, elongated in the direction of the crystal axis $a$, each lamella flattened parallel to the second pinacoid (oro), the plane of twinning. On both sides of these twinned lamellæ are slightly inclined, thin, flat, blade-like lamellæ (barbs) which are in double arrangement on each side of the shaft, as shown in cross-section (Plate II). In other parts of the composite blades these doubled barbs appear to be compounded of thin plates flattened parallel to (oro) (barbules), the doubling appearing to be due to manebach twinning. In the middle portion of such aggregates there is great confusion of detail, due to wedging of crystals and overlapping within the thin section. Crystallization appears to have advanced from the central portion of such aggregates outward, producing in some places wedge-shaped crystals or wedgeshaped aggregates of parallel tabular crystals, which may behave as a continuous crystal within the body of the aggregate, but may have an outline or surface corresponding to a parallel aggregation of smaller crystals.

The optical behavior of these feldspar aggregates indicates that their substance is homogeneous throughout, except in several places where the optical properties show that feldspar of another composition has crystallized. These portions are small in proportion to the bulk of the feldspar crystals. They are in several instances fortunately cut by the thin section, the two cleavages being alnost exactly normal to the section plane. The section is almost perpendicular to (OIO) and (OOI). In these feldspars the acute bisectrix is almost exactly normal to the plane of section; the plane of the optic axes is parallel to the basal cleavage (OOI). The acute bisectrix is the direction of vibration of the fastest ray, the mineral is optically negative, and the optical properties are those of $\mathrm{Ab}_{4} \mathrm{An}_{1}$, as shown in MichelLévy's diagram.* Apparently the feldspar compound first crystallizing was a little richer in calcium than the mixture of the solution, and feldspar of this composition continued to grow until the solution

*op.cit., Plate II. 
in places reached the composition of $\mathrm{Ab}_{4} \mathrm{An}_{1}$. But there is no evidence that the crystallization of the more calcic feldspar lad ceased before that of the more sodic feldspar began. On the contrary, they appear, judging from the shape of the aggregates, to have grown simultaneously, but toward the end of the act of solidification of the solution.

(30) and (3I). These are thin sections from one preparation, which is glassy below and erystalline above. (3I) is from the upper part of the preparation at right angles to the upper surface. It consists of a minutely crystallized aggregation with more coarsely crystallized parts composed of lath-shaped and bladed crystals, the largest being I. $8 \mathrm{~mm}$. long and $0.18 \mathrm{~mm}$. thick, there being all gradations in size from the largest to the smallest (Plate IV). 'The crystals lie at all angles, sometimes radiating, but spherulitic aggregates have not been developed. In many cases the crystals have rectangular outlines; in others they taper at the extremities, or wedge out by reason of the interference of adjacent crystals. Twinning is common, but some are not twinned. The albite law prevails, and in some erystals the synmetrical extinction angles are $45^{\circ}$. The habit of the crystals is not definitely determinable, whether tabular plates or elongated blades. The erystals are of different thicknesses within the thin section, the plates or blades being thinner than the section of the preparation. For this reason the Becke method of testing relative refringence of adjacent crystals is not applicable, as the thicker parts of crystals in glass or balsam always appear in higher relief than the thinner parts.

In (30), from the middle of the preparation, just above the glassy bottom half, there are aggregations of delicate tabular crystals in parallel and subparallel groups in various angular positions (Pl. V). In some places the tabular crystals in cross-section are sharply outlined and straight-edged. In most cases the outline is indefinite and the larger plates consist of multitudes of parallel and subparallel plates, whose outline in the plane of flattening, however, is often sharply defined. They appear to be plates parallel to (oIo), bounded by the pinacoids (OOI), ( $\overline{2} \mathrm{OI})$, and (IOI). The angle between the traces of (OOI) and $(\overline{2} \mathrm{OI})$ is about $8 \mathrm{I}^{\circ}$, and that between the traces of (OOI) and (iOI) about $52^{\circ}$. In some cases the plates are nearly equidimensional, in others they are elongated into blades parallel to (oor) or to (201). Owing to the aggregation of subparallel crystals of extreme thinness, the optical behavior is that of aggregates, and confused. In one plate of a thicker erystal cut parallel to (oro) 
the extinction angle, measured from the cleavage plane (oor), is about $33^{\circ}$. The crystals appear to be alike and homogeneous, having the composition $\mathrm{Ab}_{1} \mathrm{An}_{5}$.

\section{LABRADORITE $\left(\mathrm{AB}_{1} \mathrm{AN}_{2}\right)$.}

$\left(60^{\mathrm{a}-\mathrm{b}}\right)$. The preparation consists of radiating plates or blades, about $0.05 \mathrm{~mm}$. to less in width and as much as $0.7 \mathrm{~mm}$. long. Two to five blades intersect at various angles, wedging out at the point of intersection (Plate VI). Each plate consists of two or more twinned lamellæ. Between the thicker plates there are more delicate crystals composed of subparallel plates and skeleton growths of extremely thin blades with crystal outline, probably the traces of (oor) and ( $\overline{2} \mathrm{OI})$ on the second pinacoid (OIO). The more solid plates or blades feather out at the ends to somewhat divergent plumes. There are in some cases branching, feather-like forms in crystallographic positions suggesting the extension of a single crystal in directions parallel to the $a$ and $c$, and possibly the $b$, axes, the angles of branching being about $64^{\circ}$, and in some cases about $90^{\circ}$. Albite twins yield maximum symmetrical extinction angles of $37^{\circ}$. The crystals appear to be homogeneous.

$\left(6 \mathrm{I}^{\mathrm{a}-\mathrm{b}}\right)$. The preparation is glass, with an index of refraction higher than that of balsam, and feldspar spherulites about ro $\mathrm{mm}$. in diameter. The spherulites are very beautiful aggregations of somewhat divergent, plumose bundles of prismatic crystals (Plate VII) that appear as distinct crystals at the surface of the spherulite, from which they project at slightly different lengths into the surrounding glass, each prism, 0.003 or $0.004 \mathrm{~mm}$. in diameter, being terminated by crystal faces nearly equally inclined to the long axis of the prism. The component short bundles show similar plagiohedral terminations to the individual prisms composing them. These in some cases are flattened and blade-like, and are in subparallel aggregations, the plates having nearly rectangular outline. In one part of section $\left(6 \mathrm{I}^{\mathrm{a}}\right)$ there are groups of albite twinned feather-like aggregates similar to those in $\left(5^{8^{b}}\right)$. The groups are shorter and less parallel, and are more curved. There are longitudinal sections of radial elements of the spherulites (Plate VIII) with the same feather-like structure observed in $\left(5^{\mathrm{a}}\right)$. The feldspars of the spherulites appear to be homogeneous optically, and are probably so chemically.

$\left(23^{a-b}\right)$. An aggregation of radiating blades and possibly prisms somewhat spherulitic, the radii being $5 \mathrm{~mm}$. long in some cases (Plate IX). The apparently prismatic forms may be cross-sections of blades which are recognizable as such in other positions. They form dis- 
tinctly branching, curved, radiating aggregates, in some cases exhibiting albite twinning. In places these prismatic, rod-like forms broaden out to rectangular cuboidal shapes, which extend in short prismatic branches almost at right angles to the longitudinal direction of the long prisms. These cuboidal crystals show to a slight extent a cross twinning which is in the position for pericline twinning. The angle between the traces of the cuboidal faces is nearly $90^{\circ}$, which indicates that the crystals have been cut parallel to the basal plane and the sections are bounded by the first and second pinacoids (roo) (OIO). The sections parallel to the flat side of the blades show an intricate structure composed of parallel and subparallel thin plates with erystal outlines at several angles, the most frequent being nearly $90^{\circ}$. These aggregates of plates form bands that branch in feather-like structures (Plate $\mathrm{X}$ ). There are occasionally small rectangular but quite irregularly outlined seetions, whose shape is that of cuboidal crystals, with zonal markings about the center, which" have developed small prismatic projections parallel to one axis (?a), the prisms being located at the four comers of the rectangular section. This corresponds to the microlitic crystals of feldspar found in volcanic glasses, where the projecting prisms are delicate fibers. The feldspar crystals in this preparation appear to be homogeneous.

$\left(22^{a-b-c}\right)$. The preparation was first cooled rapidly from a melted condition, then heated again to $1250^{\circ}$ at a maximum. This has had a very interesting result, namely, two periods of crystallization, the first rapid, the second slower. The main mass of the preparation consists of bundles of feldspar fibers and delicate network of crossed fibers. The bundles of fibers are about o.01 $5 \mathrm{~mm}$. wide and o. $65 \mathrm{~mm}$. long, and occur singly or cross one another at various angles, several intersecting in the middle. Single bundles have two strong tapering fibers on the outside spreading slightly. These bundles of fibers extinguish light parallel, or at a small angle $\left(7^{\circ}\right)$, to the length of the fiber. The fastest ray vibrates nearly parallel to the fibers, which appear to be elongated in the direction of the axis $a$. There is a small amount of isotropic glass.

Within this mass are spherulites about ro $\mathrm{mm}$. in diameter, the outer shell, I millimeter thick, having a somewhat different appearance from the central portion. The central part consists of radiating, branching prisins or blades, not in straight rays but in plumose aggregations. The outer marginal zone is a blend of the inner splierulite and surrounding matrix of stuall bundles of fibers (Plate XI), and it is evident that the spherulitic feldspar erystallization had advanced in the already erystalline matrix by a process of recrystallization, the 
small bundles of fibers losing their optical orientation and finally their distinct outline. Their place is occupied by spherulitic feldspar rays whose orientation is independent of the position of the former bundles of fibers. The former position of the bundles is shown in places by pairs of stouter fibers, the outside members of the bundles of fibers; in other places by clusters of minute inclusions resembling air spaces between a network of fibers. These fade out in passing from the margin of the splierulite inward through the millimeter-thick shell. They have entirely disappeared in the central part of the spherulite. The feldspar of the spherulite is homogeneous and the small bundles appear homogeneous. They must have the composition of the prepared mixture. The small angle of extinction of the bundles of fibers is difficult to account for. It behaves more like oligoclase than labradorite.

(20). A branching spherulitic aggregation with numerous cavities elongated in the direction of the radiating fibers. The section is too thick to show well the mieroseopic structure of the parts. They appear to be prisms and blades composed of ninute subparallel parts. The feldspar appears to be homogeneous.

\section{ANDESINE-LABRADORITE ( $\left.\mathrm{AB}_{1} \mathrm{AN}_{1}\right)$.}

(26). The section of this preparation is extremely fine-grained at one end and glassy at the other, the lower end of the crucible. The crystals and spherulites become larger toward the glassy end of the section (Plate XII). The glass has lower refraction tlan balsam. There are many opaque white limps, which appear to be numelted powder. They constitute 5 to 10 per cent of the mass.

The feldspar crystals form fibrous bundles, single and in sets, crossing one another at various angles, spreading out into plumes and spherulitic groups.

In the central portion of some fibrous bundles there are rectangular, lath-shaped, and block-like crystals with albite twinning, which exhibit symmetrical extinction angles of $45^{\circ}$. These parts must have the composition of $\mathrm{Ab}_{1} A \mathrm{An}_{2}$, at least. The thinner prisms or fibers outside of these show lower extinction angles, about $25^{\circ}$. If these correspond to maxima in each case, the fibrous feldspar is about $A b_{1} A n_{1}$. The feldspars, except the central portions, which are comparatively few, appear to be lomogeneous. Some of the plumose aggregates which are albite twins are very beautiful.

(27). This preparation consists of glass with twinned prisms of feldspar in radiating groups about $1 \mathrm{~mm}$. long which are not properly spherulites. They are shown in Plate XIII. They are in most cases 
prisms, and not plates or blades. In places these are thin plates or blades in twinned aggregations, as in $\left(5^{8^{\mathrm{a}-b}}\right)$. The prisms are more distinetly developed at the ends of some of the radiating aggregates, where they are distinetly twinned according to the albite law and yield symmetrical extinetion angles of $30^{\circ}$.

$\left(59^{\mathrm{a}-\mathrm{b}}\right)$. This preparation is glass, with splerulitic aggregations about 2 mm. in diameter grading into smaller radiating bundles crossing one another in groups of 2, 3, 4, and more, as in other eases already described. The middle part of the bundles consists of stout prisms passing into extremely thin fibers. The stouter portion yields extinction angles of $30^{\circ}$. The feldspars appear to be homogeneous erystals.

$\left(64^{\mathrm{a}-\mathrm{b}}\right)$. This preparation consists of spherulitic aggregations similar to (59), and also short rectangular prisms with almost square eross-section. They are 0.04 to $0.07 \mathrm{~mm}$. long and 0.007 to $0.0101 \mathrm{~m} 111$. wide. The forms are similar to the lath-shaped feldspar microlites common in andesites. They are in some cases twinned, in others not. They yield extinction angles of $30^{\circ}$.

\section{ANDEsine $\left(A B_{2} A N_{1}\right)$.}

$\left(54^{\mathrm{a}-\mathrm{b}}\right)$. This preparation is extremely minutely crystallized. The main mass appears to be holoerystalline, composed of flake-like microlites of feldspar overlapping one another at all angles, so as to produce weak double refraction. The crystals are larger in patches and in shells about isotropic spaces, as though the erystallization was coarse about small spaces, like the walls of cavities of geodes. The feldspar crystals project into the spaces. But these spaces are filled with colorless isotropic material with refraction considerably lower than balsam, presumably glass. It amounts to several per cent of the whole. This residual glass probably has a different composition from the feldspar mass, otherwise it should not have solidified as glass, for the larger erystallization of the feldspar in juxtaposition with it indicates that the controlling conditions becane more favorable to the erystallization of the feldspar.

$\left(66^{\mathrm{a}-\mathrm{b}}\right)$. The small thin sections of this preparation are holocrystalline, without glass. The preparation consists of crossed bundles of prisms and blades, without true spherulites. The bundles vary in width from o.or $\mathrm{mm}$. to less and in length from $0.5 \mathrm{~mm}$. to less. Some of the crystals are in albite twins, others not. While the prismatic sections exhibit nearly parallel extinction in all cases, the long axis of the prism being the direction of vibration of the fastest ray, and appear 
to be alike in composition, there are rectangular sections, which at first appear to be eross-sections of square prisms with hollow centers, but are nearly equidimensional crystals which in some cases have prismatic prolongations. These rectangular crystals have rectangular spaces at the center, are twinned, and exhibit symmetrical extinction angles of about $30^{\circ}$. As in other preparations of the more sodic feldspars, there are comparatively few small crystals of more calcic feldspar, approximately $A b_{1} A n_{1}$, which began to form in cuboidal shapes, but were followed by the crystallization of the bulk of the mixture in feldspars of the average composition.

\section{OLIGOCLASE-ANDESINE $\left(\mathrm{AB}_{2} \mathrm{AN}_{1}\right)$.}

(2 I). Colorless glass, without crystals in the thin section studied microscopically.

(32). Colorless glass, with feldspar microlites and aggregates in the form of bundles about $0.1 \mathrm{~mm}$. long and in crossed bundles and to some extent in spherulitic arrangements. The isolated microlites
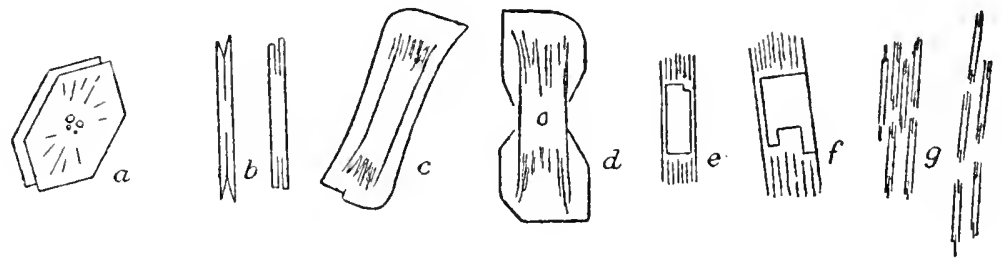

FIG. 25--Microlites of oligoclase-andesine $\left(\mathrm{Ab}_{3} \mathrm{An}_{1}\right)$.

are instructive both on account of the exhibition of the habit of the feldspar crystals in these preparations and also as an evidence of the changes in habit during the short period of their growth. There are two types of microscopic crystals, one tabular, the other prismatic. These occur near one another intermingled in the glass. They are $0.03 \mathrm{~mm}$. long and smaller.

In many cases there appears to be a nucleus of feldspar within feldspar; in some of these there are also small, irregularly shaped, colorless grains with rather strong index of refraction whose composition is not determinable. These are extremcly minute and not abundant.

The feldspar nucleus exhibits stronger refraction than the marginal feldspar, but the direction of extinction is the same in both parts, proving like optical orientation and showing that the central part of the microlite is thicker than the margin and of the same composition. The initial crystal in these cases is thicker, that is, the crystallization 
was somewhat more uniform from all sides, at the beginning, but became more rapid, developing very thin plates or prisms outside the nucleus.

These are illustrated in fig. 25. In one (a) several minute grains form a nucleus of a tabular feldspar 111icrolite, whose form indicates that it is tabular parallel to the pinacoid (010) and is bounded by (10I) and (201). The central part of this plate is thicker than the margin, and thins out in irregularly placed rays, like spurs and gulches leading from a mesa to a plain. The microlite is double, consisting of two thin plates in parallel position. A cross-section of sucl a doubleplated microlite is shown in $(b)$.

In (c) the central part is a flattened prism or blacle, passing at the extremities into fibers or needle-like prisms and then into a thin plate completely surrounding the nucleus. In $(d)$ the thin plates at both ends of the blade do not unite. The shape of the plate shows only a center of symmetry; diagonally opposite comers are sharp angles a little less than $90^{\circ}(\mathrm{IO})$ and $(201)$. The other corners are rounded or formed by two obtuse angles. The outline corresponds to the traces of the basal pinacoid (OOI) and the two pinacoids of the second kind (2OI) and (IOI) on the second pinacoid (OIO). The crystals are elongated in the direction of the crystal axis, $a$, and flattened parallel to the second pinacoid $(\mathrm{O} 1 \mathrm{O})$. In $(e)$ a small rectangular prisnatic crystal is enlarged to a more elongated form with fibrous termination. In (f) a squarish form with rectangular projections is extended in opposite directions as straight fibers. There are narrow prismatic forms with needle-like extensions at the ends. These are isolated or more often grouped in subparallel bundles and in almost parallel lines, as in $(g)$. These microscopic crystals vary in size from a length of $0.6+\mathrm{mm}$. to less. They are so small that their optical characters can not be used to determine their chemical composition. They appear to be alike and homogeneous, and may be assumed to have the composition of the preparation $\mathrm{Ab}_{3} \mathrm{An} n_{1}$.

(28). This preparation is colorless glass, with feldspar crystals in rods or prisms about $0.08 \mathrm{~mm}$. long and $0.005 \mathrm{~mm}$. wide. A few of these are isolated; most of them are crossed groups of two or more, or form radiating aggregates. Relatively few crystals have the shape of blades or plates. The prisms are frequently double, joined in the middle like an H. The central connecting part sometimes occupies a small portion of the length of the double prism, sometimes a large portion. The prisms are grouped in subparallel bundles as in preparation (32). The extinction angle is almost zero in nearly all bundles of prisms. The feldspars appear to be homogeneous, and must lave 
the same composition as the preparation, since the mass is holocrystalline in places.

$\left(25^{a}\right)$. The preparation consists of glass with spherulitic aggregations. These consist of bundles about $0.4 \mathrm{~mm}$. long, of prismatic crystals, which are definite in the middle and spread out to plumose forms at both ends, merging with others in crossed position to form spherulites in favorable positions (Plate XIV).

In the more spherulitic groups the terminal parts are made up of the most delicate fiber-like crystals. In other parts of the preparation the sheaf-like bundles are composed of more distinct, thicker prisms, which are somewhat broader in one direction than in another; that is, they are somewhat blade-shaped. In some cases these are twinned according to the albite law. In the central parts of some of the bundles there is a rectangularly jointed development of the stouter feldspar crystals which are continuous with the more prismatic crystals forming the main part of the bundles.

The optical behavior of those rectangular parts which show albite twinning corresponds to that of $\mathrm{Ab}_{1} \mathrm{An}_{1}$, there being symmetrical extinction angles of $30^{\circ}$. In the long prisms the angle of extinction is small, and the length of the prisms is the direction of vibration of the fastest ray. This corresponds to the optical behavior of a more sodic feldspar with a prismatic development parallel to the crystal axis $a$. In parts of the preparation the feldspars have crystallized in thin tabular plates parallel to the second pinacoid (o10).

(24). This preparation is similar to $\left(25^{\mathrm{a}}\right)$. It is partly glass, partly spherulitic aggregations of bundles of prismatic crystals, spreading out at the cnds. The central portions of some aggregations are of stout prisms and rectangular groups with symmetrical extinction angles of $30^{\circ}$ (Plate $\mathrm{XV}$ ). As in preparation $\left(25^{\mathrm{a}}\right)$ there was a first crystallization of feldspar with higlier content in anorthite molecules than the average of the mixture. This formed a small fraction, probably less than i per cent of the whole. The principal crystallization appears to be homogeneous and must have essentially the composition of the mixture $\mathrm{Ab}_{3} \mathrm{An}_{1}$.

The outline of the bladed crystals in the plane (o1o), judging from the optical orientation, and the elongation of the blades parallel to $a$, is determined by the pinacoids of the second kind (201), ( $\overline{3} 04)$ in some cases furnishing an angle of about $80^{\circ}$, the angle between the two being nearly bisected by the trace of the third pinacoid (oor). In other cases the blades appear to be bounded by (201) and ( $\overline{2} \mathrm{O} 3)$, with the apex angle truncated by $(\overrightarrow{2} \mathrm{O})$. Such plates are nearly 
normal to the optical bisectrix $\gamma$, and the plane of the optic axes is almost parallel to the direction of elongation of the blade.

$\left(67^{\mathrm{a}-\mathrm{b}}\right)$. This preparation consists of spherulites about $2 \mathrm{~mm}$. in diameter, and some interstitial glass. The spherulites are irregular in outline, due to mutual interference (Plate XVI). They consist of radiating sectors made up of rather distinct prisms, which start at the center of the spherulite as stout prisms and become innumerable, slightly diverging prisms which terminate at different lengths as distinct prisms terminated by a pinacoid almost at right angles to the axis of the prism, probably ( $2 \mathrm{O} \mathrm{I})$. In other cases they are terminated by two pinacoids making an acute angle. In places the terminations are somewhat rounded. The crystals in these spherulites are homogenous and correspond to the composition of the mixture.

\section{OLIGOCLASE $\left(\mathrm{AB}_{4} \mathrm{AN}_{1}\right)$.}

(29). The preparation was heated to a temperature of about $1400^{\circ}$ and allowed to cool for 15 hours to about $425^{\circ}$. The resulting solid is a glass with abundant crystals of feldspar in crossed bundles of blades or plates, and spherulite-like radiating aggregations (Plate XVII). There are numerous rounded and subangular grains of colorless quartz in the glass which have no definite relation to the feldspar crystals, and appear to be tindissolved fragments of quartz used in compounding the preparation. There are also small lumps of white aggregates, probably undissolved powder, which in many cases form centers of spherulitic crystallization, that is, they become points at which feldspar crystallization began.

The colorless glass has an index of refraction noticeably lower than that of Canada balsam, 1.5393.* The lengtl of the feldspar bundles and diameter of the spherulitic aggregates is about $0.2 \mathrm{~mm}$., the width of the bundles about o.or mm. The narrow cross-sections of the bundles of feldspar, which has a higher refraction than the glass, exhibit low extinction angles, nearly parallel to the longitudinal direction. The bundles are clearly composed of numerous parallel or approximately parallel individuals, which spread out fan-like or plumose at the extremities. In other positions these aggregates are seen to be relatively broad, blade-like, or tabular, and made up of subparallel plates of extreme thinness. This is shown by numerous crystal edges almost parallel to one another, and also by the composite character of the interference phenomena with crossed nicols, the crystal blade being mottled instead of uniformly dark in the

\footnotetext{
* 1.5393 is the index of refraction of the balsan used by the U. S. Geological
} Survey, as determined by Dr. J. E. Wolff, in 1896. 
position of extinction. The interference figure in convergent light shows a bisectrix normal to the plane of the bladed crystal bundle, the bisectrix being the direction of vibration of the ray having the greatest index of refraction, $\gamma$. The angle between the optic axes is larger, and the plane of the optic axes lies in the longer diameter of the crystal blade. This is the optical orientation of $\mathrm{Ab}_{4} \mathrm{An}_{1}$ * when the feldspar plate is tabular parallel to the second pinacoid (oro), the common case.

The angles between the crystal edges of the thin plates, the position of the plane of optic axes, and the generally low extinction angles exhibited by longitudinal cross-sections of the bundles show that the feldspar crystals are tabular parallel to (oro) and elongated parallel to the crystal axis $a$, and are probably bounded by the planes (20I) and $(\overline{3} \circ 4)$ or by $(201)$ and $\left(\overline{2} \mathrm{O}_{3}\right)$.

* Michel-Lévy, A., op. cit., Plate in. 



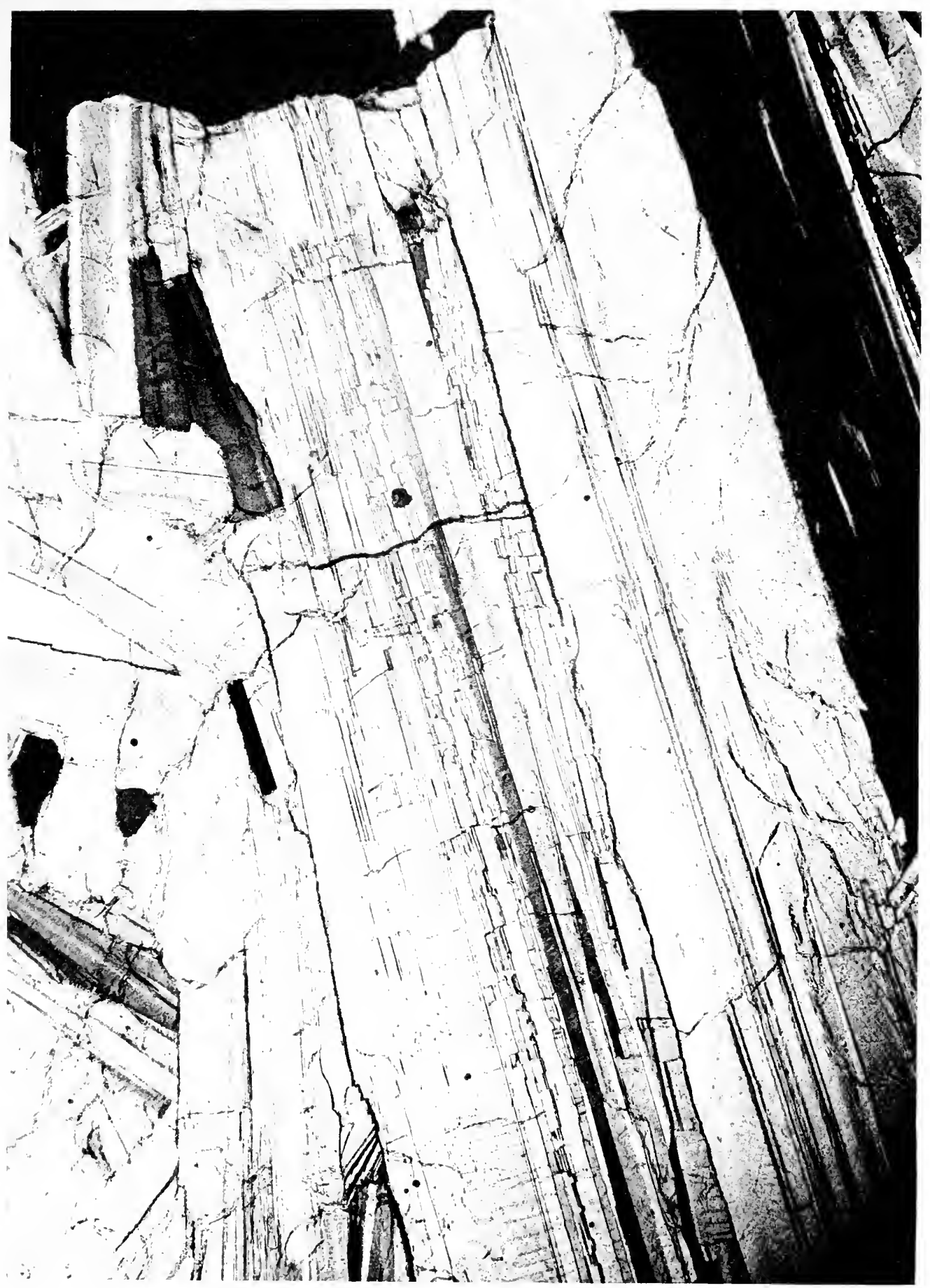




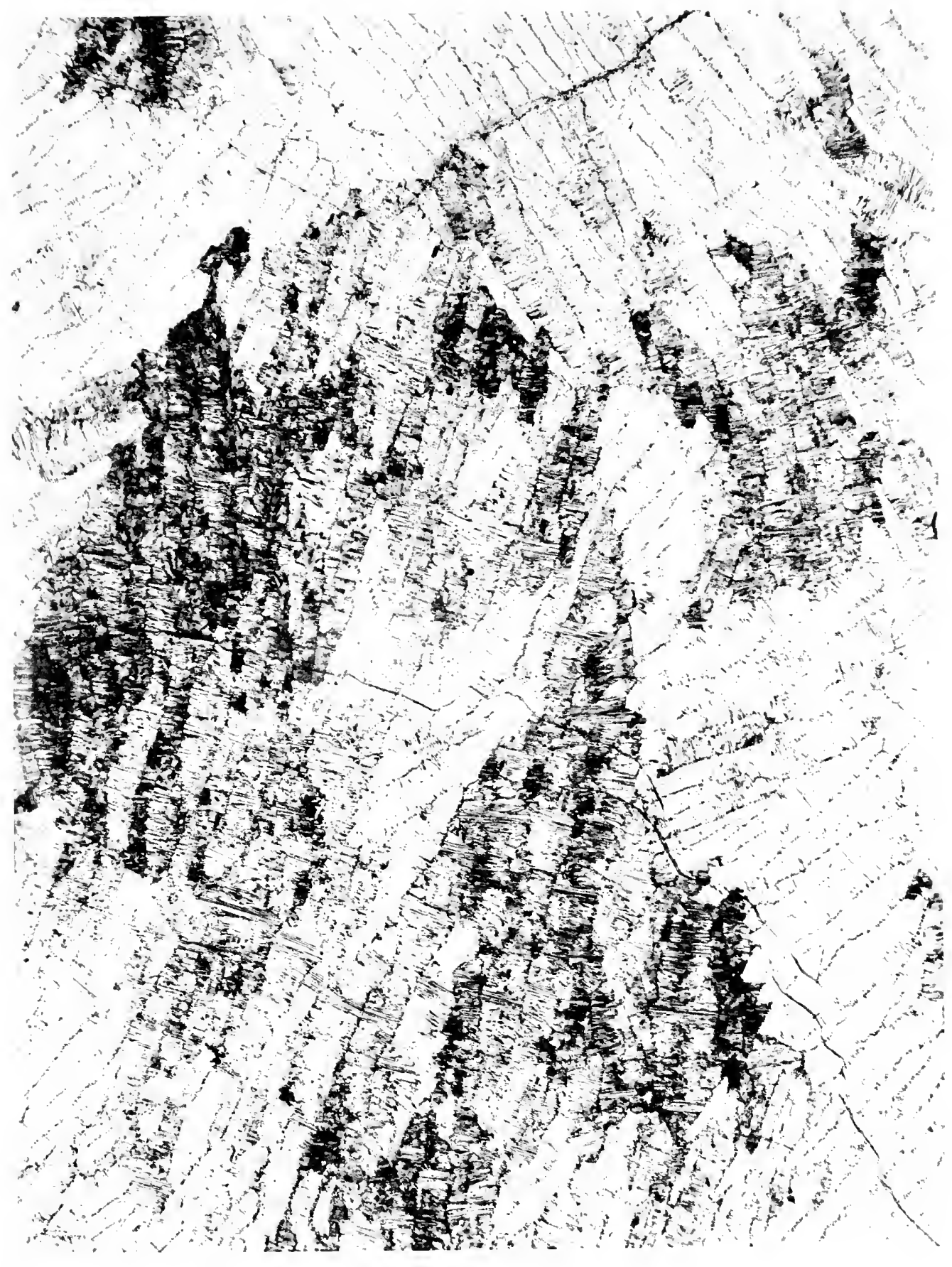





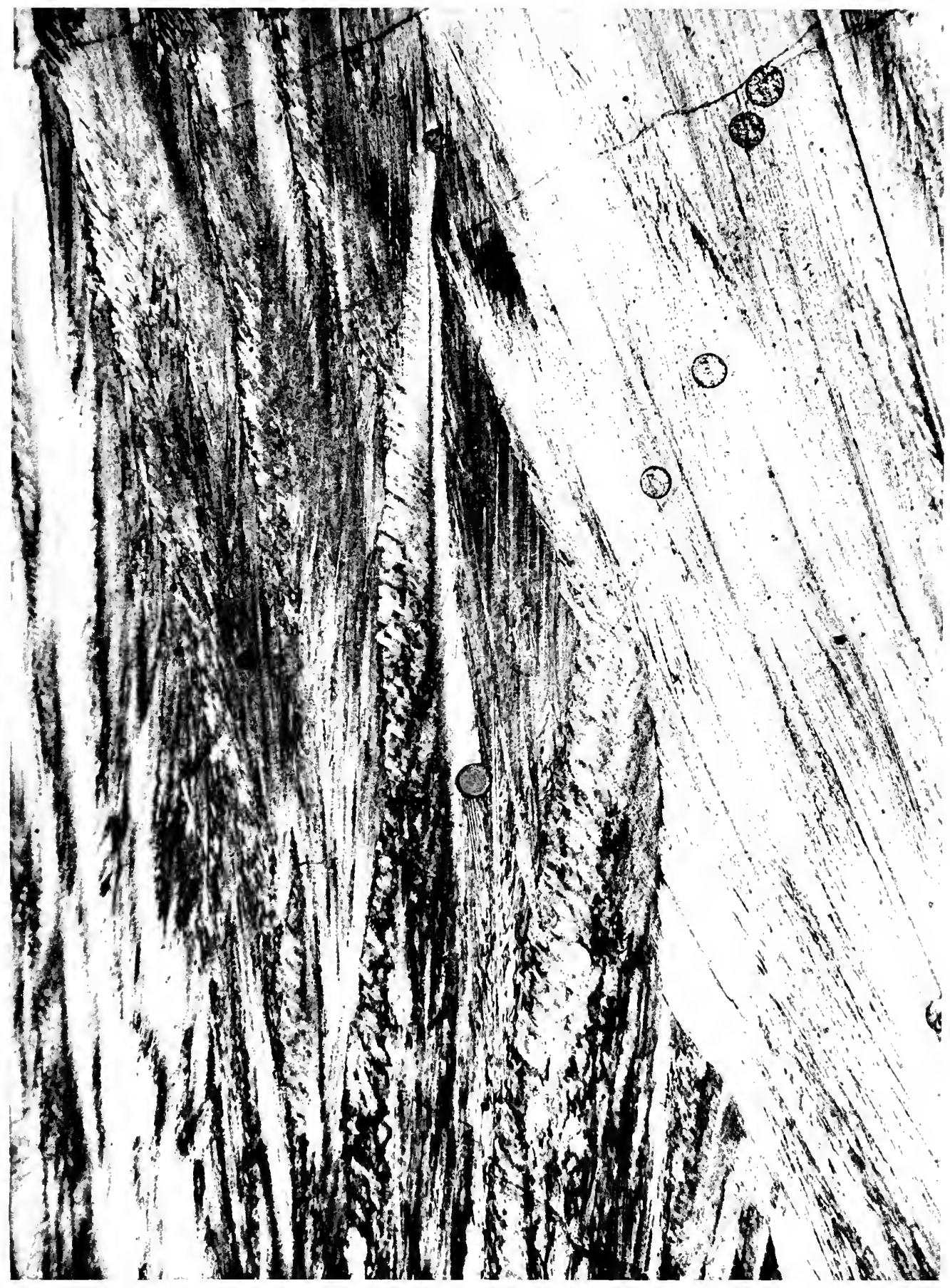




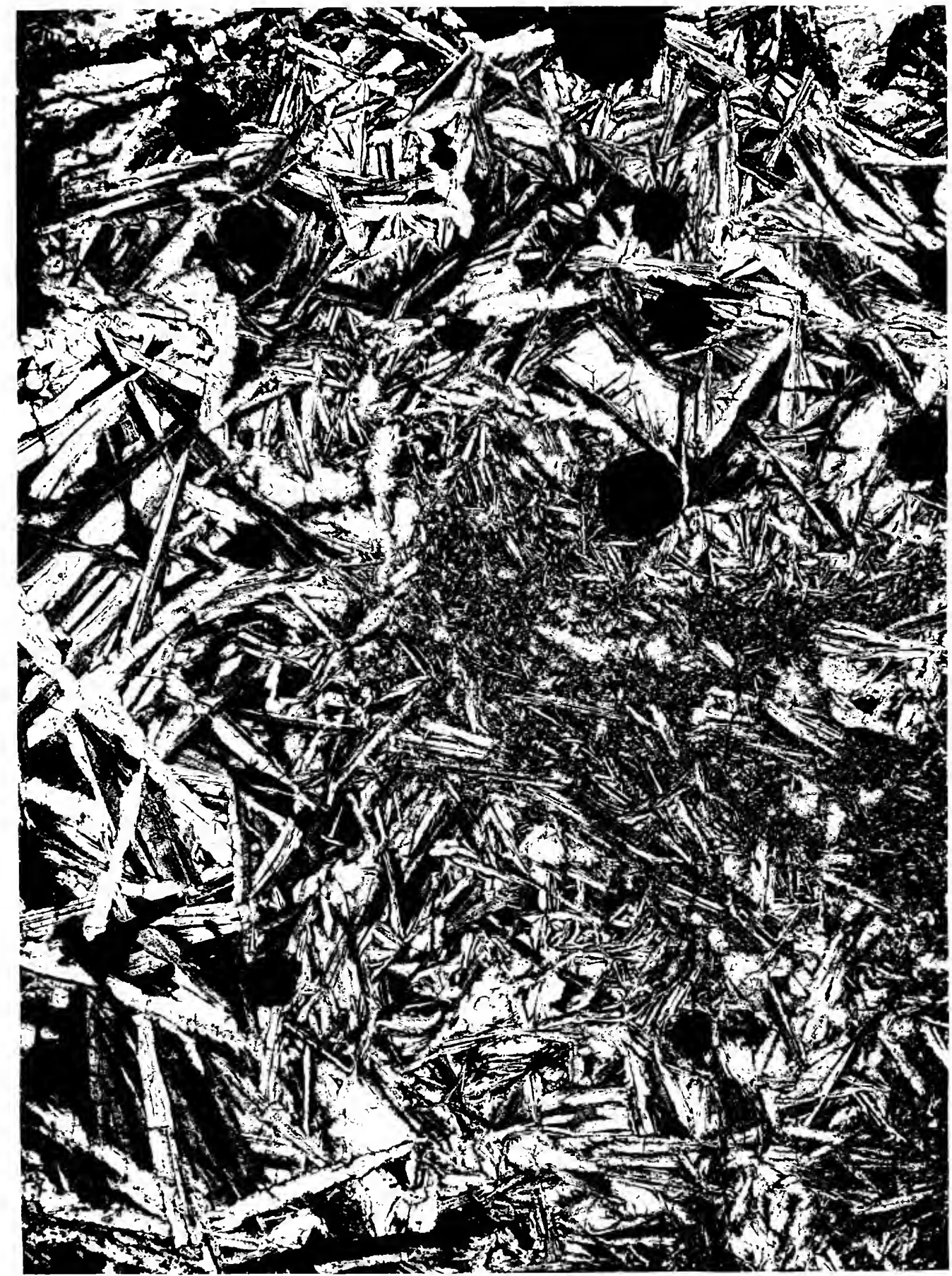


2y,

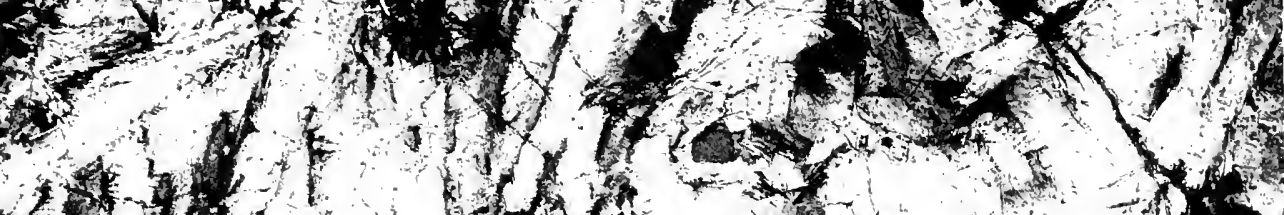
$36,14=+x-x$

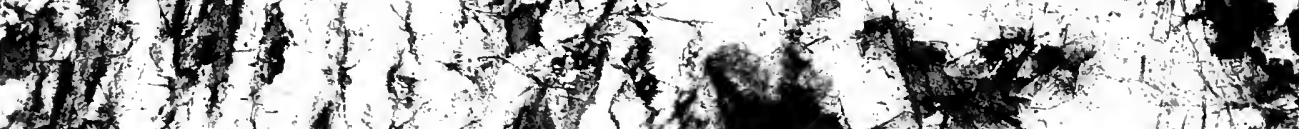

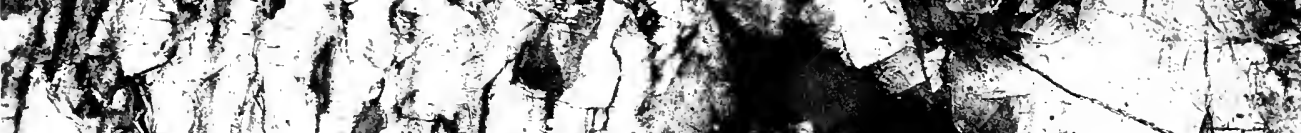

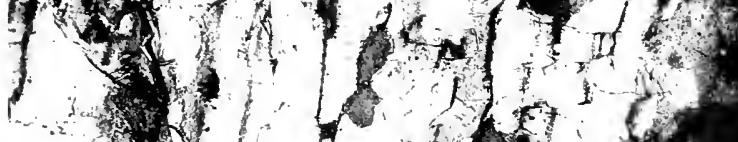

W

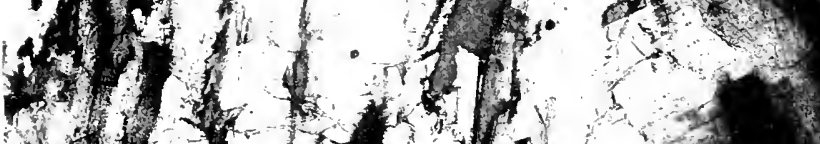
a) T.

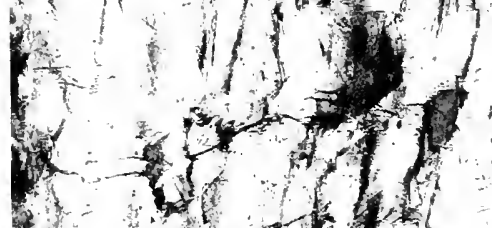
an con 10

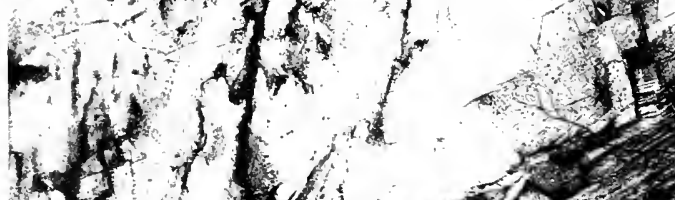
1. 1 ( 41,8 12116 $M+C$. atron Dren 1. (1) $+1$ 1. 


$$
\text { - }
$$




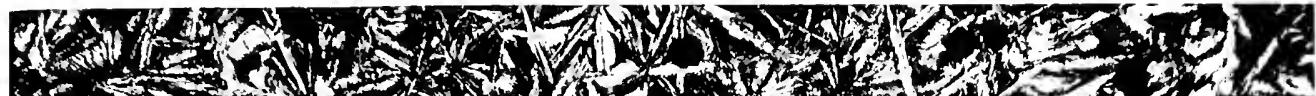
(2)

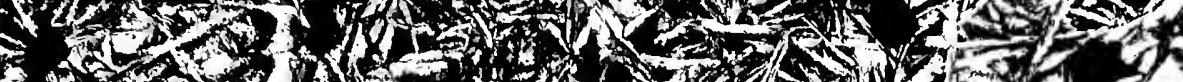

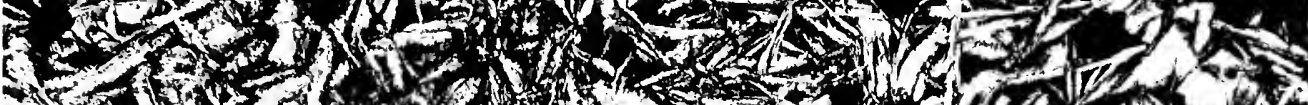
(1)

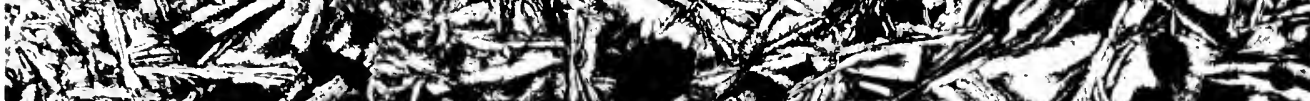
n

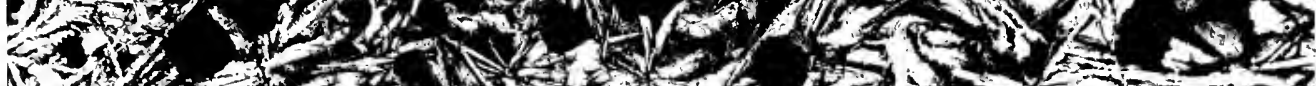

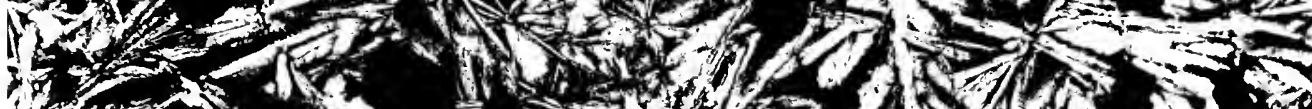
b.

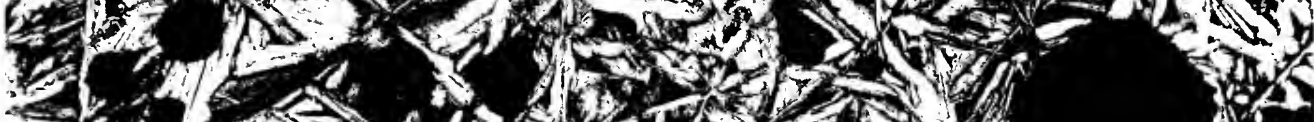
- 10010 $100 \leq 134>0$ Hor 101

$1 \%=$ 年 D. 1 .

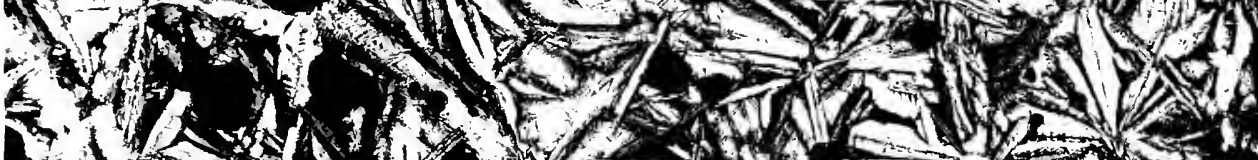

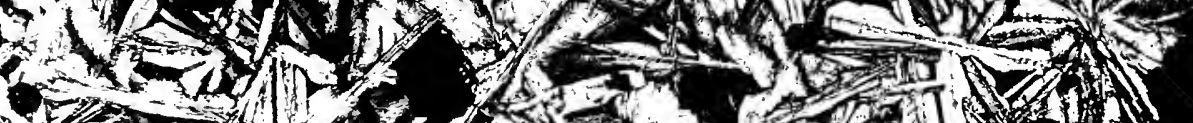

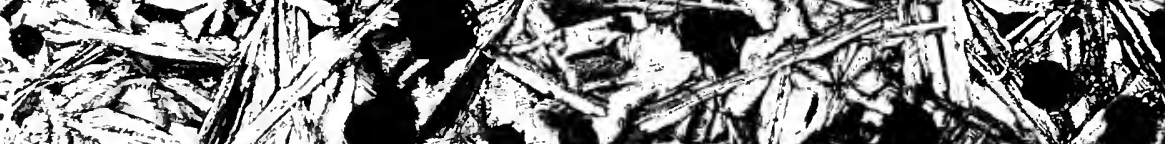

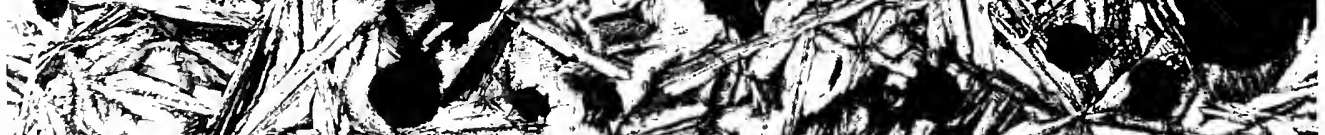

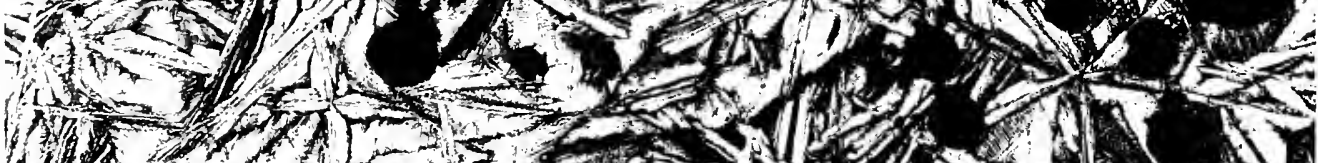

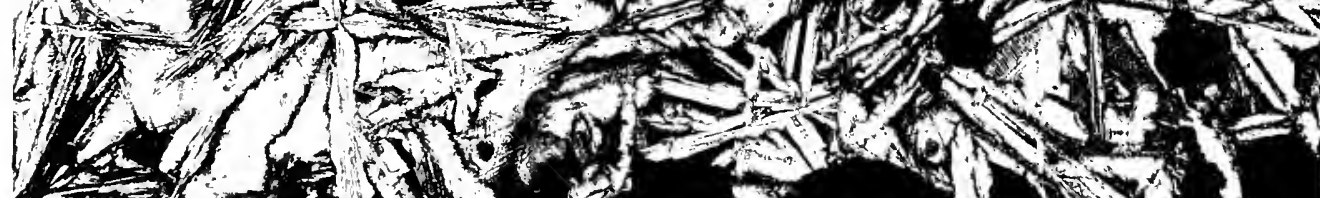

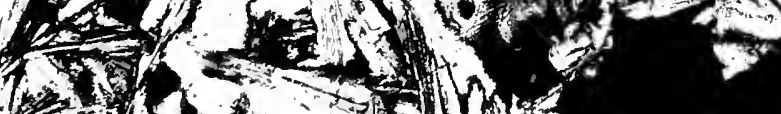
L2. ing Allin

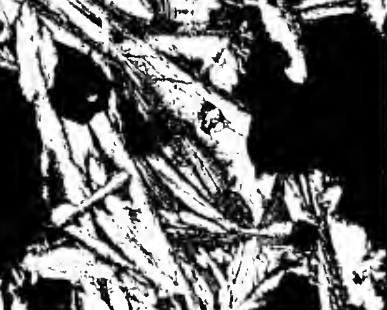




\section{。}




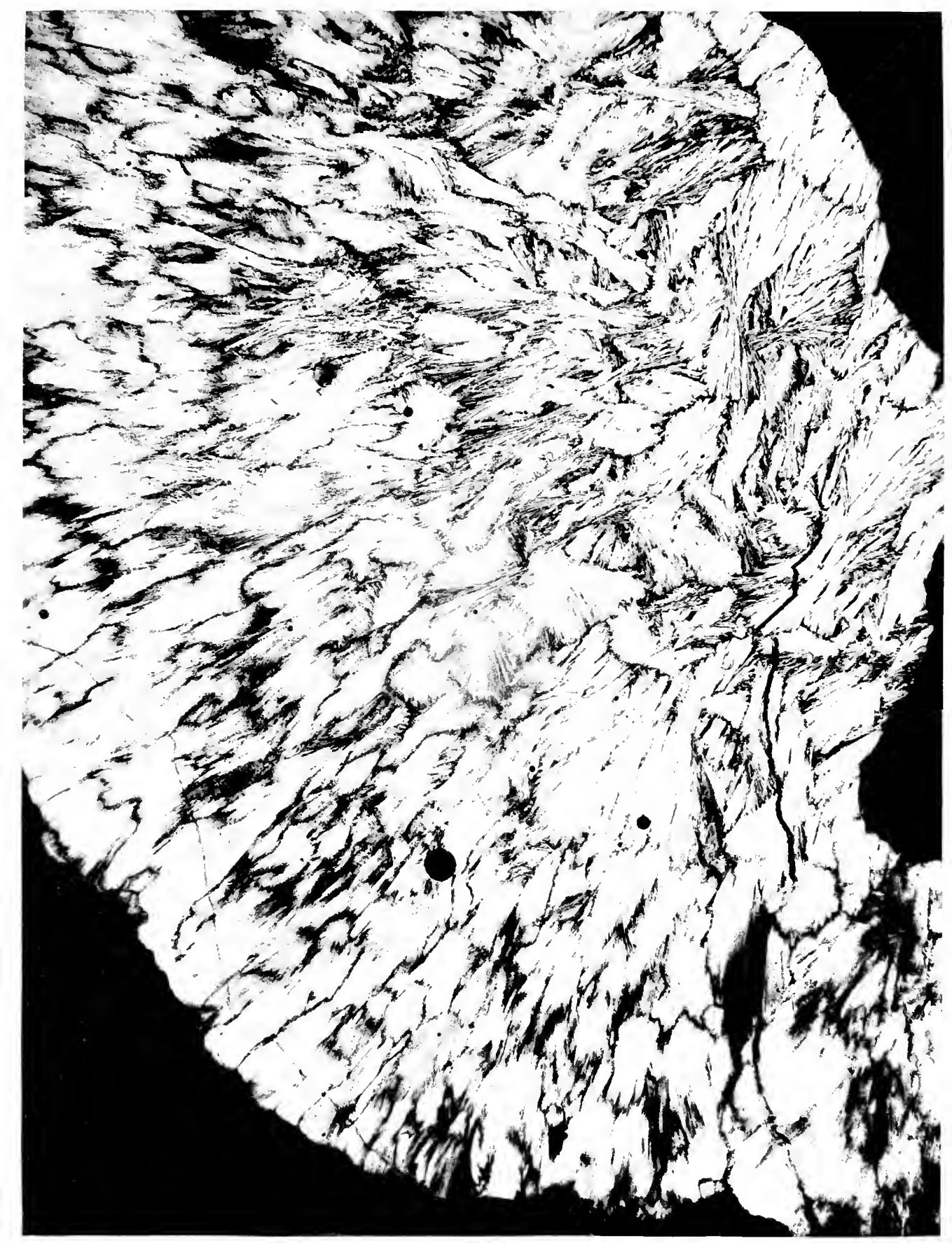




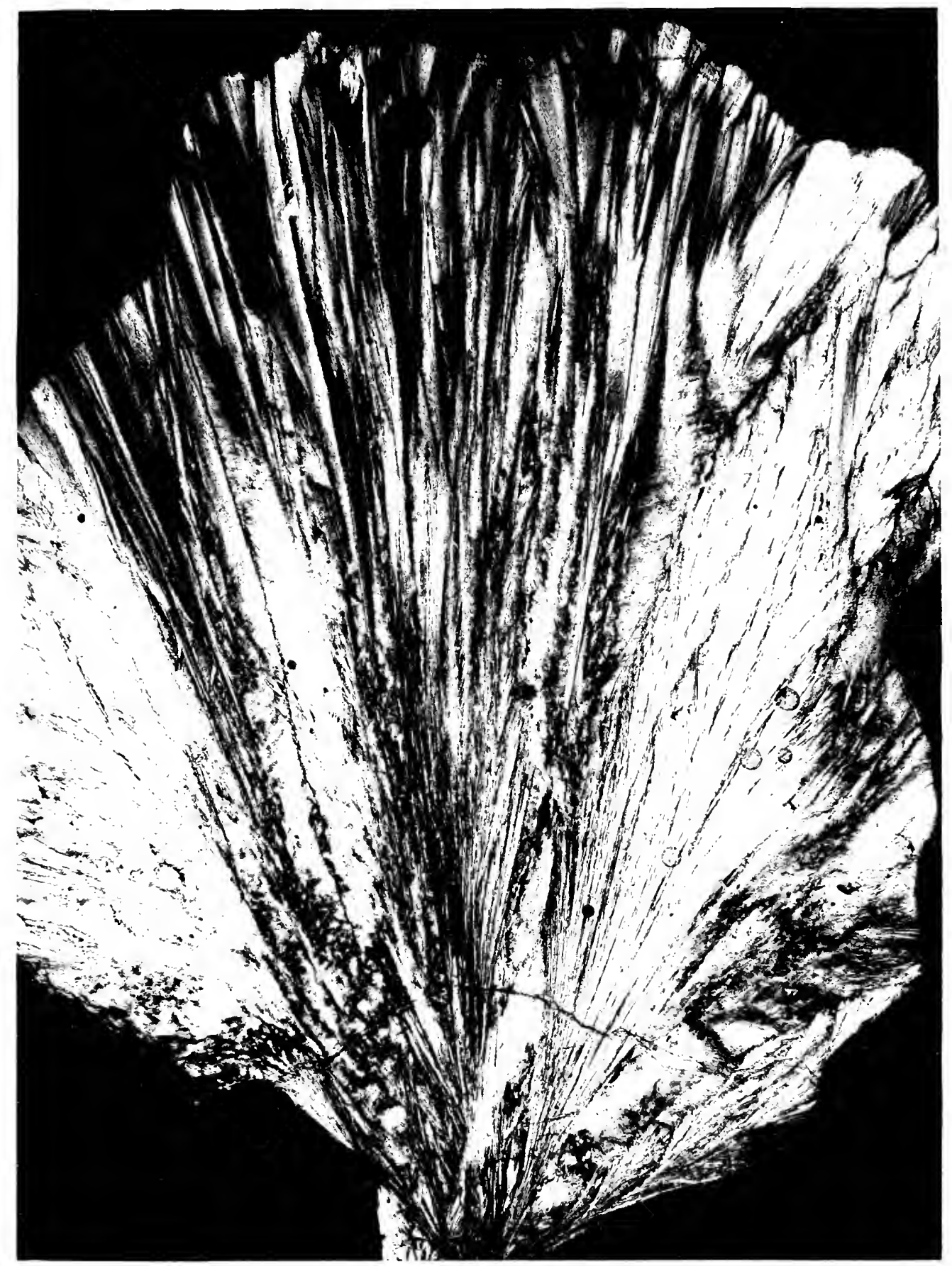




\section{-}

- 


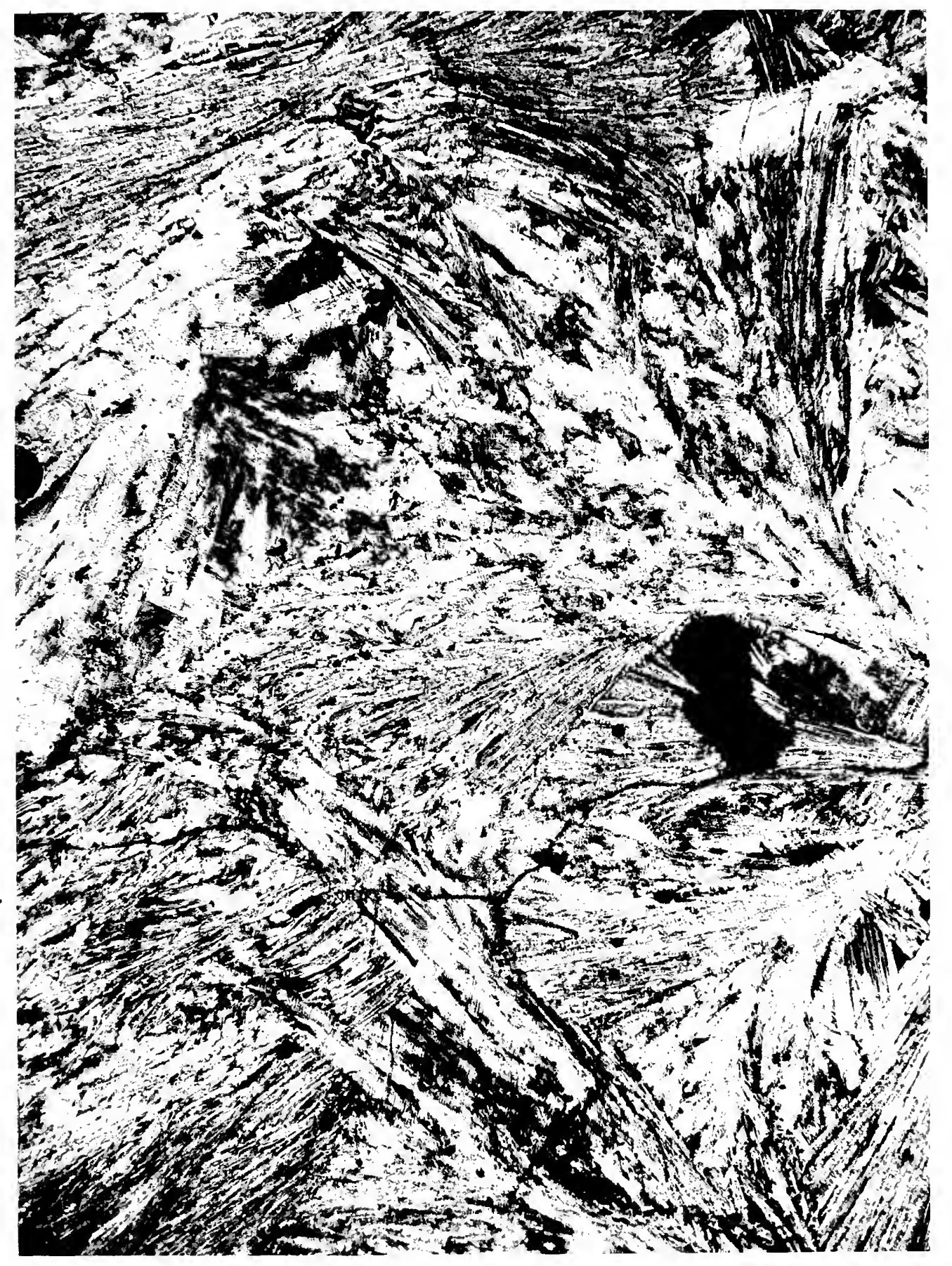




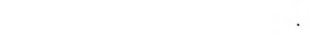




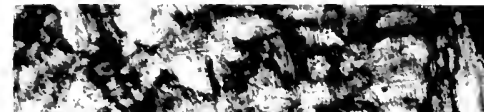

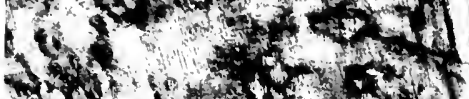

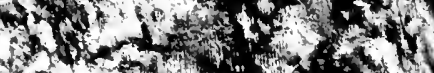

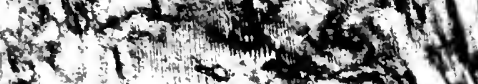
C. $14 x^{2}-4$

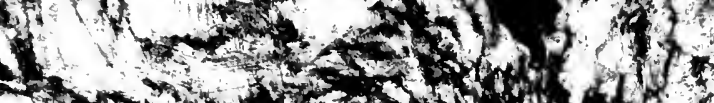
tom 1 (f)

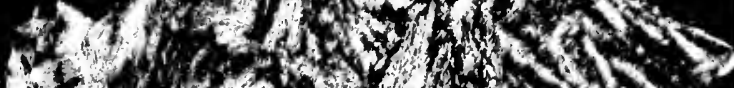

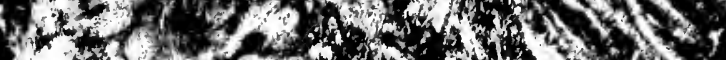

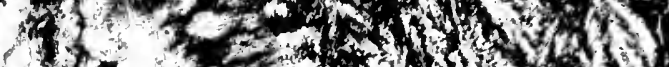

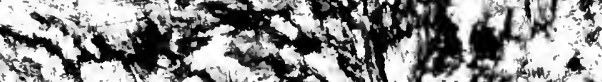

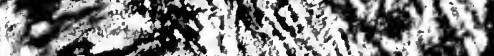

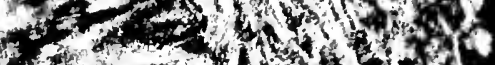

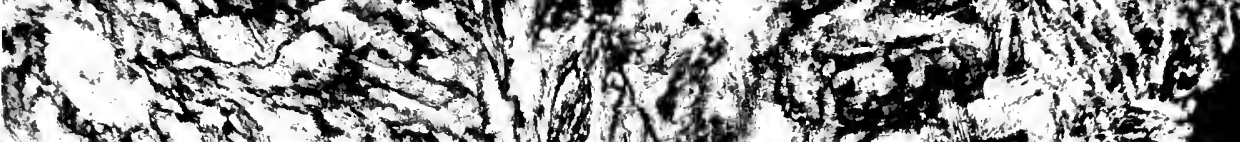

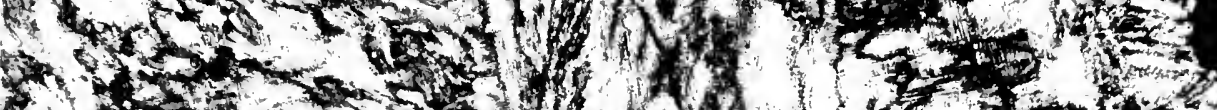

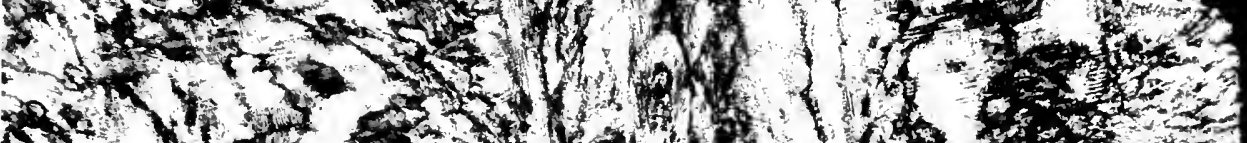

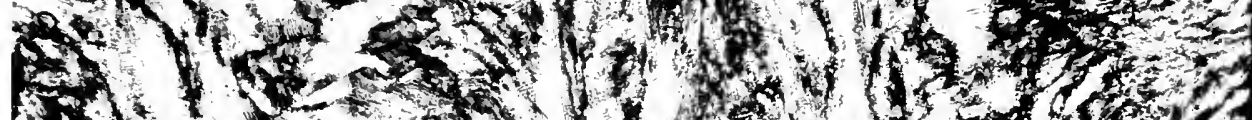

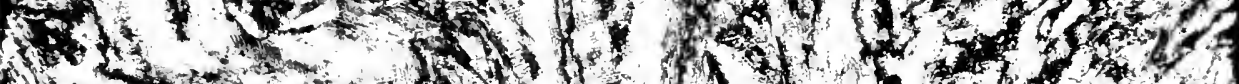

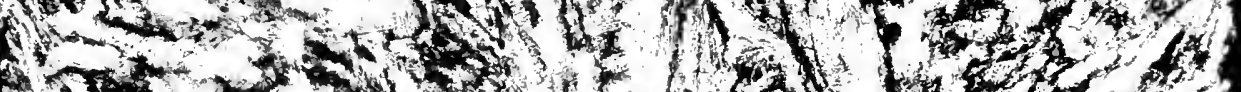

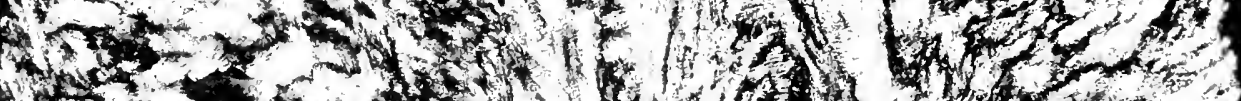
(1)

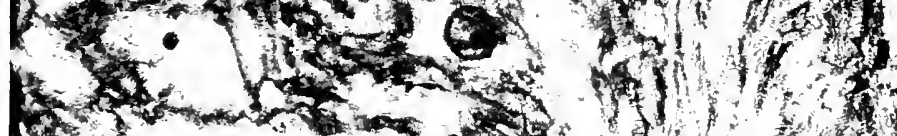

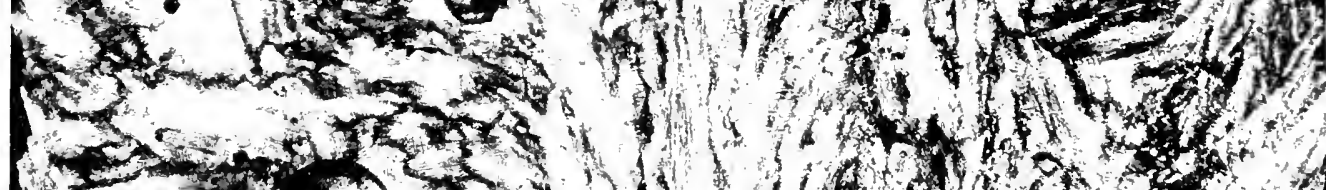

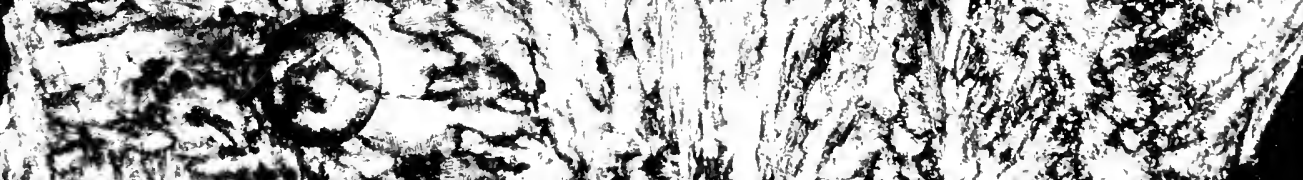

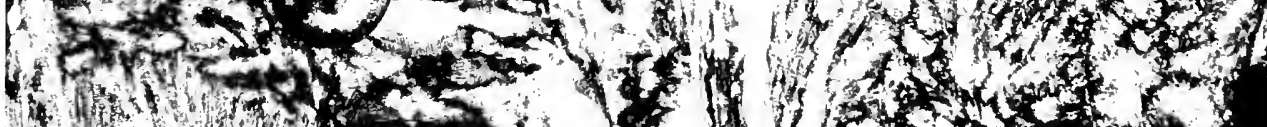

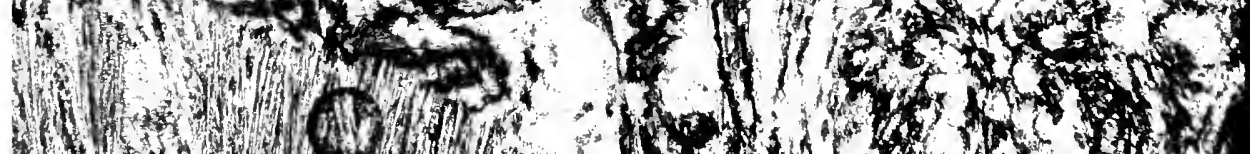
W17. (W W

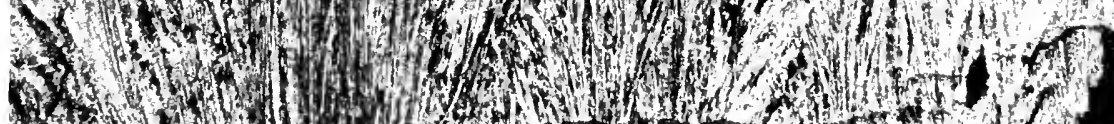
W. 



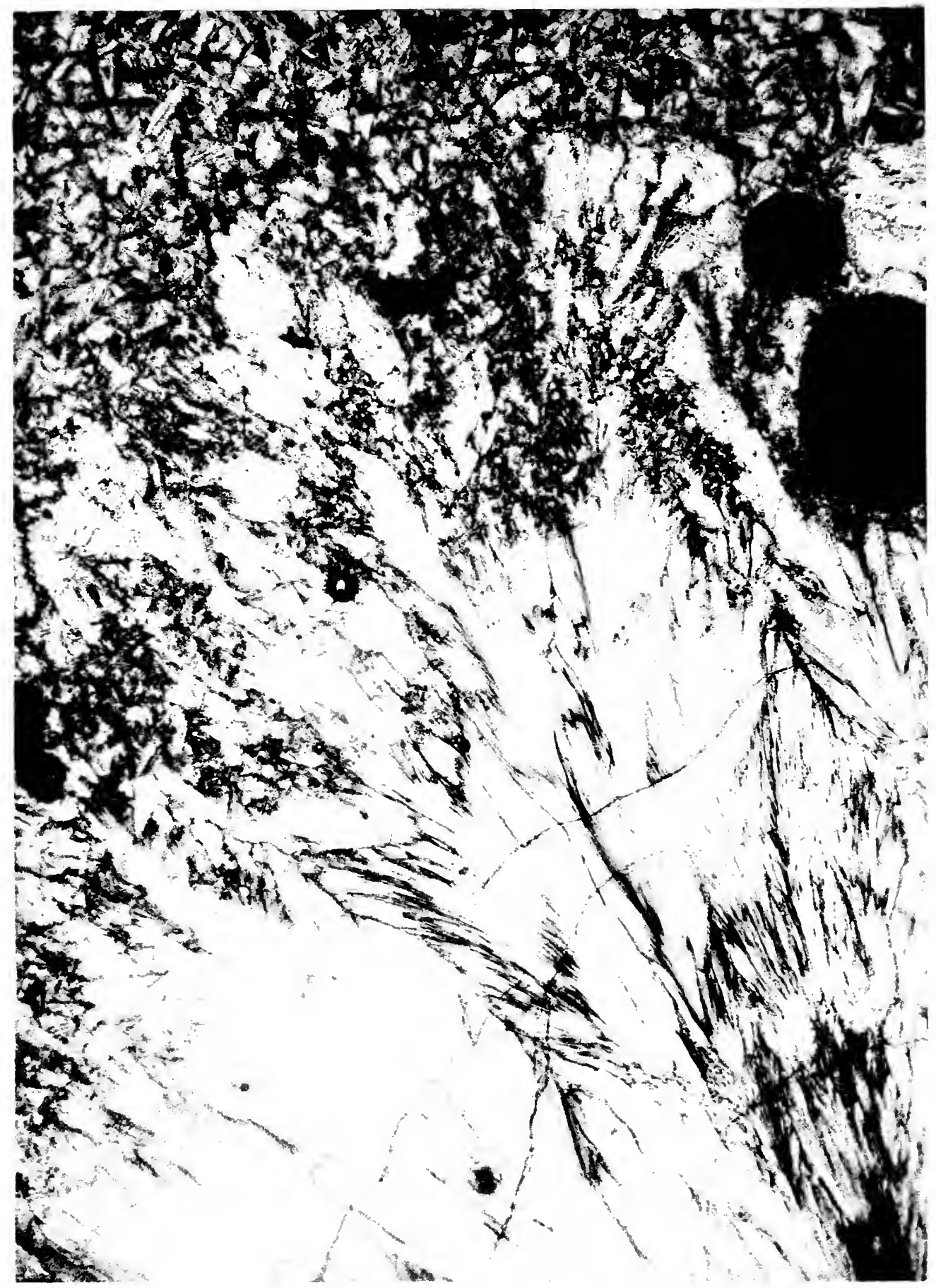




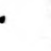




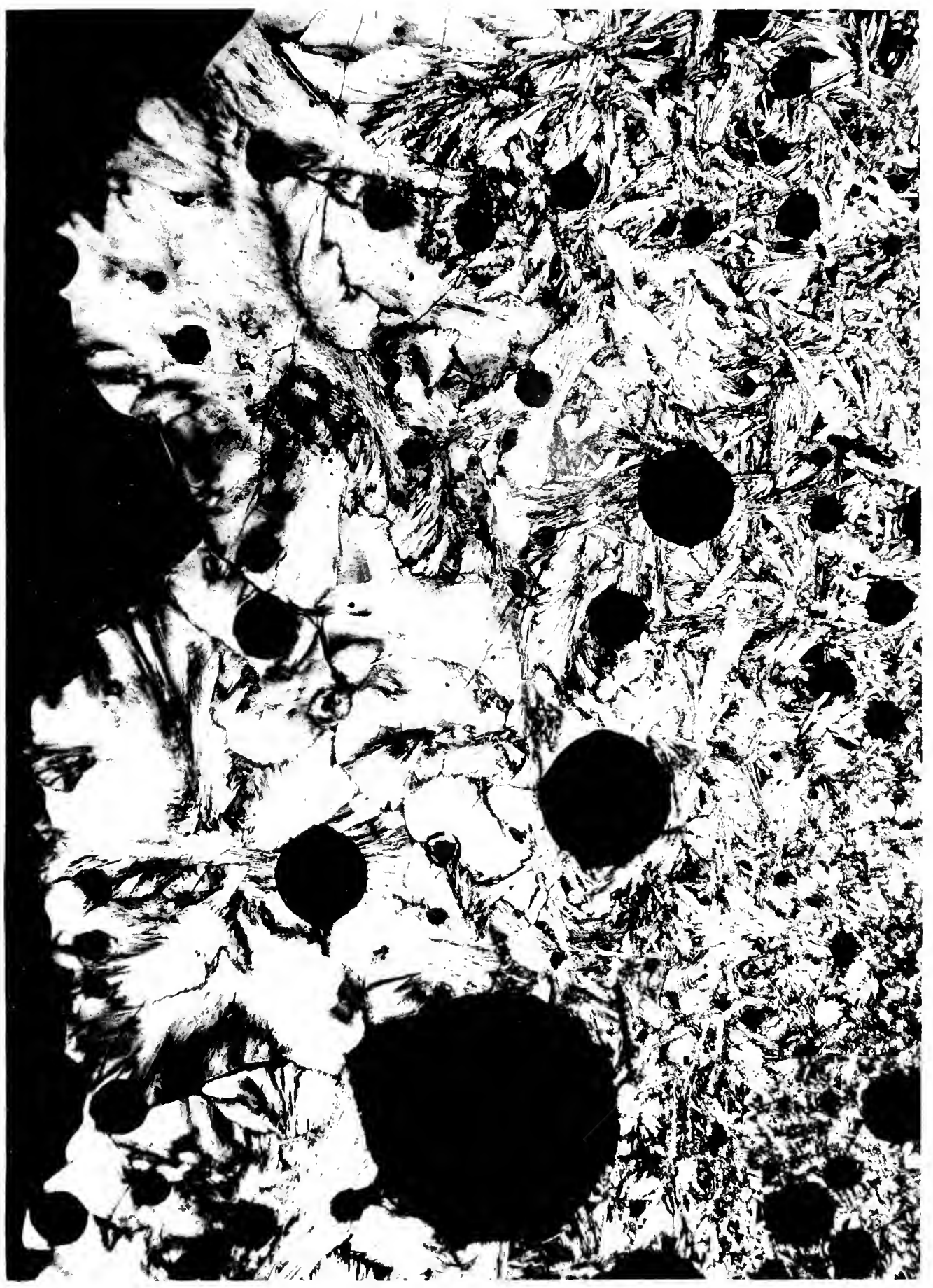





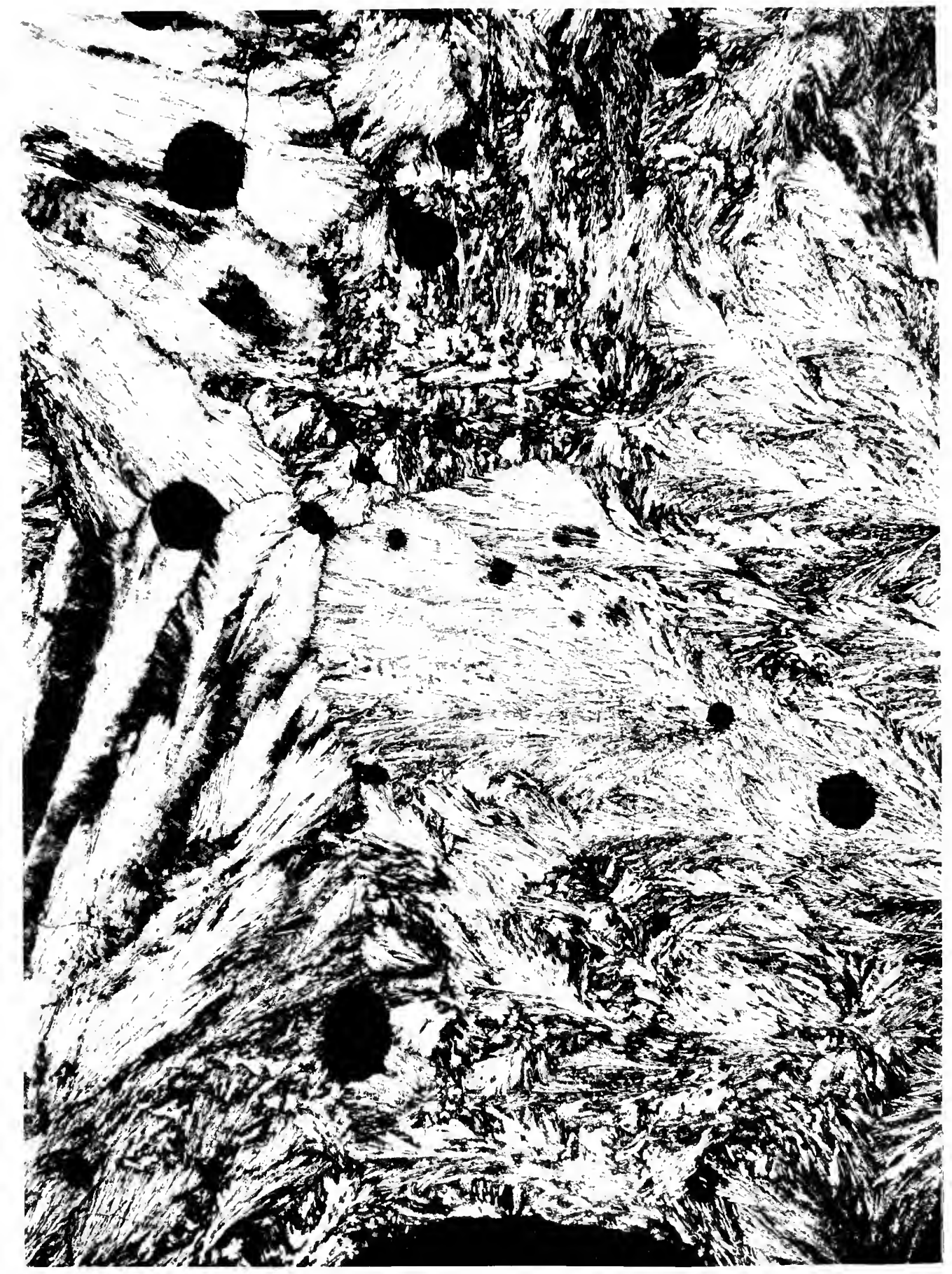


$$
\text { . }
$$ 


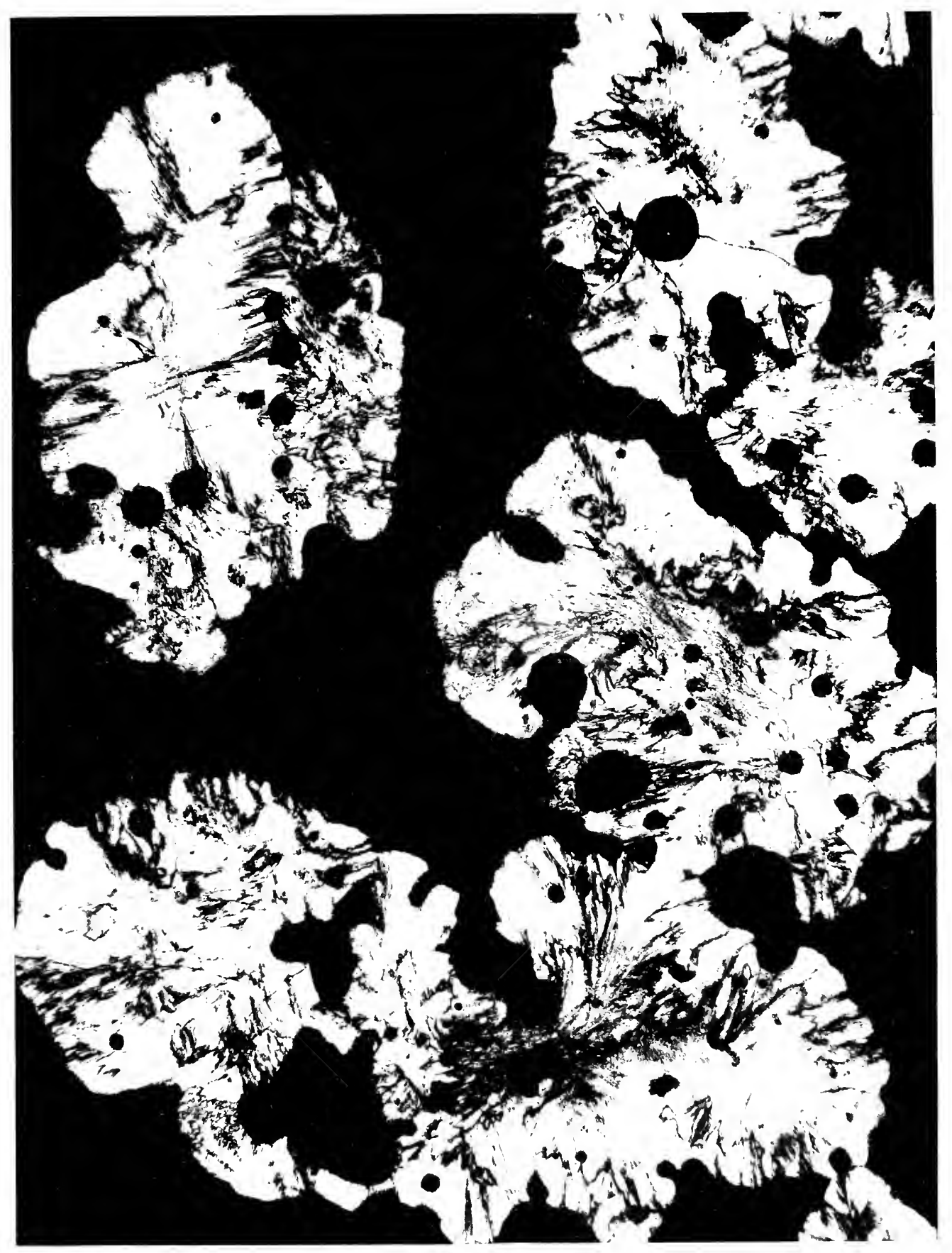





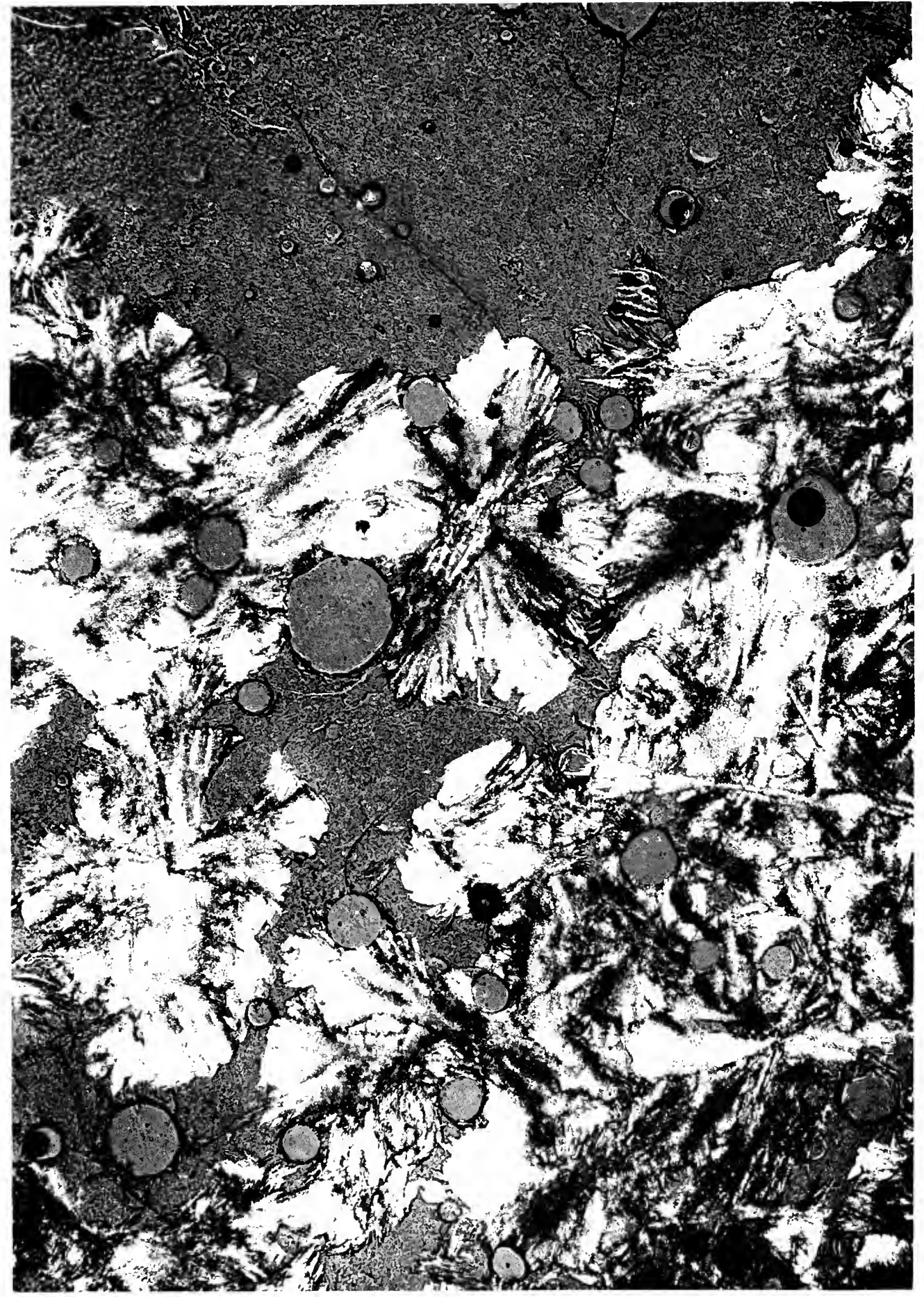




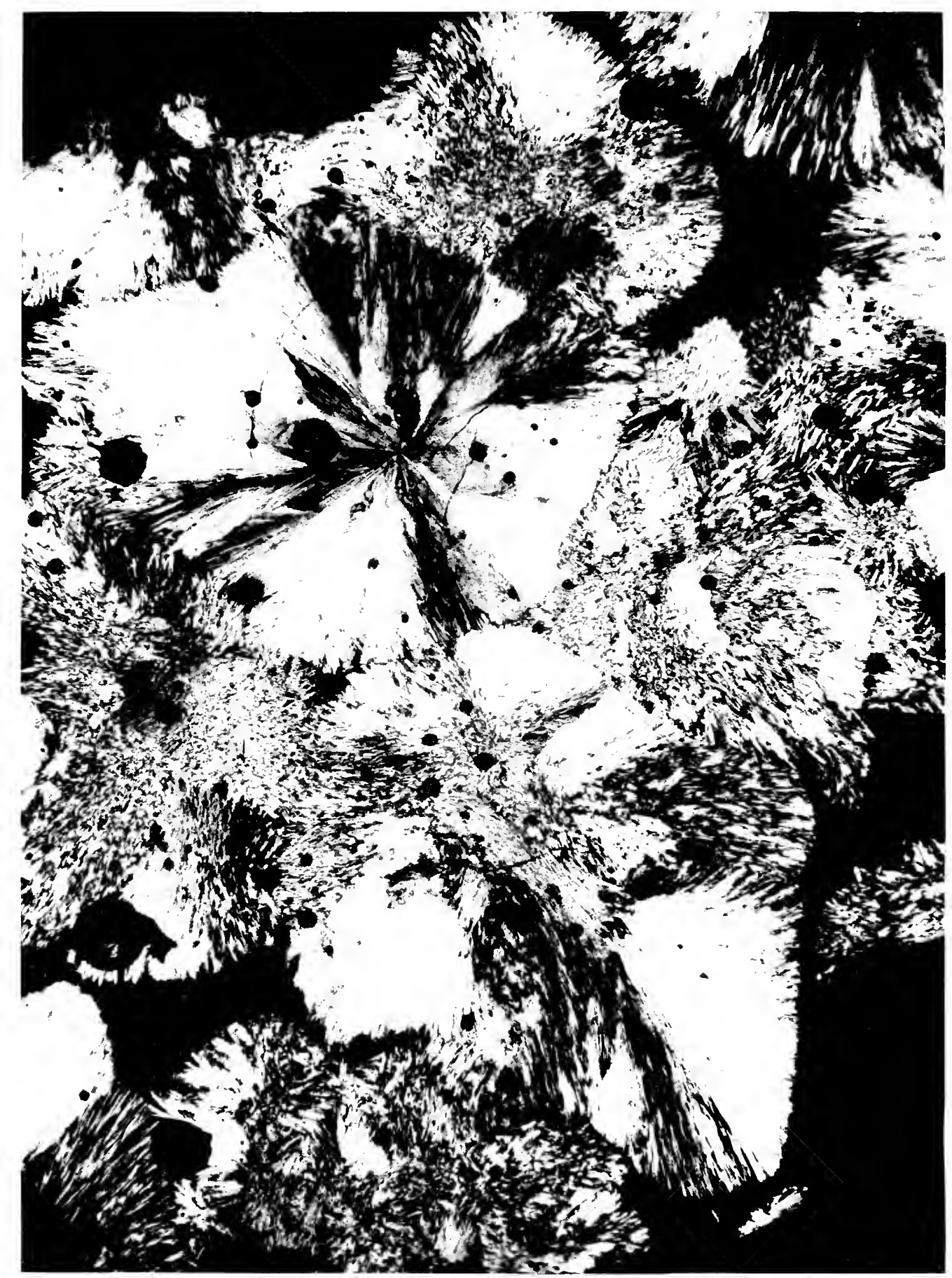




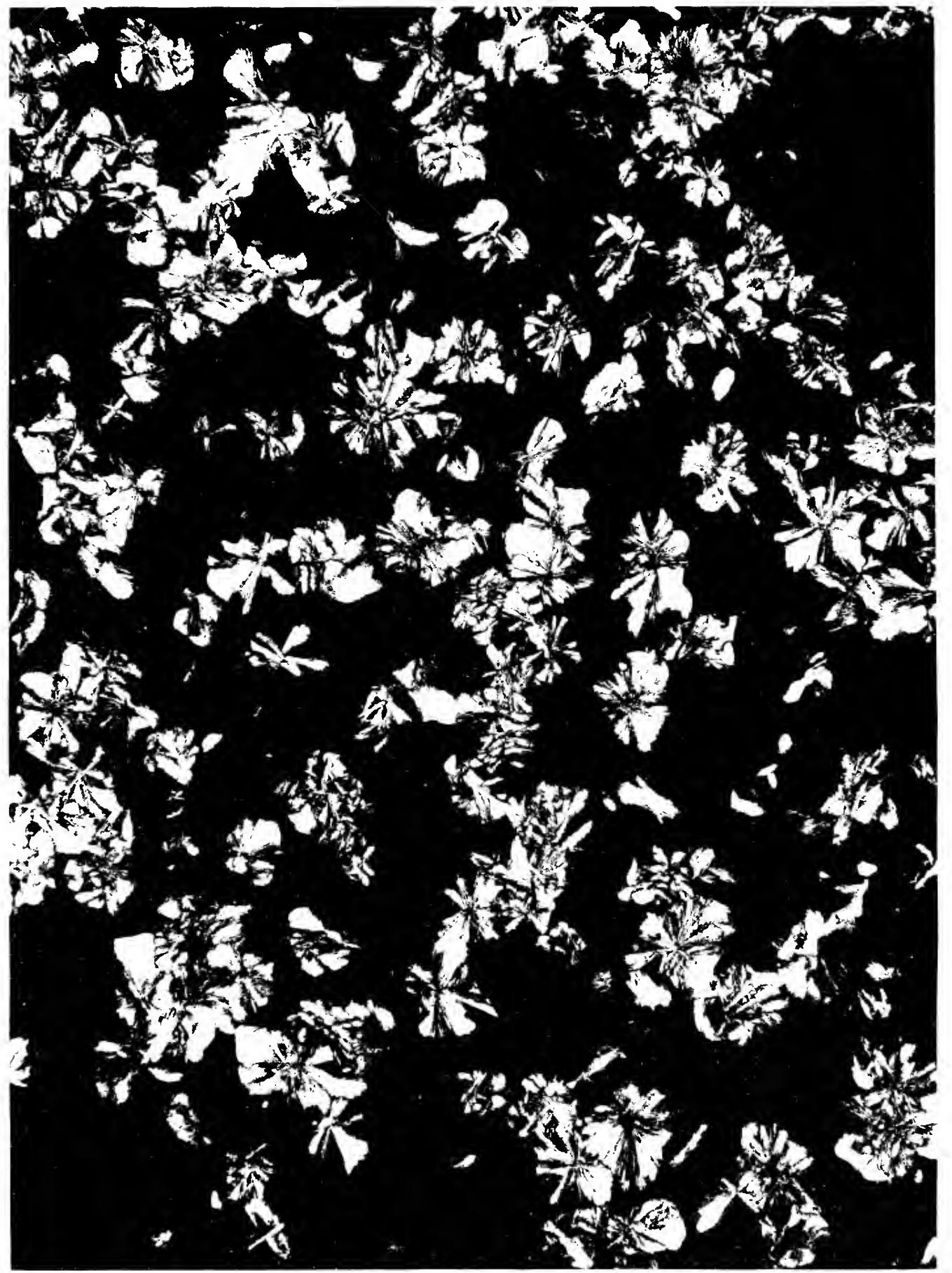




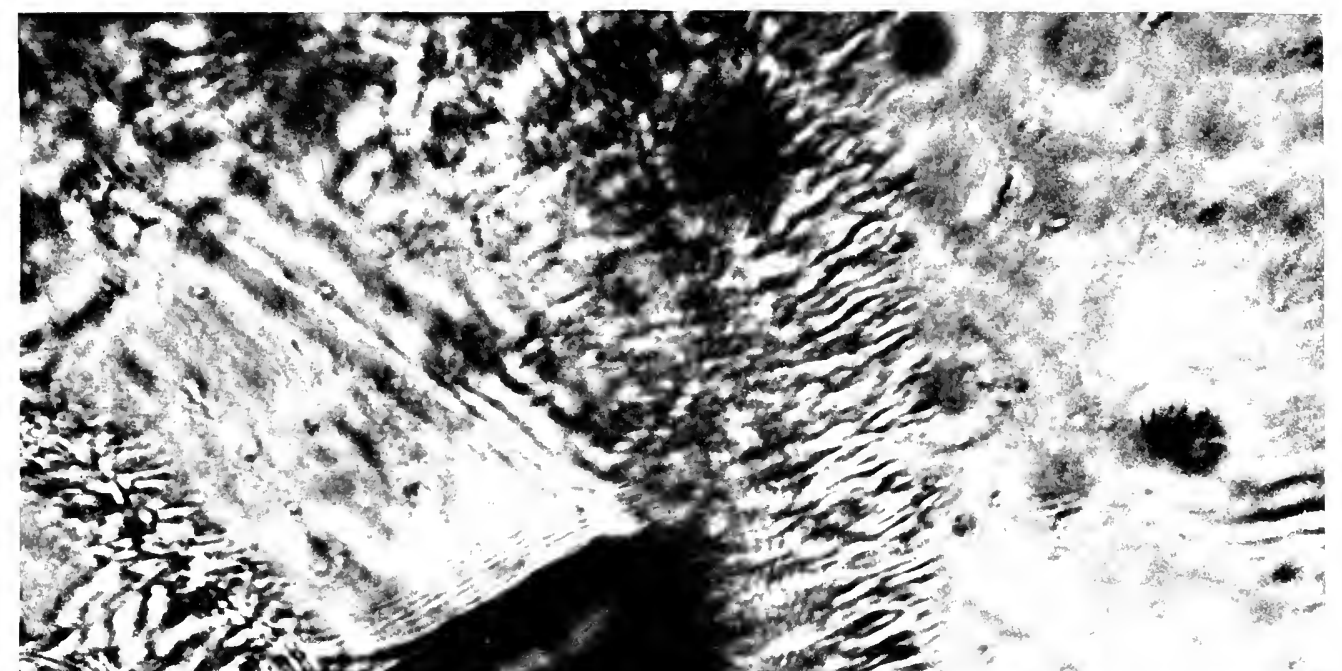

x

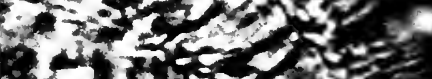

ind

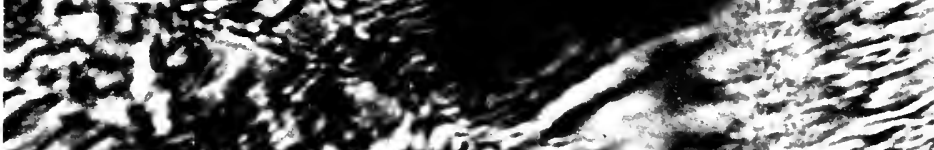

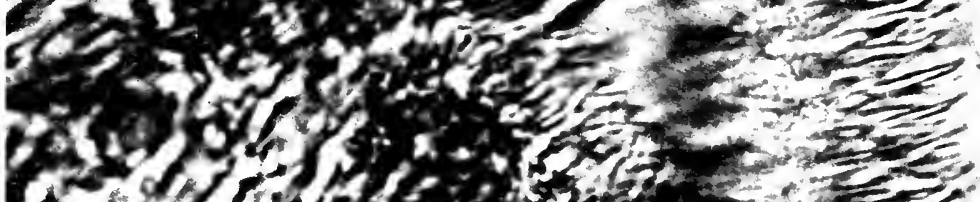

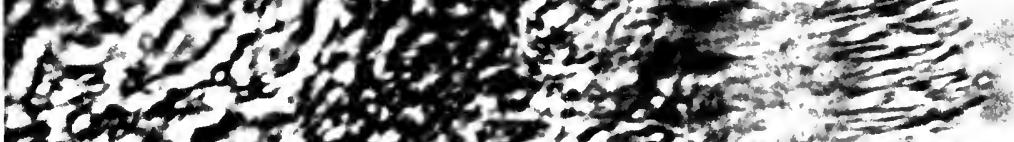

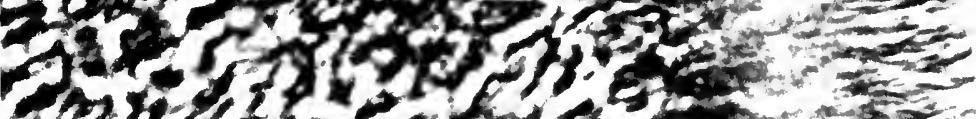

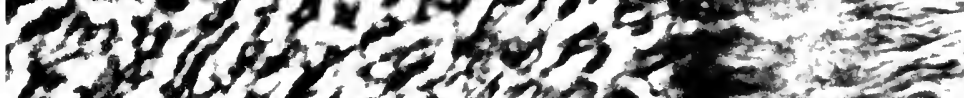

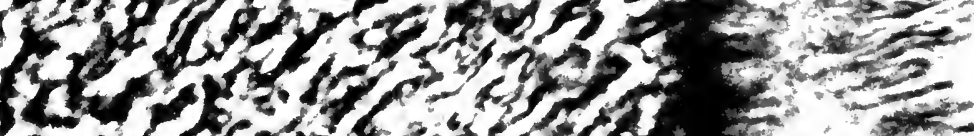

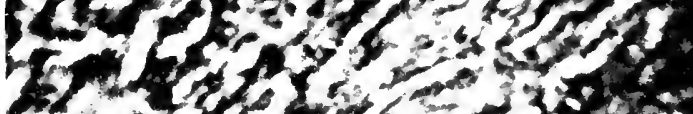

$x^{2} x^{2}=2$

1

-

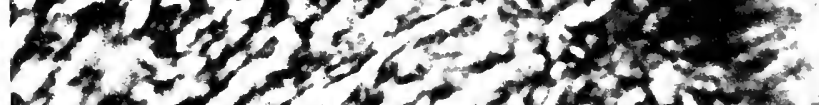

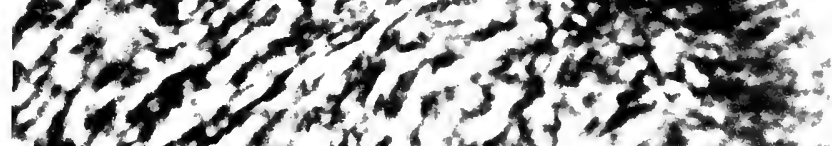

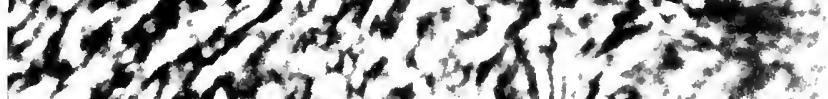
$072+212$

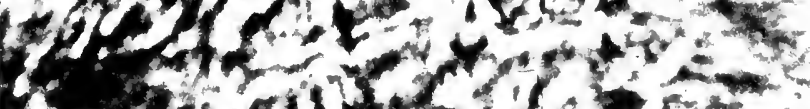

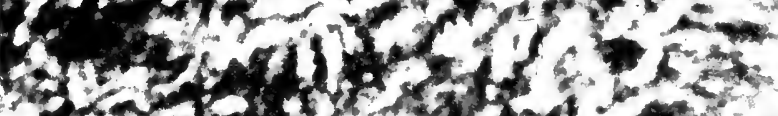

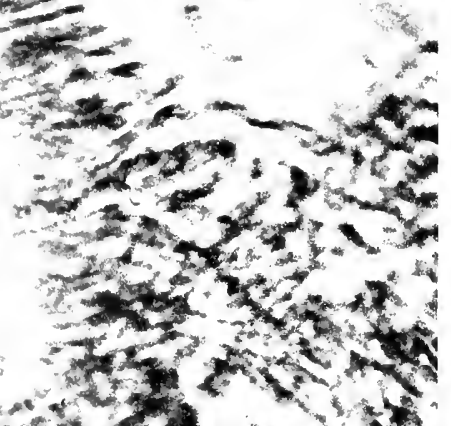

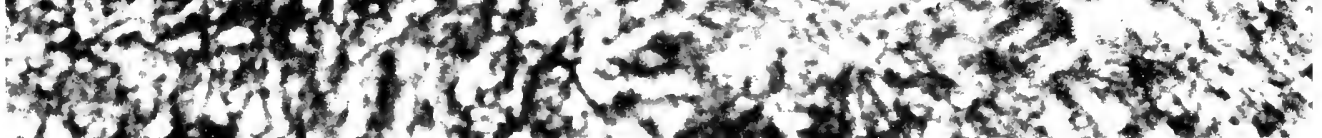





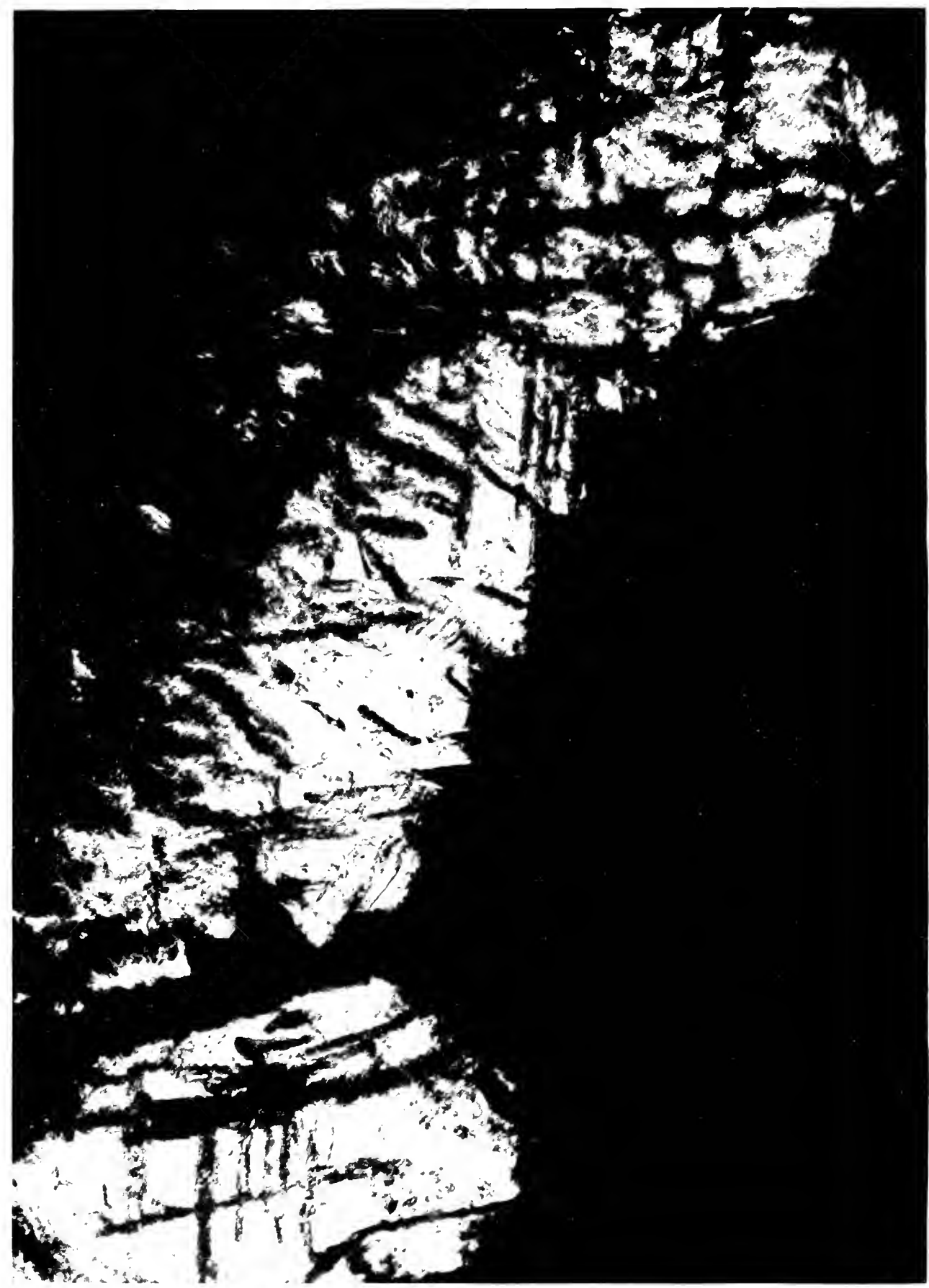




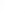


5 ref

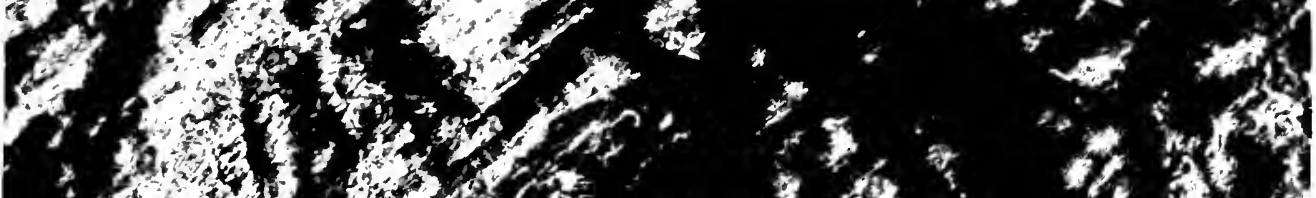

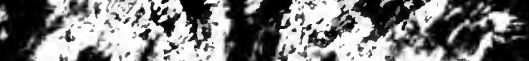
154.

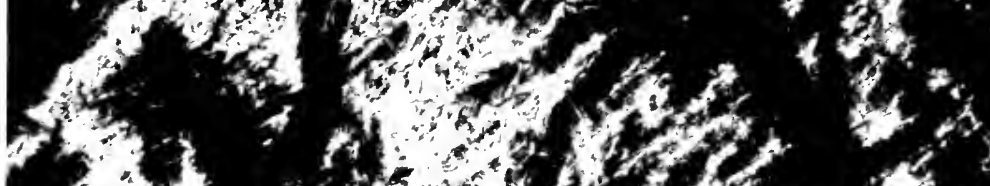

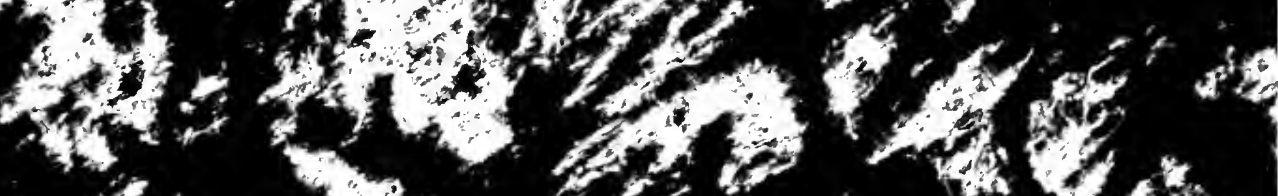

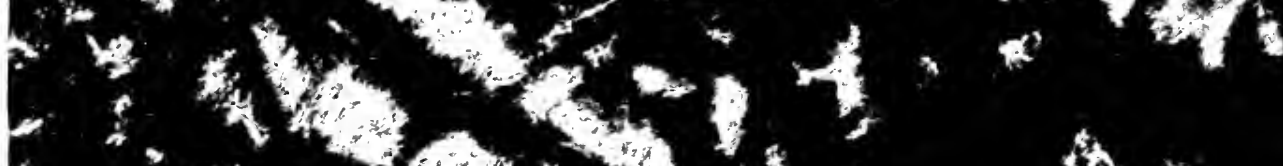

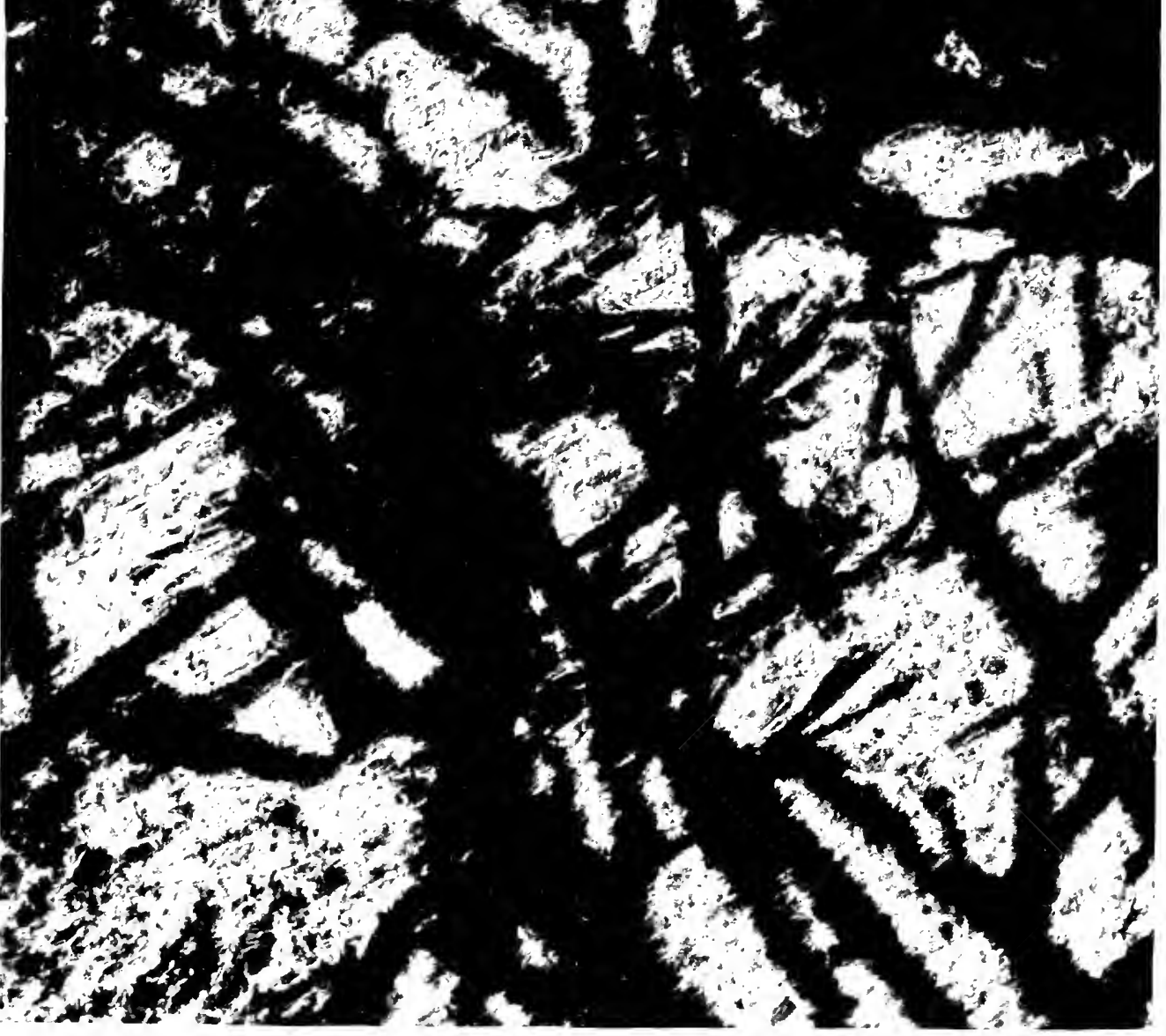





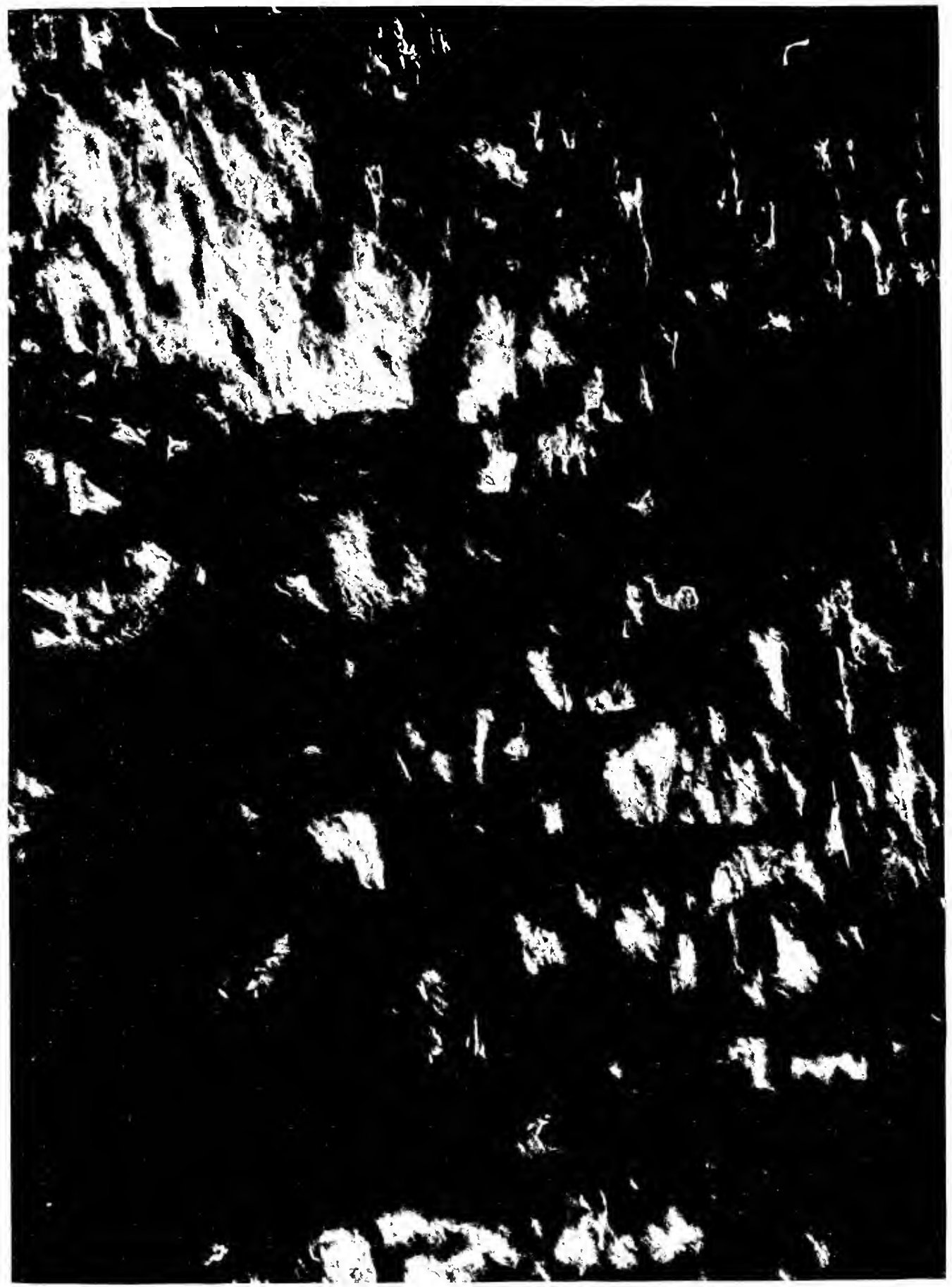




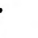




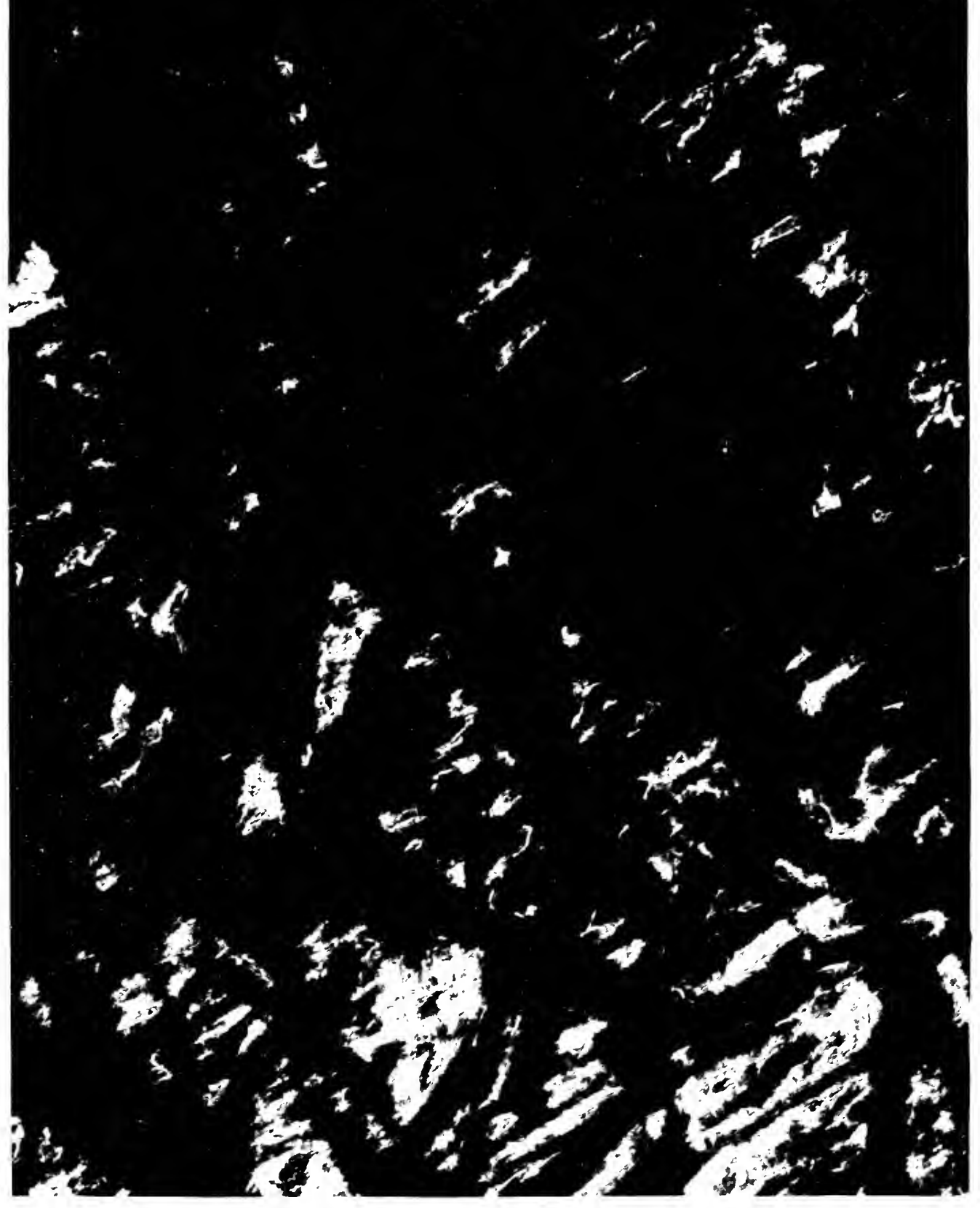




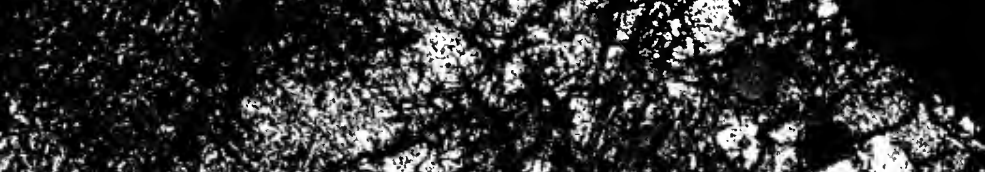

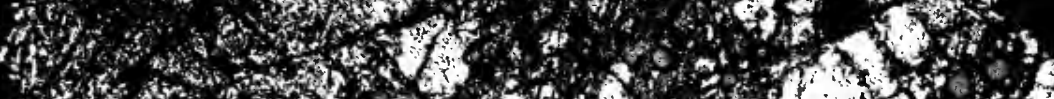
$\ddot{*}$; tof

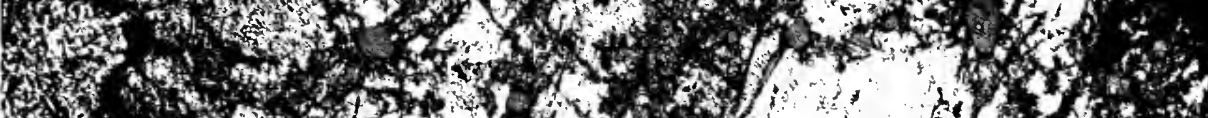
(1) 2.7.

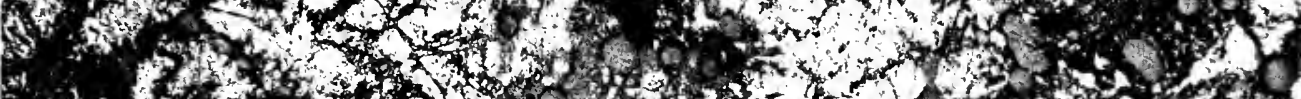

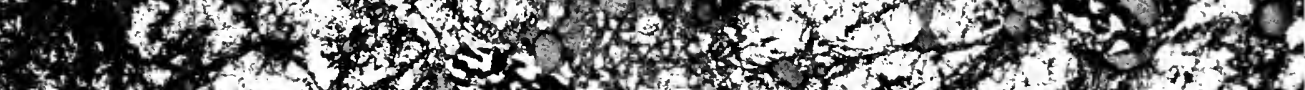

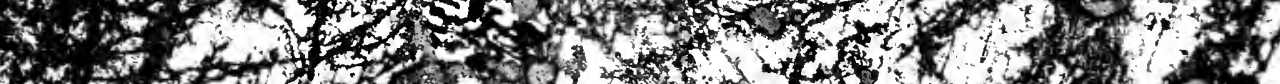

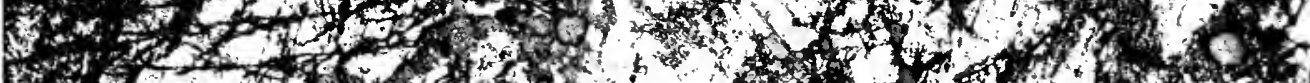

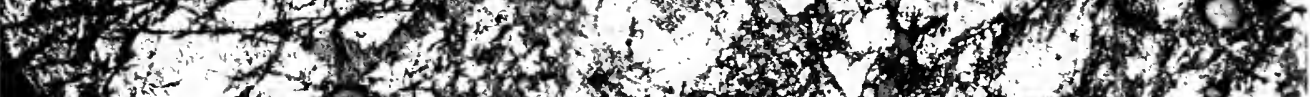

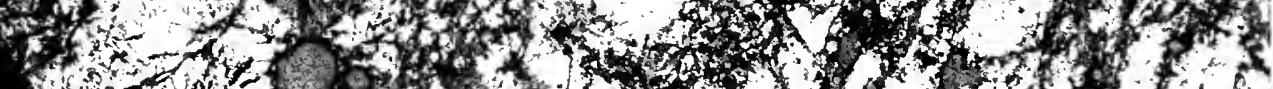
4.

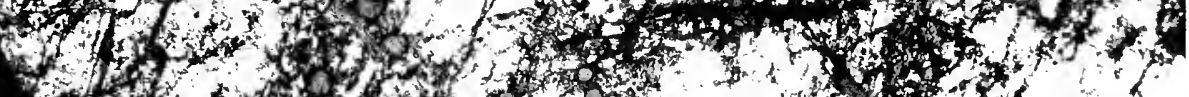

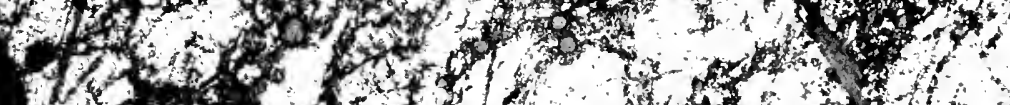

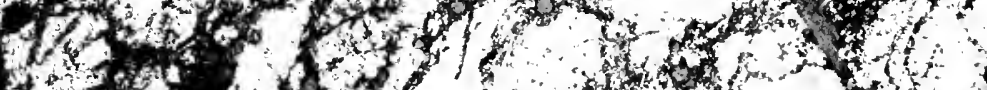
St.

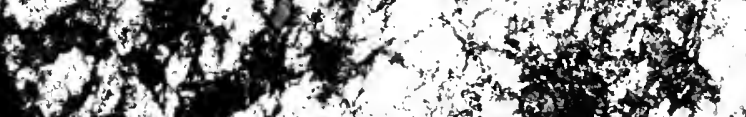
$101,12,0 x$ $-1,0,4 \mathrm{~m}$

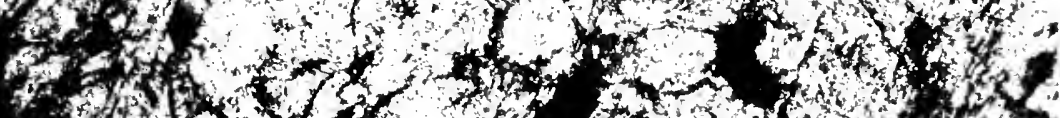

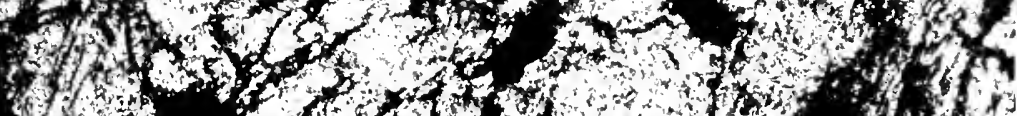

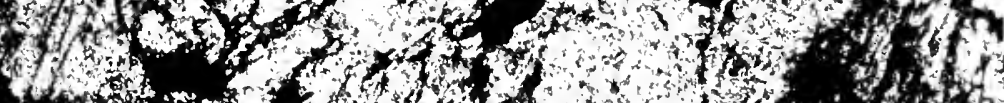

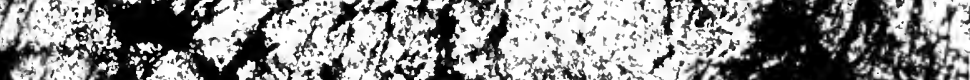

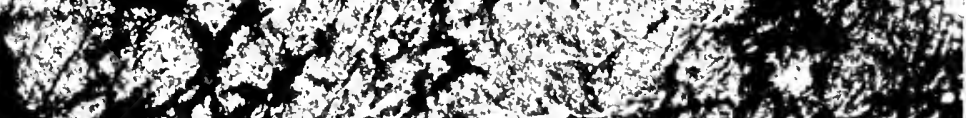

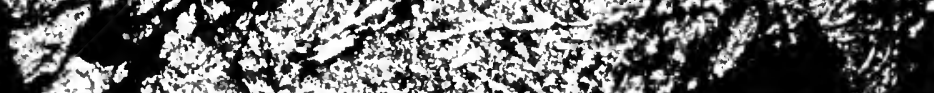




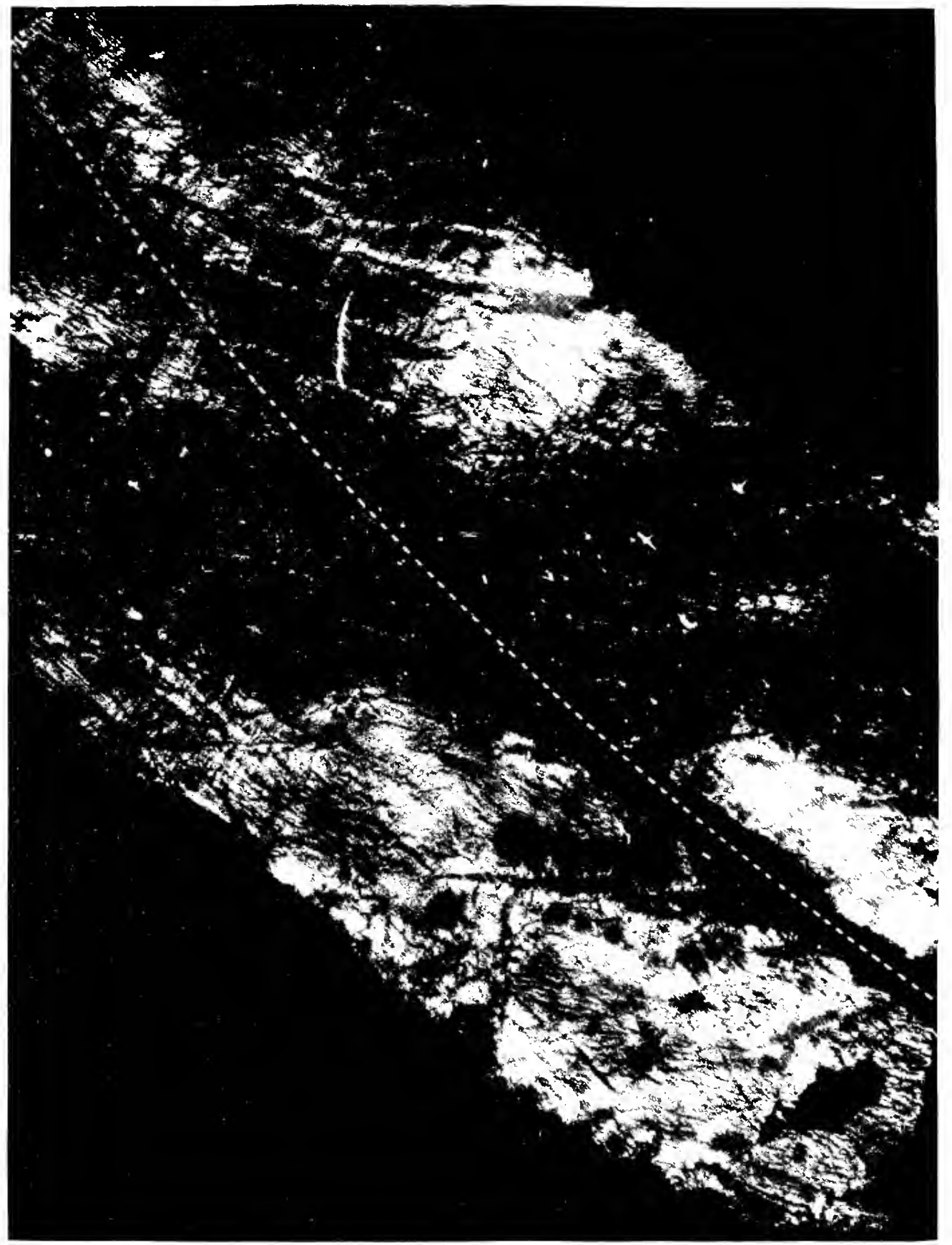




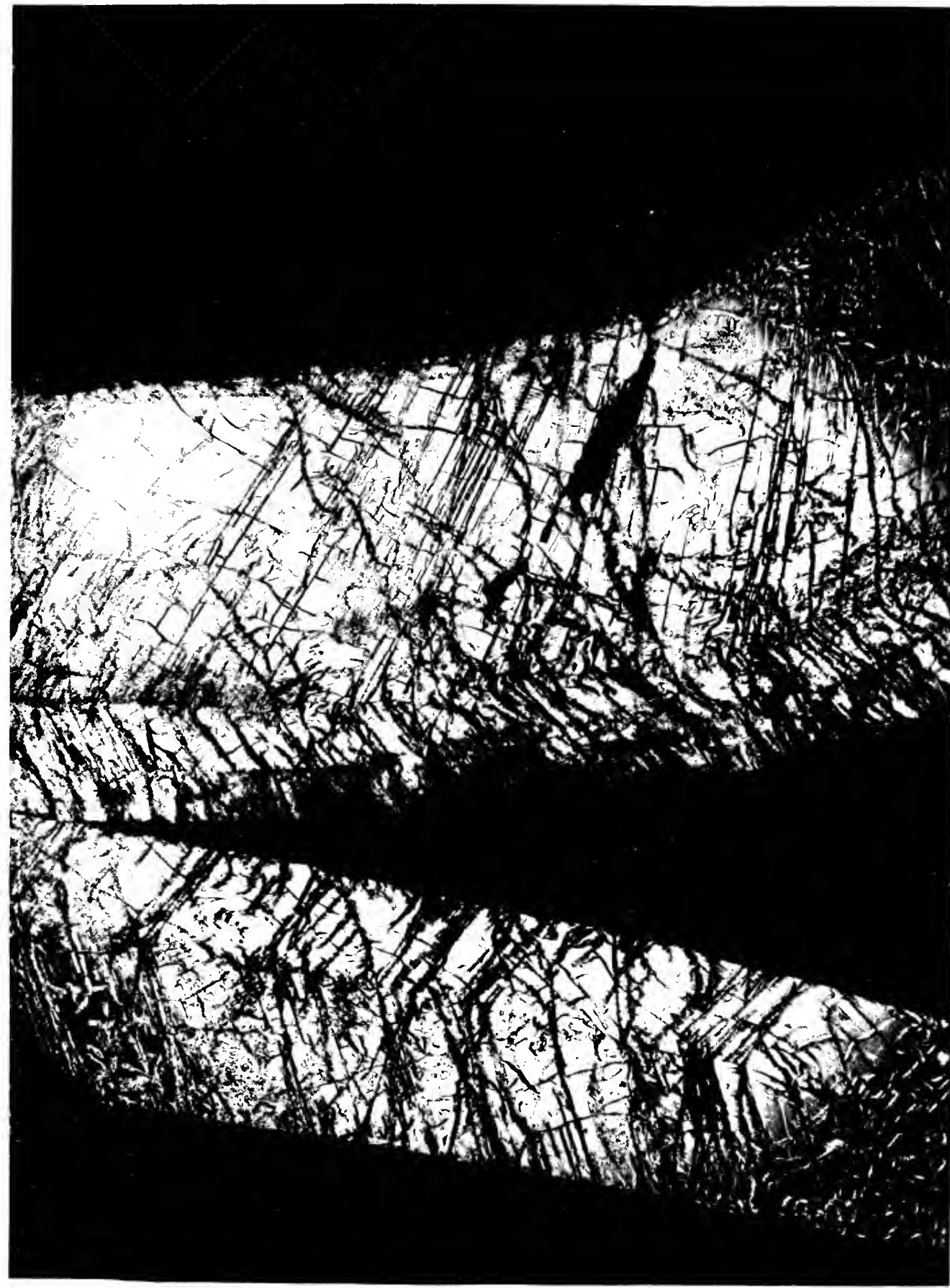


QD Day, Arthur Louis

931 The isomorphism and

D27 thermal properties of the feldspars

P\&A Sci.

PLEASE DO NOT REMOVE

CARDS OR SLIPS FROM THIS POCKET

UNIVERSITY OF TORONTO LIBRARY 
